\title{
Reaktionen metabolisierender Systeme auf experimentelle Beeinflussung, Reiz und Schädigung
}

\author{
(Grundprobleme der Quantitativen Biologie des Stoffwechsels)
}

\begin{abstract}
ALFRED LOCKER
Institut für Biologie und Landwirtschaft des Reaktorzentrums Seibersdorf-Wien (Osterreichische Studiengesellschaft für Atomenergie GmbH.), Pbysiologisches Institut und I. Medizinische Klinik der Universität Wien, Österreich
\end{abstract}

\begin{abstract}
Reactions of metabolizing systems following experimental influences, stimulation or injury (Basic problems of quantitative biology of metabolism). Metabolizing systems which follow the kinetics of open systems reveal characteristic reactions due to experimental influences, stimulation or injury. In the time-course of such reactions single or multiple transition states are observed; with a constant time parameter, a behaviour becomes manifest which was described long ago by various laws (Weber-FECHNER-Law, ARNDT-SCHulzlaw, law of initial value after WILDER). These laws are derivable from the theory of open systems. Enzyme kinetics provide us with simple models obeying these laws; they are, however, also verified by reactions of metabolizing systems of either level or organization. Specific examples of these reactions are presented from the areas of experimental liver-injury, resting and activity state, as well as metabolic differences between cold- and warmblooded animals. The limitations of quantitative methods in biology are emphazised.
\end{abstract}

\section{EINLEITUNG}

\section{Aufgabe und Ziel unserer Betrachtung}

Mit dem Ausblick auf das Ziel einer durchgehend mathematischen Darstellung sucht die quantitative Biologie Beziehungen zwischen Wirkfaktoren verschiedenster Art und biologischen Prozessen beziehungsweise Systemen zu beschreiben. Die „Quantitative Biologie des Stoffwechsels", mit der wir uns hier im besonderen auseinandersetzen wollen, läßt sich daher in bestimmter Weise von der Biochemie unterscheiden; bei ihr stehen nicht die stoffliche Natur der Reaktionsteilnehmer oder die chemischen Umsätze, d. h. die Wandlungen der chemischen Strukturen, im Vordergrund der Betrachtung. Die Ergebnisse der Biochemie können gewissermaßen als Rahmen aufgefaßt werden, innerhalb dessen untersucht werden soll

1. wie sich die Reaktionen (vor allem quantitativ, d. h. hinsichtlich ihrer Stärke und Geschwindigkeit) unter bestimmten Beeinflussungen ändern und

2. was unter diesen Einflüssen von allgemeinen Möglichkeiten realisiert wird. 
Die durch verschiedene experimentelle Anordnungen gegebenen Einflïse auf stoffwechselnde (metabolisierende) Systeme wollen wir Wirkfaktoren nennen; sie sind häufig Parameter oder, je nach Gesichtspunkt, abhängige oder unabhängige Variablen der betrachteten Prozesse. Im Hinblick auf die Reaktionen, d. h. die Antworten, Außerungen („responses") des stoffwechselnden Systems sprechen wir von Reizen (Stimuli), wenn bestimmte Kriterien erfüllt sind, durch die erkannt wird, daß der Normalzustand noch gewahrt ist ${ }^{1}$. Die Reize können zu Schädigungen (Noxen) werden, sobald gewisse Intensitätsgrade überschritten sind und für längere Zeit teilweise irreversible oder dauernd irreversible Veränderungen eintreten, die unter Umständen die Prozesse im stoff wechselnden System zum Erliegen bringen ${ }^{2}$.

Wir wollen schon hier festhalten, daß die "Quantitative Biologie des Stoffwechsels" keine eigene Disziplin ist, die etwa der allgemeinen Physiologie oder der allgemeinen Biochemie ihren Gegenstand streitig machen wollte. Sie ist vielmehr bloße Verifizierung (oder weniger streng ausgedrïckt, eine Art von Exemplifizierung) von Grundsätzen der quantitativen Biologie auf einem speziellen Gebiet. Daß wir als dieses gerade den Stoffwechsel wählen, geschieht nicht zufällig: Einerseits stellt der Stoffwechsel etwas Grundlegendes im Lebendigen dar (und zählt auch zu den wenigen, nicht streng angebbaren Kriterien lebendiger Organismen), andererseits läßt er unter einer formalen Behandlung Eigenschaften von solcher Allgemeinheit erkennen, daß die Aussage, stoffwechselndes und lebendiges System seien ein und dasselbe, greifbare Gestalt gewinnt. Daß unter der formalen (quantifizierenden) Behandlung auch die Identität mit anderen Biosystemen, wie den Nachrichten aufnehmenden und verwertenden Sinnesorganen beziehungsweise dem Nervensystem, besonders deutlich wird, darf vielleicht noch gegen Abschluß unserer Betrachtung gewürdigt werden. Versucht man, die quantitative Biologie auf der Basis des Stoffwechsels zu exemplifizieren, dann ergeben sich nicht zu unterschätzende Vorteile:

1. Wir vermögen auf eine große $Z$ ahl verwertbarer und in gewissem Ordnungszusammenhang vorliegender Daten, hauptsächlich geliefert von der Biochemie, aber auch von anderen Disziplinen, zurïckzugreifen und können versuchen, sie in einen neuen, nämlich quantitativen Zusammenhang zu stellen, der von den das Material liefernden Disziplinen selbst vielleicht nicht in wünschenswertem Maße geleistet werden kann.

2. Unter ständiger Fühlungnahme mit dem konkreten Material entgehen wir vielleicht der Gefahr, eine quantitative Biologie zu einer so abstrakten Disziplin auswachsen zu lassen, daß sie nur mehr dem Mathematiker zugänglich bleibt und der Biologe weder für seine konkrete Arbeit (im heuristischen Sinne) noch zur Zusammenschau seiner Ergebnisse (im Sinne einer Theorie) aus ihr einen Nutzen ziehen kann ${ }^{3}$.

${ }^{1}$ Freilich ist der Begriff des Normalzustandes nicht leicht $z u$ definieren; wir werden über diese und damit zusammenhängende Fragen noch ausführlich $z u$ handeln haben.

2 Wir richten unser Augenmerk daher besonders auf eine Außerung der „bionomen Organisation“ (RothschuH 1959), nämlich die Reaktivität, während die Autoaktivität mehr im Hintergrund bleibt.

${ }^{3} \mathrm{Da \beta}$ in unserer Untersuchung der Stoff wechsel der konkrete Gegenstand ist, der zur Gewinnung formaler Beziehungen (Gesetzmäßigkeiten allgemeiner Art) führen soll, obwohl es, besonders im Hinblick auf die Bedeutung der Informationstheorie in der quantitativen Biologie, die Nerven- und Sinnesphysiologie vielleicht besser vermag, hat schlieslich den persönlichen Grund, daß der Verfasser in mehr als fünfzehnjähriger Tätigkeit mit Problemen der 
Der Gang unserer Untersuchung soll der folgende sein: Ausgehend von jenen allgemeinen theoretischen Vorstellungen, die sich als Basis für unsere Betrachtung eignen, wollen wir die Gesetzmäßigkeiten stoffwechselnder Systeme feststellen, die Beziehungen zwischen beiden herstellen und die durch sie beschriebenen Gesetzeszusammenhänge auf die konkreten Probleme anwenden; eine besondere Exemplifizierung soll an Stoffwechselreaktionen der Leber, im Hinblick auf ihre Verbindung zur Morphologie, gegeben werden; zusätzliche Probleme allgemeiner Natur sollen dieser Betrachtung angeschlossen werden. Leitstern wird jedoch sein, das stoffwechselnde System stets als Ganzes zu betrachten; es erfährt natürlich jeweils auf verschiedenen Niveaus der Organisation seine Konkretisierung; zwischen diesen bestehen als Ausdruck hierarchischer Ordnung analoge Entsprechungen (die lediglich in einer perfekten Formalisierung zu isomorphen werden könnten). Die Ergebnisse, also die Veränderungen unter Beeinflussung, sollen immer in Abhängigkeit von diesem ganzen System gesehen werden. In der Darstellung wird eine Formalisierung im strengen Sinne ausdrücklich vermieden; sie beschränkt sich auf die Aufweisung anschaulicher Zusammenhänge. Der Wert der formalen und quantitativen Untersuchung (als Methode und Ziel) soll kritisch geprüft und ihre Abgrenzung wie ihre Verbindung zur qualitativen Naturbeschreibung versucht werden.

\section{Der Erklärungswert formaler Betrachtung des Stoffwechsels (Stofflicher und formaler Wirkungsmechanismus)}

Wir haben bereits erwähnt, daß das stoffwechselnde System auf Einflußfaktoren reagiert. Nachdem die Intensitäten der Wirkfaktoren von Bedeutung sind, geht die Problematik von Dosis und Wirkung (Krese 1947, Druckrey \& Küpfmüller. 1949) in die Grundlagen der quantitativen Biologie des Stoffwechsels ein; damit berührt sie sehr eng die allgemeine (oder theoretische) Pharmakologie, und die von dieser gewonnenen Erkenntnisse können für jene brauchbar sein. Bleibt es darüber hinaus aber bewußt, daß alle experimentellen Variablen mit Reizen gleichgesetzt werden müssen - unabhängig von der Frage, ob sie nun physiologische oder unphysiologische darstellen -, so ist die Schlußfolgerung nicht von der Hand zu weisen, daß alle in quantitativer Hinsicht gewonnenen Erkenntnisse die vorangestellten Bedingungen zur Grundlage oder Voraussetzung haben. Allgemeiner ausgedrïckt heißt dies: Es kann niemals die Aussage gemacht werden, dieses oder jenes Agens habe auf den Stoffwechsel diese oder jene Wirkung, ohne daß die Abhängigkeit dieser Wirkung von den vorangestellten Bedingungen berücksidatigt wird. Diese können quantitativ oder qualitativ (im Sinne eines nicht leicht entwirrbaren Komplexes) verstanden werden. Damit be-

Beeinfussung des Stoffwechsels befaße ist und sich daher in diesem Gebiet etwas sicherer als in anderen fuhlt. Die Substanzen, die ex untersuchte, sind verschiedenen biologischen Stoffklassen (Cholinesterase-Inhibitoren, Lebergifte, Karzinogene, Antibiotika, Strahlenschutzstoffe), die auftauchenden Probleme verschiedenen Disziplinen (Biochemie, Pharmakologie, experimentelle Pathologie etc.) zugehörig. Durch eine hierbei notwendig gewordene interdisziplinäre Stellung mag der Verfasser, von den Vertretern der Fachdisziplinen vielleicht als "outsider" angesehen und mit diesem Odium belastet, sich nicht scheuen missen, die schon of "outsider" angesehen und mit diesem "Stentiung eines "generalizers" zu beziehen und als solcher auch Ausblicke auf die Philosophie als selbstverständliche Abrundung seiner Bemühungen zu betrachten. 
kommt die Frage nach dem Wirkungsmechan ismus eines Agens ein besonderes Aussehen: An ihr kann recht gut der Unterschied zwischen der qualitativ-stofflichen Auffassung der Biochemie und der quantitativ-formalen ("relationalen“, RAsHevsKY 1962) Auffassung, die wir hier vorwiegend im Auge haben, demonstriert werden. Biochemisch erscheint eine Wirkung vollständig erklärt (und ein Wirkungsmechanismus befriedigend aufgeklärt), wenn der Angriffspunkt der Substanz genau festgelegt werden kann ${ }^{4}$. Solche Erklärungen, die wahrscheinlich nie an ein Ende kommen, bedeuten für die quantitative Biologie nur soviel, als durch sie gezeigt wird, daß ein formal zu beschreibender Funktionszusammenhang in bestimmter, quantitativ angebbarer Weise geändert wird. Diese Anderung ist aber - wie gleich bei der Erörterung von spezifischer und unspezifischer Wirkung dargelegt werden soll - vom Funktionszusammenhang des Systems abhängig. Jene, welche eine Erklärung allein im isolierten Vorgang oder der "rein dargestellten" Substanz, also dem „encheiresin naturae“ entsprechend, erblicken, klammern diese Abhängigkeit aus. Für die formale Beschreibung bedeutet aber gerade die Voranstellung des Systems und seiner Bedingungen vor die singuläre oder multiple Anderung des Funktionszusammenhanges ${ }^{5}$ das Wesentliche an der Erklärung. Darf dies an einem Beispiel erörtert werden: Die verschiedenen Hauptgruppen der Antibiotika (ETTLINGER 1957, FRIEDRICH 1963) zeichnen sich nicht nur durch verschiedene chemische Strukturen, sondern in Abhängigkeit von diesen durch bestimmte und sehr unterschiedliche stoffliche "Wirkungsmechanismen " aus. Fassen wir jedoch die Reaktionen von Bakterien, die unter dem Einfluß von Antibiotika stehen, quantitativ auf, dann reduziert sich die Vielfalt der (bio)chemischen Mechanismen auf einige wenige Außerungen (Schuler 1947, KLEIN 1957), die sich zunächst noch scheinbar als typische voneinander abgrenzen lassen, die aber unter einer vereinheitlichenden dynamischen Betrachtung nur mehr als in Abhängigkeit von verschiedenen Bedingungen stehend erkannt werden. In Abhängigkeit von der Proliferationsgeschwindigkeit kann z. B. eine bacterizide in eine bakteriostatische Wirkung übergehen; die Absterbegeschwindigkeit ist proportional der Wachstumsgeschwindigkeit; auf ruhende Bakterien wird meist kein Einfluß ausgeübt etc. Dadurch schwinden vielfach die Unterschiede, die bei biochemischer Betrachtung des Wirkungsmechanismus der Antibiotika im Vordergrund stehen; aber noch mehr: Gerade dadurch gelangen wir zur Kenntnis allgemeiner Eigenschaften des Systems (hier der Bakterienpopulation), die wir in erster Linie anstreben.

$4 \mathrm{Zu}$ Beginn meiner wissenschaflichen Tätigkeit, als noch die Untersuchung des Kohlenhydratstoff wedsels im Mittelpunkt des Interesses stand, betrachtete man als eine Erklärung z. B., dal eine Substanz (sagen wir Monojodessigsäure) an diesem oder jenem Enzym (etwa Triosephosphatdehydrogenase) eingreife. Seitdem ist der Nukleinsäurestoff wechsel in den Vordergrund getreten und Erklärungen werden nur dann als gültig angesehen, wenn z. B. die Störung an der messenger-RNS oder transfer-RNS oder sogar am Ubersetzungs-Code von Nukleotid- auf Aminosäuresequenz nachgewiesen ist.

5 Die Veranschaulichung dieser Anderung erfolgt durda Dosis- (bzw. Konzentrations-) Wirkungsbeziehungen, von denen man, ohne nähere Interpretation der zugrunde liegenden Vorgänge, zunächst zwei "Typen" annimmt (CLARK 1937): Stufenwirkung ("graded action") mit einem der Einflußstärke irgendwie proportionalen Effekt und Alles-oder-Nichts-Wirkung (auch "quantal response" genannt) mit Vorhandensein oder Fehlen der Reaktion. Unter Berücksichtigung des Wirkungsmechanismus (in formaler Hinsicht) gibt es jedoch viel mehr als diese zwei "typischen" Dosis-Effekt-Beziehungen. 


\section{Uber spezifische und unspezifische Wirkung}

\section{Bedeutungslosigkeit der Alternative für ein System}

Sobald in einem stoffwechselnden System mit vielen Reaktionsschritten jeder einzelne von ihnen durch definierte chemische Agentien zu beeinflussen ist, sprechen wir von spezifischer Wirkung, falls es für jede dieser Reaktionen nur einen ganz bestimmten Hemmer gibt. Dies ist noch ein rein qualitativer Aspekt von Spezifität, der sich zu einem quantitativen verfeinert, sobald die Annahme gemacht wird, daß zwar jeder Einzelschritt durch eine Vielzahl von Stoffen beeinflußt werden kann, daß es aber unter dieser nur einen oder ganz wenige Stoffe gibt, die bei einem Minimum in ihrer quantitativen Relation zum System (ausgedrückt etwa als Anzahl der Moleküle pro Zelle oder Enzym) zur Wirkung kommen.

Die quantitative Transformation des Begriffes der spezifischen Wirkung wird auch unter einem etwas anderen Blickwinkel ermöglicht. Es kann das einwirkende Agens an sehr vielen Stellen im System eingreifen, so daß die Zahl der Angriffsstellen von Bedeutung wird. Auch hier wird die Wirkung um so spezifischer sein, je kleiner diese Zahl ist (man spricht in diesem Fall auch von selektiver Wirkung). Unter Vergleichung verschiedener Agentien (und verschiedener Angriffspunkte im System) wird es möglich sein, mehrere Spezifitäts-Grade anzunehmen. Vielleicht dürfen wir hier wieder eine Exemplifzierung vornehmen, und zwar an einem Modellsystem gedanklicher Natur ${ }^{\mathbf{j}}$, mit welchem wir noch des öfteren zu tun haben werden, nämlich an einem EnzymModell, im einfachsten Fall repräsentiert durch Enzym und Substrat. Ein Enzym ist nicht spezifisch, wenn ein Substrat positiv mit allen Enzymen reagiert; dagegen liegt eine spezifische Reaktion vor, wenn nur e in Enzym mit einem Substrat in Reaktion tritt. Freilich muß ein solches Enzym-Substrat-System mehr als 2 Enzyme enthalten; dann ist der Grad der Spezifität der Reaktion um so höher, je einzigartiger die eintretende Reaktion ist; mit anderen Worten: Der Grad der Spezifität ist proportional der Anzahl der Enzyme (Quastiter 1953).

In Fortführung unserer quantitativ orientierten Betrachtung läßt sich jedoch etwas Eigenartiges am Problem der Spezifität nicht verbergen. Bei einem System muß nämlich angenommen werden, daß jedes Agens, für welches eine spezifische Wirkung (im qualitativen oder quantitativen Sinn) nachgewiesen werden $\mathrm{kann}$, auch in unspezifischer Weise mit mannigfachen Angriffspunkten und Beeinträchtigungen vieler Reaktionen eingreift. Daher wird schließlich in bezug auf den Eingriff wieder das ganze System betrachtet werden müssen. Beide Arten von Einflïssen vermögen das System nicht über seine Reaktionsmöglichkeiten hinaus zu verändern; ja durch das stete Auftreten von bestimmten, gleichsam system-typischen Reaktionen bei Einflüssen verschiedenster Art wird uns die Hinfälligkeit des Unterschiedes zwischen spezifischer und unspezifischer Wirkung demonstriert. Vom Gesichtspunkt der Einzelreaktion (des System-Elements, des Detail-Prozesses) mag er von gewisser Bedeutung sein, vom

6 Diese Modelle wollen wir streng von jenen Analogie-Modellen unterscheiden, die aus nicht-biologischem Material hergestellt, die Verknuipfungsgesetze zwischen Elementen oder Vorgängen in Organismus strukturell und dadurch auch funktionell ( $z$. B. im Verhalten) nachahmen. 
Blickwinkel des ganzen Systems, dem wir uns hauptsächlich widmen, verliert er völlig an Schärfe. Daher sind die, namentlich in der Enzym-Biochemie, bekanntgewordenen Formen spezifischer Wirkung für uns uninteressant. Ein Phänomen jedoch wollen wir seiner Ubiquität wegen, und weil es die Systembetrachtung unterstützt, herausheben.

\section{Die strukturelle Nicht-Spezifität.(Der FERGUSON-Effekt)}

Es steht außer Frage, daß Biosysteme beeinflußt werden können, wenn einwirkende Faktoren bestimmte biochemische Reaktionen stören. Es muß aber auch in Betracht gezogen werden, daß es eine Anzahl von Stoffen gibt, bei denen, in bezug auf bestimmte Wirkungen, nicht die chemischen Eigenschaften (und die damit zusammenhängende Bindung an einen Rezeptor), sondern die physikalischen entscheidend sind. Sie ermöglichen die Anhäufung des Stoffes in der Zelle, entsprechend einem bestimmten Verteilungskoeffizienten zwischen Zellinnerem und Umgebung. Diese von der chemischen Struktur unabhängige Wirkung wird Ferguson-Eiffekt (FErguson 1939) genannt. Unter den Stoffen, die diesem Effekt gemäß wirken, finden sich auch solche, bei deren Wirkung man geneigt ist, an gewisse Strukturbeziehungen zu denken, wie z. B. Karzinogene. Beispiele sind bei Alber T (1951) angeführt.

\section{ALLGEMEINE EIGENSCHAFTEN METABOLISIERENDER SYSTEME}

\section{Phasenreaktionen}

Die allgemeinen Grundlagen der Kinetik offener (im Fließgleichgewicht stehender) Systeme, auf welcher Basis wir die Reaktionen unter Beeinflussungen betrachten müssen, hat mein verehrter Lehrer, Herr voN BERTALANFFY schon in seinem Einleitungsvortrag umrissen (sieh auch: v. BERTALANFFY 1953). Für unsere Betrachtung ist die sich aus der Kinetik offener Systeme ergebende Folgerung wichtig, daß das System Kräfte gegen seine Veränderung entwickelt. Dementsprechend verlaufen die Veränderungen metabolisierender Systeme, die Störungen des Fließgleichgewichts darstellen, als sogenannte Übergangsphänomene ab. Diese Übergänge lassen sich unter zweierlei Gesichtspunkten studieren:

1. im zeitlichen Verlauf,

2. unter Konstanthaltung des Zeitparameters, wodurch die Beziehung der Reaktion zur Intensität des Einflusses leicht dargelegt wird. Im zeitlichen Verlauf beobachten wir nach Beeinflussungen sogenannten "transition-states"; sie können linear oder exponentiell sein, einen Durchgang durch ein Maximum haben und anschließend wieder zum Ausgangszustand zurückkehren (wir sprechen in einem solchen Fall von einem Cyclus) oder „overshoots" beziehungsweise "false starts“ zeigen. Bei Beobachtung mehrerer Reaktionsteilnehmer kann ein ganzes Spektrum von Bewegungen gefunden werden, in welchem jeder einzelne Reaktionsteilnehmer seine eigene Form des Übergangs offenbart. Es ist wichtig, schon an dieser Stelle darauf hinzuweisen, daß die Zeit-Wirkungsbeziehungen (also die Verläufe und Übergänge in der Zeit) und die 
Dosis-Wirkungsbeziehungen (bzw. Konzentrations-Wirkungsbeziehungen, also die Reaktionen bei Konstanthaltung der Zeit) sich aus Systemgründen weitgehend gestaltlich gleichen können. Diese Gründe werden wir noch später anführen. Daher können auch die gleichen vielfältigen Spektren von Übergängen an Dosis-Wirkungsbeziehungen beobachtet werden.

Zeitunabhängig äußern sich Übergänge, in Zusammenhang mit der Intensität der einwirkenden Agentien, als Hemmung oder Aktivierung. Rein quantitativ gesehen (ohne Berücksichtigung der zugrunde liegenden chemischen Reaktionen) kann auch scheinbare oder wirkliche Einflußlosigkeit bei konstantem Verhalten des betrachteten Systems resultieren. Auch bei einem tatsächlichen Effekt, entsprechend einer bestimmten Dosis-Wirkungsbeziehung, kann bis zu einem bestimmten Dosisbereich Einflußlosigkeit bestehen; die Grenze zwischen diesem und dem Wirkbereich wird als Schwelle charakterisiert.

\section{Enzymkinetik als Modell für Fließgleichgereichtssysteme}

Veranlaßt durch das didaktische Verfahren, die allgemeinen Gesetzmäßigkeiten der Reaktionen metabolisierender Systeme zunächst an einfachen Modellen zu studieren, wenden wir uns wieder dem Modell der Enzymkinetik zu. Von früheren, meist nur historisch zu würdigenden Ansätzen abgesehen, nimmt diese ihren Anfang mit der Gleichung von Mrchaelis \& Menten (1913). Nach dieser wird die Wirkung eines Enzyms in seiner Verbindung mit dem Substrat unter reversibler Bildung eines Enzym-Substrat-Komplexes gesehen, der seinerseits wieder in Enzym und Produkt zerfällt:

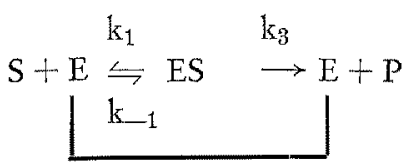

Dadurch wird das Enzym wieder für eine neue Reaktion frei: Wir sprechen von einem Enzym-Cyclus. Enzymreaktionen sind direkt schwer verfolgbar; erst in letzter Zeit sind subtile Methoden zur direkten Messung (oder Identifizierung der Reaktanten) gefunden worden; dazu zählen die sogenannten Ergesschen Relaxationsspektren. Enzymreaktionen können im Analog-Computer vorausgesagt werden. Es sei übrigens daran erinnert, daß schon BuRTON (1939) zur Veranschaulichung von Übergangsphänomenen einfache (hydrodynamische) Analoge erdacht hat. Heute werden vielfach Analogoder Digital-Computer verwendet (letztere sind genauer und besonders gut geeignet, wenn sie mit einem Analog-Sichtgerät verbunden sind). Die Micraelis-MentenReaktion ist im Analog- und Digital-Computer von CHANCE (1960) dargestellt worden; vielgliedrige Systeme analysierte Hess (1963).

Einen Fortschritt von der Betrachtung einer einzigen Enzymreaktion (die für sich genommen, kein Fließgleichgewicht darstellt, obwohl sie durch ihren irreversiblen Reaktionsanteil, repräsentiert durch die Konstante $\mathrm{k}_{3}$, zu Teilen eines Systems werden kann) zur Fließgleichgewicht-Behandlung („steady-state“-Kinetik) selbst stellt der 
Ansatz von Briggs \& HALDANe (1925) dar. Die „steady-state“-Kinetik hat im wesentlichen zwei Voraussetzungen (ALBerty 1959):

1. muß die Substratkonzentration sehr groß gegenüber der Enzymkonzentration sein, so daß sie keine Anderung in der Zeit erfährt und

2. darf sich der ES-Komplex praktisch nicht ändern. Wenn doch Maxima (wie in der einfachen Mrchaelis-Menten-Beziehung) auftreten, sollen diese vor Einstellung des Fließgleichgewichts erreicht werden.

Schließlich wurde ein weiterer Fortschritt dadurch erzielt, daß ganze EnzymSysteme (nicht nur Einzelenzyme) der Anwendung der Fließgleichgewichtstheorie unterworfen wurden. Dieser Schritt war möglich, sobald alle Eigenschaften der Enzyme selbst (Konzentration, Wechselzahlen, pH-Optimum etc.) bekannt waren und sich die Aufgabe stellte, das ganze System nun so zu beschreiben, daß präzise Voraussagen iiber seine Veränderungen nach Beeinflussungen gegeben werden können ${ }^{7}$. Diese Behandlung ist besonders am System der Glykolyse beziehungsweise an einzelnen Enzymreaktionen aus diesem System möglich geworden. Bücher \& RüssMANN (1963) gehen in ihrer Darstellung vom anschaulichen Modell der Gegenüberstellung eines wilden und eines regulierten Wasserlaufs aus, bei welchem durch Einbau einer Barriere eine Ordnung in Stau- und Fallstrecken erfolgt; letztere fungieren als limitierende Glieder.

Bei Bestimmung der Quotienten der stationären Metabolitgehalte und ihrem Vergleich mit den Gleichgewichtskonstanten werden im System der Glykolyse zwei Klassen von Quotienten unterschieden, nämlich

1. solche, deren Größenordnung jener der Gleichgewichtskonstanten (Massenwirkungskonstanten) entspricht und

2. solche, bei denen diese Entsprechung fehlt und die Metabolitquotienten erheblich kleiner als die Gleichgewichtskonstanten sind. Hierin offenbart sich das Bestehen eines Ungleichgewichts (Fließgleichgewichts). Die glykolyrischen Reaktionen lassen sich in 3 Gruppen unterteilen: jede besteht aus leicht reversiblen, in der Nähe des Massengleichgewichts verlaufenden Reaktionen und aus einer im Ungleichgewicht befindlichen Reaktion, der quasi-irreversiblen phosphatübertragenden (HEss 1963). Sie lassen sich wie folgt formulieren:

$$
\mathrm{A} \underset{\mathrm{k}-1}{\leftrightharpoons} \mathrm{X}_{1} \underset{\mathrm{k}-2}{\mathrm{k}_{1}} \mathrm{X}_{2} \ldots \ldots \ldots \mathrm{X}_{\mathrm{n}} \stackrel{\mathrm{k}_{\mathrm{n}+1}}{\longrightarrow} \mathrm{B}
$$

Da sich der Umsatz aus dem Produkt des letzten Intermediats der (reversiblen) Reaktionen mit der Konstanten der irreversiblen ergibt, sind nur jene Intermediate, die diese Reaktion einleiten, wie u. a. ATP, Fructose-6-phosphat etc. von Bedeutung.

* Dieser Schritt vollzog sich in der Biochemie selbst. Dies zeigt, daß eine zur quantitativen Betrachtung hindrängende Richtung sich auch innerhalb einer Disziplin durchsetzen kann. Allerdings soll nicht verschwiegen werden, daß die Mehrheit der Biochemiker in der quantitativen Beschreibung weder Methode noch Ziel ihrer Forschung erblickt. 


\section{Master-Prinzip und limitierende Reaktion}

Schon seit Blackman (1905) und Crozrer (1924/25) wird das limitierende Glied in einer Reaktionskette mit dem schwächsten Glied einer tatsächlichen Kette verglichen und insbesondere die langsamste Reaktion als solches betrachtet. Diese Vorstellung des "Master-Prinzips" (oder auch der Schrittmacher-Reaktion) hat durch BURTON (1936) eine weitere reaktionskinetische Behandlung erfahren. Er konnte zeigen, daß dieses Prinzip bei Beeinflussung eine Bedeutung bekommen kann, wobei eine Reaktion sich auf das Gesamtsystem um so stärker auswirkt, je langsamer sie im Vergleich zu den anm deren Reaktionsschritten ist. HINSHEL WOOD (1946) konnte ergänzend dazu nachweisen, $\mathrm{daß}$ die Reaktionsgeschwindigkeitskonstanten voneinander nicht unabhängig sind und $\mathrm{daß}$ besonders auch bei sogenannten limitierenden Reaktionen die Geschwindigkeitskonstanten der übrigen Reaktionen im System mitbestimmend sind; Voraussetzung allerdings ist, daß die Konstanten größenordnungsmäßig nicht allzusehr differieren. Lediglich eine Konstante, welche im Vergleich zu den anderen sehr groß ist, wie dies häufig bei chemischen Reaktionen vorkommt, kann vernachlässigt werden. Auch die Betrachtung des Master-Prinzips und der limitierenden Reaktionen stellt demnach das System als Ganzes vor die Einzelreaktion.

\section{Übergänge in Fließgleichgewichten bei böher organisierten Systemen}

Infolge der komplexen Struktur stoffwechselnder Systeme zeigen diese gegenüber Beeinflussungen nicht bloß einfache (einmalige), sondern schwingungsartige multiple Übergänge mit Dekrement, bisweilen auch Inkrement der Amplitude nach der Zeit.

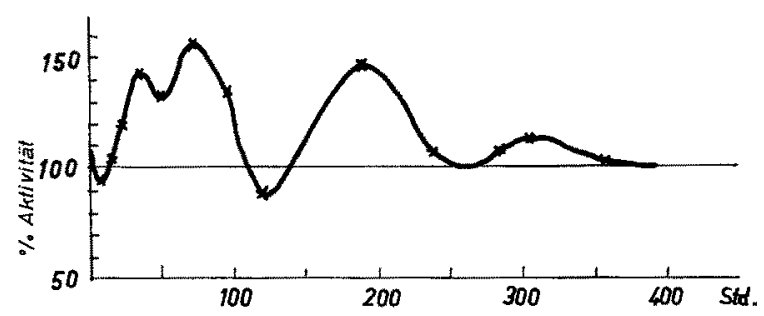

Abb. 1: Schwingungen des Sauerstoffverbrauchs der Rattenhaut (in $\%$ der Normalaktivität) nach einmaliger medhanischer Traumatisation mit Dekrement nach der Zeit (Std.). (Nach Vraud et al. 1958; umgezeichnet)

Diese Schwingungsphänomene treten besonders am Stoffwechsel einzelner Zellen oder organisierter Gewebe nach verschiedenen physikalischen oder chemischen Einflüssen auf. Hier gewinnt nicht nur der Zusammenhang mit der Intensität des einwirkenden Agens, sondern mit weiteren bedingenden Faktoren, wie der Durchblutung und dem Substratgehalt, an Bedeutung. Wird durch besondere Maßnahmen die Durchblutung rhythmisch geändert (so an der Rattenhaut in bestimmten zeitlichen Intervallen nach mechanischer Traumatisierung) (Vraud et al. 1958), dann ändert sich die schon normalerweise stetige und feine Vasomotion (Chambers \& ZWEIFACH 1947) und den 
thythmischen Funktionsänderungen der Haargefäße folgt der $\mathrm{O}_{9}$-Verbrauch außerordentlich genau nach (Abb. 1). Schwingungen im Stoffwechsel können auch unabhängig von Durchblutungsänderungen zustande kommen und müssen dann Ausdruck quantitativer Alterationen an biochemischen Reaktionen sein, wiederum besonders unter dem Einfluß des Stoffwechselsubstrats. Als ein Beispiel sei der schwingungsartige

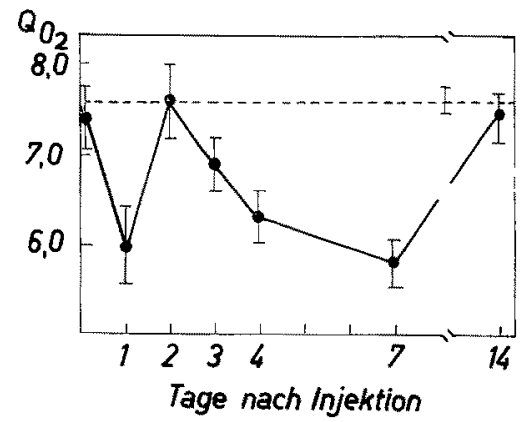

$\mathrm{Abb}$. 2: Sauerstoffverbrauch der Rattenleber in vitro (nach Inkorporation von $5 \mu \mathrm{C}{ }^{32} \mathrm{P} / \mathrm{g}$ Körpergewicht), Ordinate: Q02, Abszisse: Zeit in Tagen. (Nach IRving \& Perkinson 1960; umgezeichnet)

Verlauf des Sauerstoffverbrauchs der Rattenleber nach 32P-Inkorporation (,innerer Bestrahlung") genannt (Irving \& Perkinson 1960) (Abb. 2). Die anaerobe Glykolyse zeigt genau das gleiche Verhalten. Etwas diesen Reaktionen durchaus Entsprechendes wird am $\mathrm{O}_{2}$-Verbrauch der Leber und anderer Gewebe von Mäusen gefunden, die

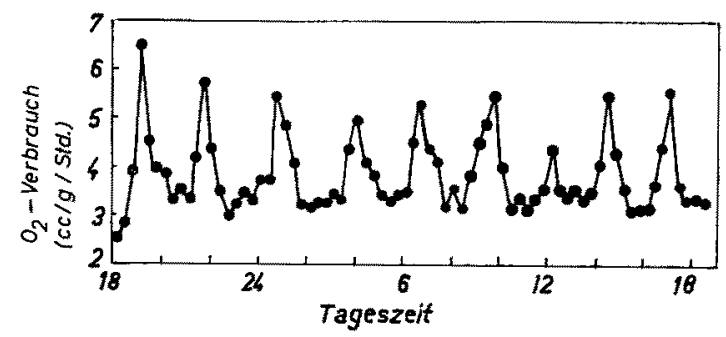

Abb. 3: Rhythmische Schwankungen des Sauerstoff verbrauchs des grönländischen Lemmings in Verlaufe eines Tages. Genaue Periodizität von 2,2-3,8 Std. (Nach Frsher \& NeEdler 1957; umgezeichnet)

einerseits längere Zeit tiefer $\left(2^{\circ} \mathrm{C}\right)$, andererseits hoher Temperatur $\left(38^{\circ} \mathrm{C}\right)$ ausgesetzt waren (JASPER et al. 1958). Hier macht sich übrigens eine gewisse Hierarchie im Reagieren bemerkbar: Gegenüber den lebhatten Änderungen auf dem Niveau der Gewebsatmung, etwa nach Röntgenbestrahlung (Locker 1964a), sind die Reaktionen des Gesamt-O2-Verbrauchs gering (Locker 1963a).

Von solchen Phasenreaktionen mit Dekrement oder Inkrement sind die rhythmischen Reaktionen des Stoffwechsels zu unterscheiden, die nicht als Antworten auf Außeneinflisse auftreten, sondern endogene (autonome) Ursachen haben: Wie die genaue Mehrstunden-Periodizität des Gesamtstoffwechsels des grönländischen Lemmings (FISHER \& NEEDLER 1957) (Abb. 3) und viele andere, in den Geweben sich ab- 
spielende Stoffwechselfunktionen. Sie sind nicht Ausdruck von Übergangsphänomenen, d. h. Wiederherstellung gestörter Fließgleichgewichte, sondern von thythmischen Spontanaktivitäten, die wohl auch (zumindest was die beiden Niveaus der Ruhe und Aktivität betriff) unter dem Bild des Fließgleichgewichts verstanden werden können, für welche es aber andere Erklärungsmodi gibt, auf welche wir zum Schluß unserer Betrachtung kurz einzugehen haben.

\section{REIZ-REAKTIONS-GESETZE AN METABOLISIERENDEN SYSTEMEN}

\section{Hemmungserscbeinungen und das WEBER-FECHNERsche Gesetz}

Kinetik der Enzymhemmung

Die „klassischen" Formen der Hemmkinetik an Enzymreaktionen werden durch die kompetitive Hemmung, bei der das Substrat durch einen strukturähnlichen Inhibitor vom aktiven Zentrum abgelenkt wird, durch die nichtkompetitive Hemmung, bei der sich der Hemmstoff unabhängig von der Anwesenheit des Substrats mit dem Enzym verbindet und die unkompetitive Hemmung, bei welcher eine Bindung des Hemmers an den ES-Komplex, nicht aber an das freie Enzym eintritt, repräsentiert. Die Hemmkinetik der Enzymreaktionen, der vorwiegend bearbeitete Teil der Enzymkinetik, hat in der letzten Zeit eine Bereicherung durch die Einführung einer neuen Nomenklatur (Cleland 1963) erfahren. Diese Enzymkinetik geht über die vordem genannten Hemmtypen hinaus und untersucht weitere Hemmungsformen, nämlich die Produkt-Hemmung, die sogenannte alternierende Produkt-Hemmung und die Totpunkt-Hemmung („dead end inhibition“). Für typische, diese Hemmformen realisierende Fälle wurden auch die Geschwindigkeitskonstanten errechnet. Auf Aktivierungsvorgänge, die wir später noch eingehend betrachten müssen, wurde die neue Kinetik bisher nicht angewandt.

Hemmreaktionen in höheren Systemen

(Das WEBER-FECHNERsche Gesetz)

Besonders bei Hemmungsreaktionen biologischer Prozesse, allerdings nicht nur ausschließlich bei diesen, wird eine formale Beschreibung häufig als den Gegebenheiten angemessen gefunden, die als WEBER-FECHNERsches Gesetz bekannt ist. Dieses besagt, daß bei logarithmischer (geometrischer) Reizzunahme eine arithmetische Reaktionszunahme erfolgt. Zunächst ist seine Gültigkeit in der Psychologie und Sinnesphysiologie erkannt worden (hier durchaus nicht zur Beschreibung von Hemmungsreaktionen), es kann aber als allgemeines Reiz-Reaktionsgesetz biologischer Systeme überhaupt aufgefaßt werden. Burton (1939) und Spiegelman \& ReIner (1945) haben versucht, es aus dem allgemeinen Ansatz eines Fließgleichgewichts abzuleiten. Burtov (1939) legte dar, weshalb in einem dem WEBER-FEchnerschen Gesetz gehorchenden Prozeß Hemmungsvorgänge zunehmend an Einfluß gewinnen. Es läßt sich nämlich in 
gewissem Sinne als Folgerung aus dem oben erwähnten "Master-Prinzip“ ansprechen. In einem „steady-state“-System kann man durch verschiedene Einflüsse eine Größenveränderung seiner Geschwindigkeitskonstanten herbeiführen. Wird durch diese Beeinflussung eine bestimmte Reaktionskonstante und die Fließgleichgewichts-Konzentration des nachfolgenden Intermediats größer, dann wird infolge der Kräfte, die das System gegen seine Veränderung entwickelt, der Einfluß auf dieses fortlaufend geringer, und zwar entsprechend einem exponentiellen Verlauf. Wird dieser so aufgetragen, daß die logarithmische Abszisse die Geschwindigkeitskonstante und die Ordinate die „steady-state"-Konzentration des Intermediats repräsentieren, kommt eine S-förmige Kurve zustande, deren mittlerer Anteil über einem bestimmten Bereich weitgehend linear erscheint. Obwohl also (z. B. beim Reagieren eines Sinnes-Rezeptors) eine Aktivierung angenommen werden kann, wird diese durch die Reaktivität des Systems (das bereits der Rezeptor als solcher darstellen kann oder durch seine Verbindung mit anderen Rezeptoren entsteht) zunehmend eingeschränkt. Insofern beschreibt das WEBER-FECHNERsche Gesetz eine Hemmreaktion.

In stoffwechselnden Systemen finden wir die ihm gehorchenden Reaktionen (Hemmungen) dann, wenn beispielsweise bei logarithmischer Abszisse, welche die Dosis oder
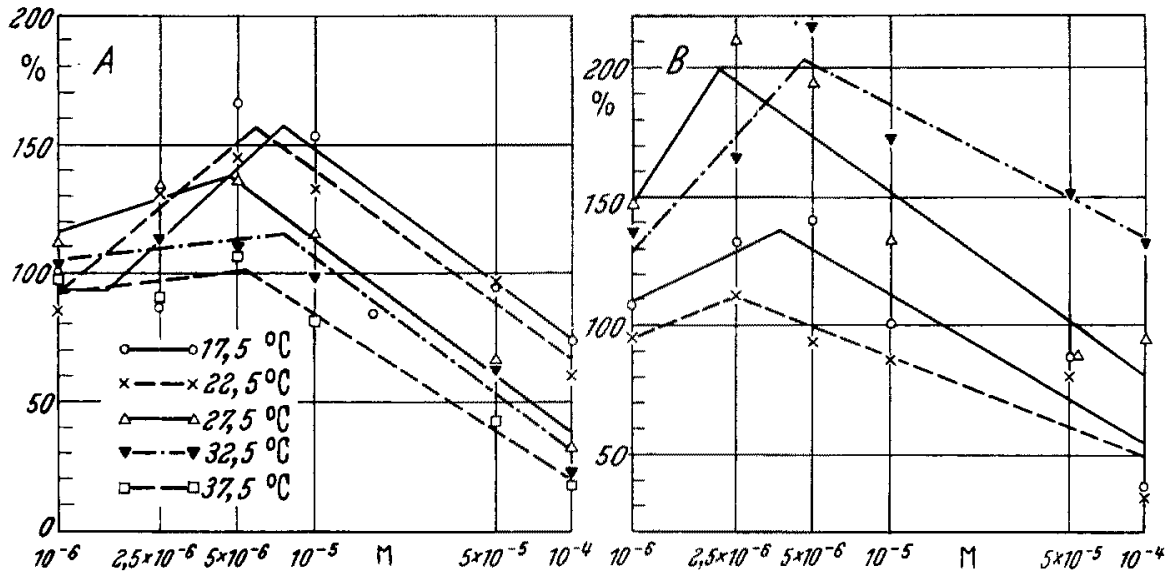

Abb. 4: Charakteristische 2-phasische Dosiswirkungskurven unter dem Einfluß von DNOC verschiedener Konzentrationen auf den $\mathrm{O}_{2}$-Verbrauch der Leber von Maus (A) und Winterfrosch (B) im Temperaturbereich $17,5^{\circ}$ bis $37,5^{\circ} \mathrm{C}$. Ordinate: Aktivität in Prozent, Abszisse: Molare Konzentration. (Nach Locker, Naturwiss. 46, 77-78, 1959)

molare Konzentration darstellt, eine lineare Einschränkung der Aktivität (aufgetragen an der Ordinate) eintritt, wie wir es etwa in Abbildung 4 sehen. Allerdings ist in stoffwechselnden Systemen sehr häufig nicht allein Hemmung festzustellen, sondern auch Aktivierung. Mit diesem Phänomen wollen wir uns nun beschäftigen. 


\section{Aktivierungserscheinungen und das ARNDT-SCHuzzsche Gesetz \\ Die Gegebenheiten im Enzym-Modell}

Den oben erwähnten typischen Hemmformen der Enzymaktivität entsprechend, wurden im letzten Jahrzehnt Aktivierungsformen beschrieben (OGSTON 1955, LAIDLER 1956), die gewisse Komplikationsgrade aufweisen können und in Analogie zu den Hemmformen kooperative, nicht-kooperative und un-kooperative Aktivierung genannt werden. Um die Aktivierung einer Enzymreaktion verständlich zu machen, kann im Modell von der Annahme ausgegangen werden, daß der einwirkende Stoff (I) nicht direkt am aktiven Zentrum des Enzyms angreift, an welchem er hemmen würde, sondern nur in dessen Nachbarschaft, wodurch es, vielleicht durch Einschränkung des Reaktionsraumes und dadurch bedingter Konzentrationszunahme des Substrats, zu Aktivierung konmt (Alberty 1959). Wir schreiben in diesem Fall die Reaktion wie folgt:

$$
\mathrm{S}+\mathrm{E}+\mathrm{I} \leftrightharpoons \mathrm{IES} \longrightarrow \mathrm{IE}+\mathrm{P}
$$

und drücken durch Anschreiben von I links von E seine zu einer Aktivierung führende Funktion aus. Eine etwas komplexere Modellvorstellung, die ich nach den Autoren, die sie zuerst angaben, OGsTon-LAIDLER-Modell nennen möchte (und welche anscheinend weite Anwendbarkeit besitzt) ist die folgende: Das Enzym E verbindet sich mit $\mathrm{S}$ und I unter Bildung eines ternären Komplexes ESI $. \mathrm{K}_{1}, \mathrm{~K}_{2} \ldots$. bedeuten die Dissoziationskonstanten, $\mathrm{k}_{3}$ ', $\mathrm{k}_{3}{ }^{\prime \prime}, \mathrm{k}_{3}{ }^{\prime \prime}$, die Zerfallskonstanten der gebildeten Komplexe:

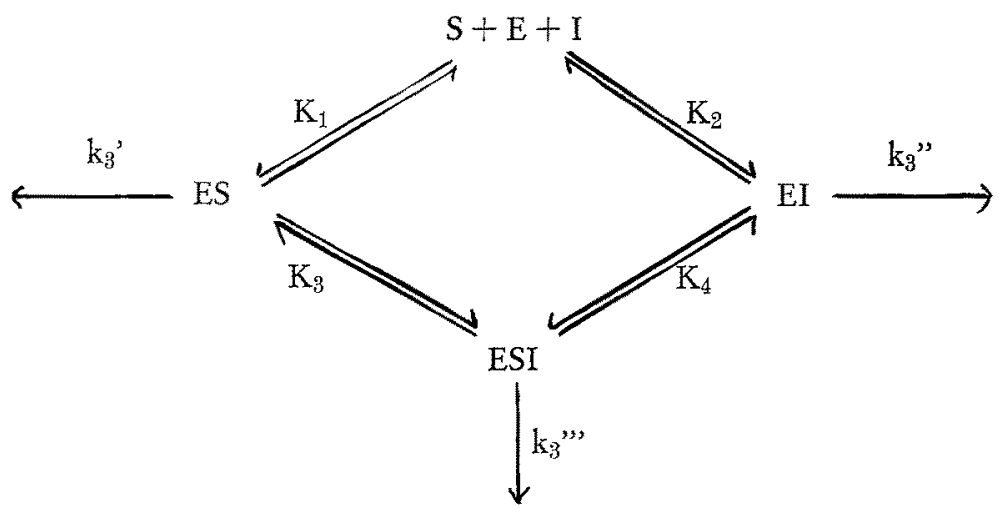

Unter bestimmten Bedingungen, etwa wenn [S] [E], [I] $>[\mathrm{E}]$ und $\mathrm{K}_{2}>\mathrm{K}_{3}$ sind, kann die Bildung des ESI-Komplexes beginstigt werden, so daß die Bildung des EIKomplexes, die eigentliche Hemmreaktion, zurïckbleibt. Das Resultat davon ist eine Aktivierung. In diesem System findet sich eine charakteristische Konzentrationsabhängigkeit: Bei Konstanz von $S$ geht Hemmung in Aktivierung über, wenn I abnimmt; aber auch bei Konstanz von I findet ein Ubergang von Hemmung in Aktivierung statt, wenn $S$ zunimmt. In beiden Fällen muß sich allerdings die Zunahme von $S$ (relativ aber absolut) in bestimmten Grenzen halten, damit es nicht zur bekannten Erscheinung der Substrathemmung kommt. 
Nach dem Ogston-Laidlerschen Modell ist also das eigentliche Movens der Aktivierung das Substrat. Aktivierung als Folge einer Substratmobilisation, d. h. Verfügbarkeit des Substrats für den Eingriff der Enzyme, wurde schon von Holtz et al. (1948) bei der Interpretation von Befunden, die sie bei Aktivierung der Atmung und Gärung der Hefe erhielten, in Erwägung gezogen. Aus dem Ogston-LaIdLerschen Modell der Aktivierung kann eine wichtige Folgerung gezogen werden, nämlich, daß es zur Förderung einer Reaktion (oder Funktion) stets nur auf Kosten einer weiteren, mit dieser gekoppelten Reaktion (oder Funktion) kommen kann. Diese Kopplung ist hier vorwiegend kinetisch und nicht energetisch gesehen. Besonderes Augenmerk muß auf die Feststellung gelegt werden, daß es sich um ein relatives Zurückbleiben beziehungsweise eine relative Aktivierung handelt, also um eine Veränderung innerhalb des Systems und in bezug auf die anderen Glieder. Diese Tatsache soll uns für später als Handhabe zur Unterscheidung von Aktivierung und Schädigung dienen.

\section{Beispiele für Aktivierungserscheinungen in mehrgliedrigen Systemen}

Nachdem der Mechanismus der Aktivierung modellmäßig an enzymatischen Reaktionen veranschaulicht werden kann, nimmt es nicht Wunder, daß wir ihn in analoger Weise in jedem Bereich des Lebendigen wiederfinden, wo Aktivierung zustande kommt. Auch ein künstliches System in vitro, nämlich eine Kultur von Bakterien, welche zusammen mit Leukozyten gezüchtet werden und auf welche Phenol wirkt, zeigt dieses Verhalten (Flemmg 1946). Es können die Phenolkonzentrationen so gewählt werden, daß die Leukozyten, welche durch Phagozytose das Bakterienwachstum in Schranken halten, zugrunde gehen, die Bakterien aber überleben, ja sogar nach Verschwinden der Leukozyten eine Wachstumsbeschleunigung erfahren. Ein sehr brauchbares Beispiel für den dem Ogston-LAIDLER-Modell folgenden Aktivierungsmechanismus liefert die Entkopplung der oxydativen Phosphorylierung, d. h. die Förderung der $\mathrm{O}_{2}$-Aufnahme bei gleichzeitiger Hemmung der Phosphataufnahme. Letztere kann als bloß relative eintreten, wenn trotz Erhöhung der $\mathrm{O}_{z}$-Aufnahme die absolute Phosphorylierungsrate normal hoch bleibt, meist einem theoretisch angebbaren Wert entsprechend (LAMPRECHT et al. 1957). Der P/O-Quotient allein, der hier absinkt, kann darüber nicht genügend Auskunft geben.

Wir werden auf die oxydative Phosphorylierung noch einmal zu sprechen kommen; hier sei nur festgehalten, daß sie auch gefördert werden kann (unter Umständen gekoppelt mit Henmung anderer Reaktionen, etwa bestimmter Formen von Substratveratmung). So haben STANbury \& Mudge (1954) in Homogenatsystemen mit bestimmten Substraten unter Einfluß von Dinitrophenol (DNP) „polyphasische Wirkungskurven" beobachtet, an denen neben einer Zunahme des $\mathrm{O}_{2}$-Verbrauchs eine Beschleunigung der oxydativen Phosphorylierung bemerkenswert war. Nadh LEE \& EILER (1953) wird durch DNP die Phosphorylierung am ersten Zwischenprodulkt, dem Y-Phosphat, beschleunigt; nach Moriwaki (1958) wird durch bestimmte AzidKonzentrationen der Gehalt an energiereichen Phosphatverbindungen in der Krötenblastula erhöht. 


\section{Die Gültigkeit des ARNDT-SCHulzschen Gesetzes}

Zunächst das Resultat rein intuitiver Erkenntnis, später auch experimenteller Untersuchung, besagt das ARnDT-Schulzsche Gesetz, daß starke Reize die „Lebenstätigkeit" zwar hemmen, schwache sie aber zu fördern vermögen. Damit ist zum Ausdruck gebracht, daß ein System unter Einfluß yon Wirkfaktoren zwei Reaktionsphasen zeigen kann: Eine Aktivierungs- und eine Hemm-Phase, wie es dem Ogston-LaIdLerschen Modell entspricht. Für Reaktionen, die unter dem Bild zweier Phasen beschrieben werden können, lassen sich zahlreiche Beispiele anführen. Ich nenne neben
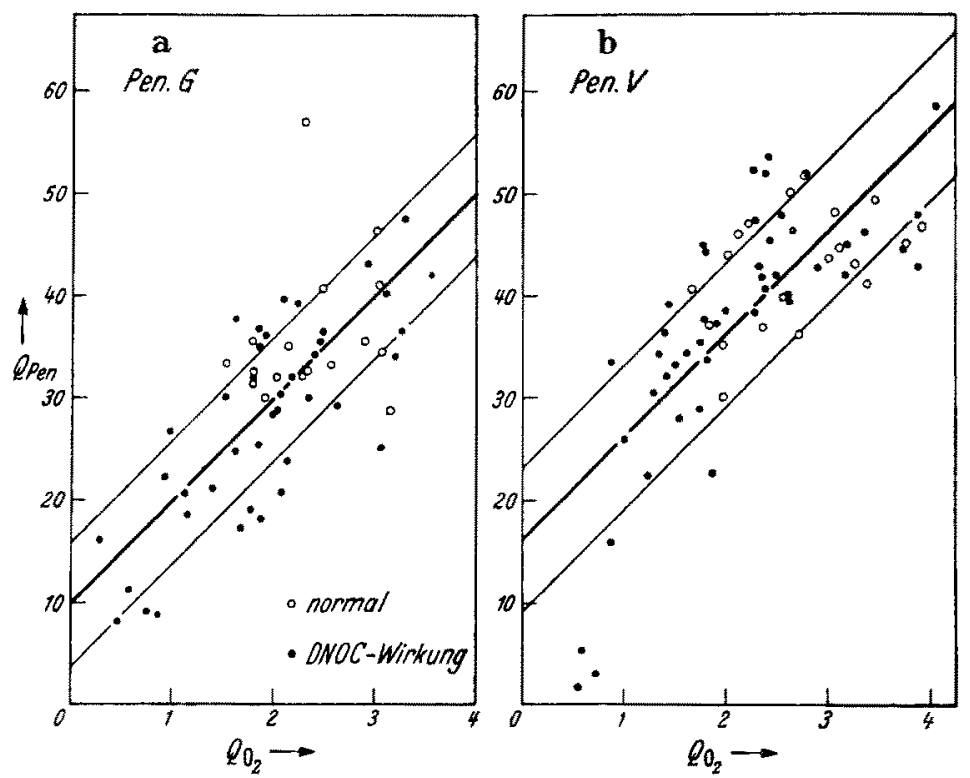

Abb. 5: Der Zusammenhang zwischen der Penicillin-Inaktivierung (QPen als Ordinate) und dem Sauerstoffverbrauch ( $\mathrm{Q}_{\mathrm{O} 2}$ als Abszisse) von Leberschnitten hungernder Meerschweinchen in vitro. Durch DNOC bestimmter Konzentrationen wird sowohl Penicillin-Inaktivierung als Atmung gehemmt oder gefördert, so daß zwischen beiden Größen eine lineare Korrelation besteht. Entsprechend von Hemmung oder Aktivierung würde (bei anderer Auftragung) eine 2-phasische Kurve (s. Abb. 4) resultieren. (Nach Locker \& SPITzy 1956)

der Steigerung und Hemmung des $\mathrm{O}_{2}-$ Verbrauchs des Rattenzwerchfells durch niedrige und hohe Röntgendosen in vitro (Dose 1958) und der Förderung und Hemmung der oxydativen Phosphorylierung durch Thyroxin (BRoNK 1960) aus eigenen Untersuchungen die Förderung und Hemmung der Penicillin-Inaktivierung durch atmendes Lebergewebe unter Einfluß von 4,6-Dinitro-o-kresol (DNOC) (Locker \& Spitzy 1955a) (Abb. 5; s. auch Abb. 4). Für die Inaktivierung von Penicillin wie auch von anderen Antibiotika (z. B. Tetrazyklinen) in vitro (Locker \& SPITZy 1955b) muß ein wahrscheinlich adaptiv (induktiv) gebildetes hydrolytisches Enzym verantwortlich gemacht werden, das in endergonischen Reaktionen aufgebaut wird. Wieder haben wir hier einen Hinweis darauf, daß die sogenannten Entkoppler, die in bestimmten Konzentrationen viele synthetische Reaktionen (wie die Zellteilung, Spermienmotilität, 
Zilienaktivität, Lichtproduktion bei Leuchtbakterien, Schalenproduktion bei Muscheln etc.) hemmen, in anderen Konzentrationen diese auch zu fördern vermögen. So wird beispielsweise die Regeneration von Planarien, wohl unbestritten ein synthetischer Prozeß, durch DNOC beschleunigt (LOCKER 1949; unpubl.); das älteste Beispiel dieser Art ist aber wohl die Beschleunigung der Amphibienmetamorphose durch Thyroxin. Hier darf auch das Phänomen der „kompetitiven Förderung" des aktiven Transports (WILBRANDT 1963) erwähnt werden, das ebenfalls einen zweiphasischen Aspekt bietet, obendrein auch durch ein viergliedriges Modellsystem kinetisch erklärt wurde (CHRISTENSEN 1962).

Von der deutschen Pharmakologie wurde unter Führung Heubners das ARndTSchulzsche Gesetz überprüft und, erstaunlicherweise, für invalid befunden. Brock (1938), ein Schüler Heubners, referierte zusammenfassend die zur Ablehnung des ARNDT-Schulzschen Gesetzes Anlaß gebenden Resultate: Keine eindeutige Beziehung zwischen niederen Stoffkonzentrationen und Förderungserscheinungen (auch hohe Konzentration, z. B. einem Gewebsschnitt in vitro zugesetzt, rufen vorübergehende Atmungssteigerung hervor); niemals wirkliche Förderung eines Prozesses etc. Wir sehen sofort, daß diese Ablehnung mehrere Ursachen hat:

1. das Mißverständnis, unter "Förderung der Lebenstätigkeit" absolute Förderung zu verstehen und zu erwarten; was entsprechend dem OgsTON-LAIDLERschen Modell nicht erfüllt werden kann,

2. die Unzulänglichkeit der Interpretation der Befunde (etwa im Referat von Brock) und

3. die zu geringe Kenntnis des Materials zum Zeitpunkt der "damnatio".

Heute, mit den reichhaltigen Befunden als Basis, läßt sich an der Gültigkeit des ARNDTSchulzschen Gesetzes nicht mehr zweifeln ${ }^{8}$. Es kann, bei der Beschreibung der Reaktionen an Biosystemen, mit dem WEBER-FECHNERschen Gesetz in Verbindung gebracht werden; häufig (siebe Abbildung 4) folgt der Hemmanteil, oft auch der Aktivierungsanteil, bei logarithmischer (Reiz)-Abszisse einer Linearitä $t^{9}$.

\section{Kleiner Exkurs über Scheinerklärungen}

Nachdem die Entkopplung der oxydativen Phosphorylierung, von der wir oben gesprochen haben, ein fast obligatorisch bei Beeinflussungen des Zellstoffwechsels durch Agentien bestimmter Stärke eintretendes Phänomen darstellt, wird man auch Vorsicht bei ihrer Interpretation im Zusammenhang mit physiologischen Prozessen walten lassen. Die bei Kälteadaptation festgestellte Verminderung der P/O-Quotienten (Smith \& Fatrhurst 1958) in dem Sinne aufzufassen, daß die aus der Oxydation stammende Wärme unmittelbar zur Wärmeproduktion verwendet wird, impliziert die

${ }^{8}$ Die deutsche Pharmakologie, besonders die Arbeitsrichtung des HeurNer-Schülers HerKEN, wird sich von dieser späten Rehabilitierung des ARNDT-SchUlzschen Gesetzes nicht berührt zeigen, da sie sich in einer rein "biochemischen Phase“ befindet.

9 Die schon genannte gestaltliche Ahnlichkeit von Dosis-Wirkungs- und Zeit-Wirkungskurven findet auf der Basis des ARNDT-Schulzschen Gesetzes ihre Erklärung: Im zeitlichen Herantreten an den Rezeptor können niedere Konzentrationen (bzw. Dosen) aktivierend wirken, auch wenn die spätere Vollwirkung durch höhere zu einer Hemmung führt. 
Notwendigkeit, normal hohe oder sogar erhöhte Absolutwerte in der Phosphorylierungsrate nachzuweisen, um diese $\mathrm{P} / \mathrm{O}$-Verminderung eindeutig von einer durch Schädigung erzielten zu unterscheiden. Dieser Nachweis ist aber bisher nicht unproblematisch geblieben (Zimny \& Gregory 1958, Chaffee et al. 1961, Kristoffersson 1961). Unzulänglich bleibt auch eine Erklärung, wenn für eine bestimmte Schädigung (z. B. einen pathologischen Prozeß, sagen wir eine Psychose) eine Verminderung der $\mathrm{P} / \mathrm{O}-\mathrm{Quotienten}$ nachgewiesen wird, aber zugleich auch für die den Prozeß therapeutisch becinflussenden Pharmaka.

\section{Das Problem der Ausgangslage}

\section{Das Ausgangslagengesetz (WILDEsches Gesetz)}

Nach dem. Ogston-LaddLerschen Modell entscheidet das Konzentrationsverhältnis von [I] zu [S] bzw. [E] über das Vorliegen einer Hemmung oder einer Aktivierung (der effektive Übergang von niederen zu hohen Konzentrations-Quotienten kann als ARNDT-Schulzsches beziehungsweise Weber-Fechnersches Gesetz beschrieben werden). Zeitunabhängig wird also in diesem Modell ein mittlerer Aktivitäts$z u s t a n d$ (das ist der Normalzustand) vorausgesetzt, von dem ausgehend Hemmung oder Aktivierung eintreten kann. Das aber ist der Inhalt des Ausgangslagengesetzes von WILDER (neuere Zusammenfassung: 1958), das an ganz anderen als den uns hier interessierenden metabolisierenden Systemen gewonnen worden ist, sich aber in der Enzymkinetik (wie schon gezeigt) und im Zellstoffwechsel (wie noch zu zeigen ist) verifizieren läßt. Allgemein formuliert besagt es, daß die Reaktionen eines Systems vom vorgegebenen Zustand des Systems abhängig sind; bei allen Untersuchungen eines metabolisierenden Systems ist dessen vor der Beeinflussung bestehende Aktivitätshöhe, die Ausgangslage, zu beachten.

Die Bedeutung dieses Gesetzes bringt es mit sich, daß das Problem der experimentellen Bedingungen einer besonderen Erörterung bedarf. Bevor wir uns dieser Aufgabe widmen, wollen wir zeigen, wie es sich im Zellstoffwechsel verifizieren (exemplifizieren) läßt. Dies kann an Hand der Befunde von Peiss \& Field (1948) geschehen: An Rattenhirnschnitten wurde durch bestimmte Konzentrationen von DNP der $\mathrm{O}_{2}$-Verbrauch bis zu einer Höhe aktiviert, die genau mit der eines mit allen nötigen Zusätzen (Substraten, Kofaktoren) versehenen Ganzhomogenats übereinstimmt (Abb. 6). Ganzhomogenat bedeutet, daß eine Auftrennung in Strukturelemente (Mitochondrien, Ribosomen, Lysosomen etc.) nicht vorgenommen wurde. Nun dürfte es selbstverständlich sein, daß das Homogenisieren eines Gewebes, verbunden mit der Zerstörung aller Zellen, das Maximum einer Schädigung darstellt (eine Auffassung, die freilich nicht biochemisch ist, sondern die intakte Zelle als die letzte, einen Organismus vertretende Einheit versteht). Entspricht nun der $\mathrm{O}_{2}$-Verbrauch bei dem Maximum dieser Schädigung genau demjenigen, der sich an intakten Zellen (bzw. Gewebsschnitten) mit bestimmten Konzentrationen von DNP erzielen läßt, so ist der Grad einer Schädigung folgendermaßen quantitativ bestimmbar: Bei Zugabe einer aktivierenden Dinitrophenol-Verbindung zu einem Gewebe wird die Atmung um so stärker stimuliert, je geringer die Schä- 
digung des Gewebes ist. Dies konnten Locker \& Spitzy (1951) am Oz-Verbrauch der Leber von mit Luminal oder Diphtherie-Toxin vergifteten Ratten zeigen (Abb. 7), wobei wieder DNOC zur Anwendung kam. War die Atmung durch die vorgegebene Schädigung bereits maximal erhöht, war durch zusätzliche Beeinflussung nur mehr eine
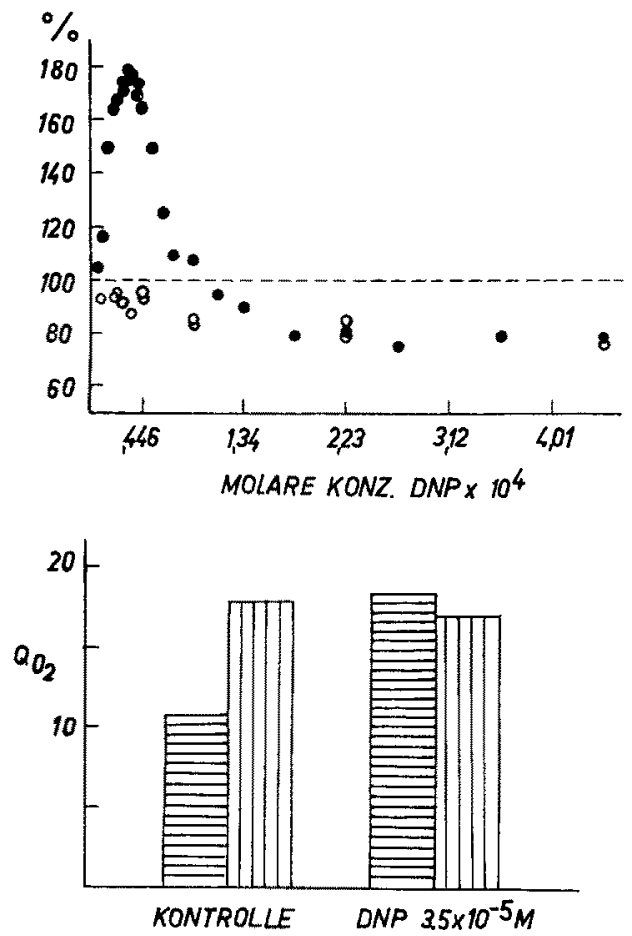

Abb. 6: Oberer Teil: Konzentrations-Wirkungskurve des Sauerstoffverbrauchs (in \%) von Gehirnschnitten $(\bullet)$ und eines verstärkten Ganzhomogenates $(0)$ unter dem Einfluß verschiedener Konzentrationen von DNP. Unterer Teil: Der Effekt von DNP auf die Atmung von Gehirnschnitten (horizontale Linien) und eines Gehirnhomogenates (vertikale Linien). Kontrolle: DNPfreie Atmung. Anstieg der Gehirnatmung auf ein Maximum, welches der (durch DNP praktisch nicht veränderten) Höhe des $\mathrm{O}_{2}$-Verbrauchs des Homogenates entspricht. (Nach PeISS \& FIELD 1948; umgezeichnet)

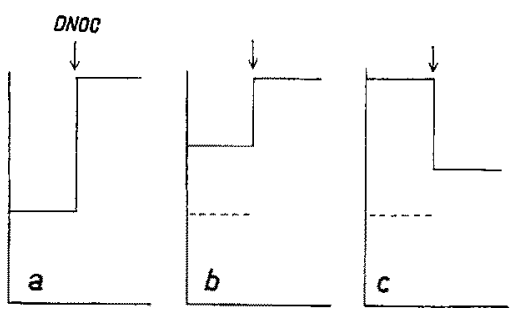

Abb. 7: Wirkung von DNOC bestimmter Konzentration auf die Atmung normaler (a) oder geschädigter Gewebe (b, c). Das DNOC-bedingte Inkrement wird kleiner, wenn bereits die Atmung vorher höher war. Bei maximaler Atmung wird durch DNOC lediglich Herabsetzung hervorgerufen (c). (Nach Locker \& SPITZY 1951) 
Verminderung zu erzielen. Dieser Befund legt die Abhängigkeit des Effekts von der Ausgangslage darto.

Methodische Bedingungen und "Schädigungsstoffwechsel"

Bei Messung des $\mathrm{O}_{2}$-Verbrauchs von Zellen, die als solche schon in situ vorliegen (z. B. Bakterien oder Leukozyten), wird die Frage des adäquaten Mediums (z. B. einer
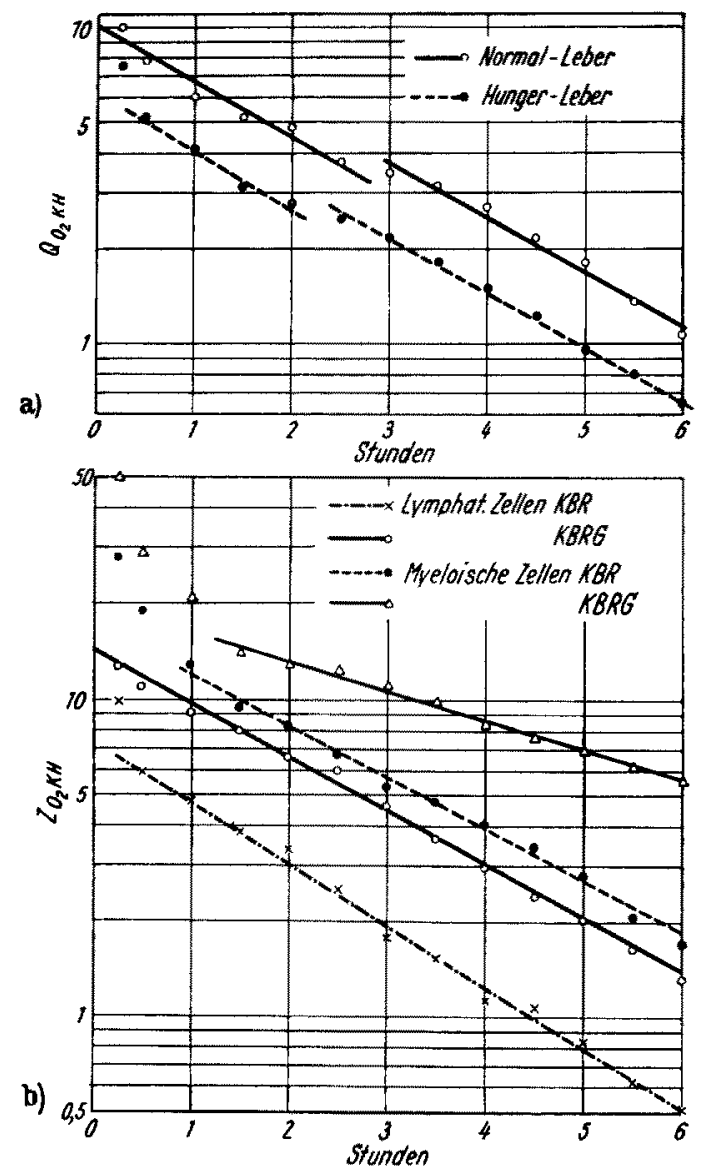

Abb. 8: Logarithmischer Abfall der Kohlenhydrat-Oxydation bei der Rattenleber (a) und bei leukämischen Leukozyten (b). (Nach Locker \& Spitzy 1956a)

Salzlösung bestimmter Zusammensetzung, die optimale Beschaffenheit der Zellen garantiert) im Vordergrund stehen. Die Zellen selbst werden zunächst (wenn sie schonend gewonnen und gewaschen wurden) nicht verändert sein. Ganz anders ist jedoch die

10 Dieses Verfahren bezeichneten wir kurz als "DNOC-Test" und verwendeten es auch zur Charakterisierung anderer Formen von Schädigung (siehe später). 
Situation, wenn Gewebe aus einem Organismus herausgenommen, also beispielsweise Organschnitte (entsprechend der WARBURG-Technik) hergestellt werden müssen. An der Oberfläche des Schnittes befinden sich geschädigte Zellen; ihr Antell am Schnitt ist um so größer, je dünner der Schnitt ist. Es war das Verdienst DrUCKReys (1936), erstmals auf den Zusammenhang der Atmungshöhe und des Verlaufs in vitro (sowie des Auftretens einer aeroben Glykolyse) mit methodischen (und schädigenden) Bedingungen aufmerksam gemacht zu haben. Er prägte den Begriff des "Schädigungsstoffwechsels“, der durch anfänglich hohe Atmung und raschen Atmungsabfall in vitro definiert wird. Seither ist eine große Literatur uber die optimale Behandlung von Zellen in vitro entstanden. Zellen und Gewebe verlieren in vitro (in flüssigem Medium) nicht nur an Substanz (AEBI 1952), sondern verbrauchen, wenn man lediglich ihre endogene Atmung betrachtet, auch thr Substrat (Locker \& SPITZy 1956a) (Abb. 8), weshalb es notgedrungen zu einem Abfall der Atmung in vitro kommen muß. Die Unterbredhungen im (formal monomolekularen, d. h. dem Glucose- bzw. Glykogen-Verbrauch entsprechenden) Atmungsabfall können durch das Mitwirken zusätzlicher methodischer Bedingungen (wie hohen $\mathrm{O}_{2}$-Gehalts des Mediums, Quellung und mechanischer Schädigung der Schnitte) erklärt werden. Von Warburg et al. (1957) wird auf die Notwendigkeit, an Stelle eines Salzmediums homologes Serum zu verwenden, hingewiesen. Neuere methodische Anordnungen (Huston \& MARTIN 1954, Hosein et al. 1962) vermeiden überhaupt die Suspension des Schnittes in der Flüssigkeit. Trotz der zahlreichen methodischen Einschränkungen wird sich die WARBURG-Technik weiter erhalten und kann auch tatsächlich als "physiologische Methode" angesprochen werden, deren Resultate Modellcharakter für ein stoffwechselndes System haben (LockER \& SPITZy 1956a), zumal ein solches nie isoliert von bedingenden Faktoren betrachtet werden kann.

Auch die Frage, worauf der Zellstoffwechsel bezogen werden soll, ist nicht leicht zu lösen. Üblicherweise benützt man das Trockengewicht, aber auch das Feuchtgewicht, den N-oder DNS-Gehalt (SIEBER T 1954); neuerdings auch den Hydroxyprolingehalt als Repräsentanten für Kollagen (ReEs 1960). Alle Bezugsbasen sind mit einer grundsätzlichen Problematik belastet; of muß der Experimentator selbst entscheiden, welches die beste Bezugsbasis ist. Wird beispielsweise an der Froschleber der $\mathrm{O}_{2}$-Verbrauch auf Trockengewicht bezogen, so ist er beim Winterfrosch tiefer (LOckeR \& DONEFF 1958), wie es dem Gesamtstoffwechsel des Tieres in Zusammenhang mit der Jahreszeit entspricht (Fromm \& JoHNSON 1955). Bezieht man aber auf Stidkstoff, eliminiert also den starken Unterschied $z$ wischen beiden Saisonformen in Glykogengehalt, resultiert eine gleich hohe Atmung. Ganz ähnliche Diskrepanzen, die allerdings nicht völlig einer Interpretation unzugänglich sind, treten bei Anwendung verschiedener Bezugsbasen in der Untersuchung des Zusammenhangs der Gewebsatmung mit der Körpergröße auf (LOCKER 1961a) ${ }^{11}$.

11 Aus der Erörterung dieser Schwierigkeiten dürfte der Schluß gezogen werden können, $\mathrm{daB}$ es bei einem konkreten stoffwechselnden System unmöglich ist, sicher $z$ wischen schon präexistierenden Systembedingungen und experimentellen Bedingungen zu unterscheiden. Nur Grenzbedingungen wird man dort herausheben können, wo eine bislang monotone Funktion abbricht und durch eine andere ersetzt wird. 
Ausgangslage und Gesamtstoffwechsel

(Das Problem des Basalstoffwechsels)

Nicht nur am Zellstoffwechsel, sondern vor allem auch am Gesamtstoffwechsel (und in der Reaktivität eines ganzen Organismus) stellt sich das Problem der Ausgangslage in seiner ganzen Tragweite dar. So ist seit langem bekannt, daß sich gegen-

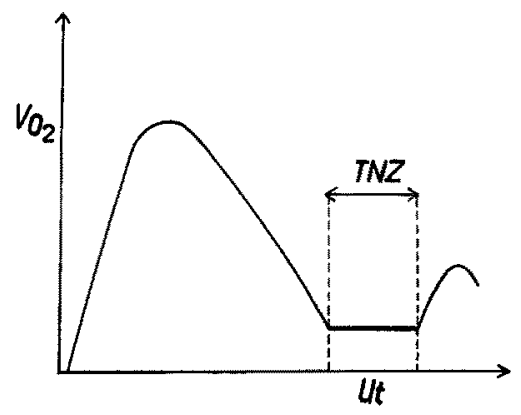

Abb. 9: Charakteristische Beziehung zwischen dem Gesamt-Og-Verbrauch $\left(\mathrm{VO}_{2}\right)$ und der Umgebungstemperatur (Ut) bei Säugetieren. Im Bereiche der Thermoneutralitätszone ('T'NZ) liegt der niedrigste Stoff wechsel vor

über bestimmten Giften Kalt- und Warmblüter verschieden verhalten (HiESTAND et al. 1956): Erstere sind im allgemeinen bei höherer, letztere bei tiefer Umgebungstemperatur empfindlicher. Kaltblüter sind (wohl wegen ihres niederen Stoffwechsels) auch gegenüber ionisierenden Strahlen resistenter als Warmblüter (Locker 1962a) ${ }^{12}$. Bei Kalt- und Warmblitern ist die Stoffwechselhöhe und damit die Stoffwechselreaktivität weitgehend von der Umgebungstemperatur abhängig.

Auf der Suche nach einer biologischen Ausgangslage des Gesamtstoffwechsels stoBen wir in erster Linie auf den Begriff des Basals tof f wechsels. Beim Warmblüter (Säugetier und Vogel) ist dieser relativ leicht zu definieren, weil hier eine bestimmte Beziehung zwischen Umgebungstemperatur und Stoffwechsel herrscht (Abb. 9), die einen Bereich des niedrigsten Stoffwechsels deutlich heraushebt: die Thermoneutralitätszone, die mit gewisser Berechtigung als physiologische Ausgangslage angesprochen werden kann. Sie ist verbunden mit geringster (motorischer) Aktivität, niedrigster Körpertemperatur und repräsentiert zugleich eine Art Behaglichkeitszone des Tieres. Bei tieferen Umgebungstemperaturen als jenen, welche der Thermoneutralitätszone entsprechen, kommt es - als Maßnahme zur Konstanterhaltung der Körpertemperatur - zur sogenannten Kältegegenregulation. Auch die bei einer beliebigen tieferen Umgebungstemperatur vorliegende Höhe des Stoffwechsels ist eine Ausgangslage bestimmter, eben den experimentellen Bedingungen entsprechender Natur, der man Rechnung tragen muß, sobald man nun die Reaktion auf eine Beeinflussung studieren will. Die Thermoneutralitätszone ist bloß eine „biologische Konstante“, also selbst wieder weitgehend von Bedingungen abhängig und daher relativ leicht zu verändern, etwa durch den Hungerzustand (Locker 1962b) (Abb. 10). Was den Hungerzustand betriff, darf erwähnt werden, daß er natïrlich nur in Abhängigkeit von einer arbiträren Vor-

12 Uber Unterschiede zwischen Kalt- und Warmblïtern werden wir noch sprechen. 
entscheidung zur Geltung kommt: Eine 24 Stunden hungernde Maus ist einer härteren experimentellen Belastung unterworfen als ein Kaninchen oder Hund mit viel niedrigerem Stoffwechsel durch eine Fastenzeit gleicher Dauer.

Beim Kaltblüter (poikilothermen Wirbeltier und Wirbellosen) ist eine Ausgangslage, die als physiologisch oder als Basalstoffwechsel anzusprechen wäre, viel schwieriger herzustellen und zu definieren. Es bestehen hier verschiedene Möglichkeiten, was

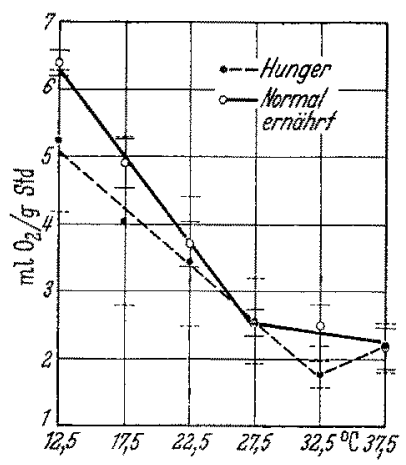

Abb. 10: Verschiedenartige Beziehung des Sauerstoffverbrauchs von normalernährter und

$24 \mathrm{Std}$. hungernder Maus gegenüber der Umgebungstemperatur. (Nach LocKer. 1962b)

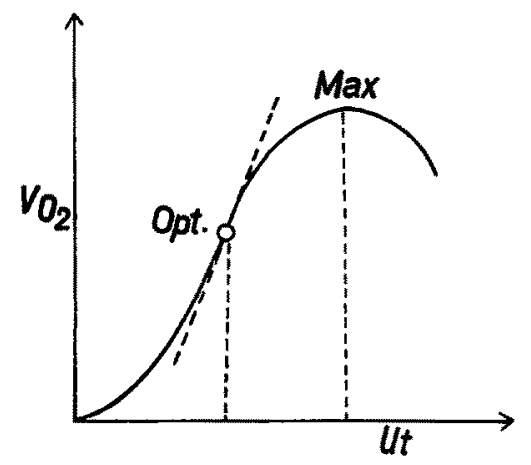

Abb. 11: Schematische Darstellung der Beziehung zwischen Gesamt- $\mathrm{O}_{2}$ Verbrauch $\left(\mathrm{VO}_{2}\right)$ und Umgebungstemperatur (Ut) beim Kaltblüter. Die Gegend um den Inflektionspunkt charakterisiert ein Optimum, das in spezifischer Weise vom Maximum unterschieden ist

wieder unsere Vorentscheidung und dic Abhängigkeit des Resultats von dieser demonstriert. So wurde der Vorschlag gemacht (FonTaINe 1956) und (allerdings beim Warmblüter) in die Tat umgesetzt (Heusner 1956), den bei verschiedenen definierten Aktivitäten gemessenen Stoffwechsel auf eine niemals realisierbare Null-Aktivität zu extrapolieren, um den Basalstoffwechsel zu erhalten. Hier bedeutet er eine abstrakte Größe.

Eine andere Möglichkeit besteht darin, den Stoffwechsel bei verschiedenen Temperaturen zu messen ${ }^{13}$. Aus der Stoffwechsel-Temperaturkurve, die bei nicht-adap-

${ }_{13}$ Freilich ist er schon durch die vorhergegebene Temperatur und die Adaptationsdauer an diese mitbestimmt. 
tierten Tieren etwa S-förmig ist ${ }^{14}$ (Abb. 11) läßt sich im Bereich des Inflektionspunktes ein Stoffwechsel-Optimum bestimmen, das sich deutlich von einem Maximum unterscheidet; Optimum deswegen, weil hier der Temperatureinfluß nach oben und unten am größten ist und damit, entsprechend dem Ausgangslagengesetz, einen mittleren (physiologischen) Reaktivitätszustand voraussetzt ${ }^{15}$. Es ist tatsächlich bei wechselwarmen Tieren eine Differenz zwischen dem Thermopräferendum (oder Vorzugstemperatur, die etwa der Thermoneutralitätszone der Homoiothermen entspricht und vielleicht die durchschnittliche Biotop-Temperatur repräsentiert) und dem Temperaturmaximum des Stoffwechsels weit verbreitet (z. B. Doudoroff 1938; weitere Literatur bei Precht 1955).

Schließlich eröffnet sich, bei Betrachtung der Beziehung zwischen Stoffwechselhöhe und Körpergröße, noch eine Möglichkeit, beim Kaltblitter die physiologische Ausgangslage zu bestimmen. Die Stoffwechselreduktion (LeHMANN 1951), auf die wir später noch
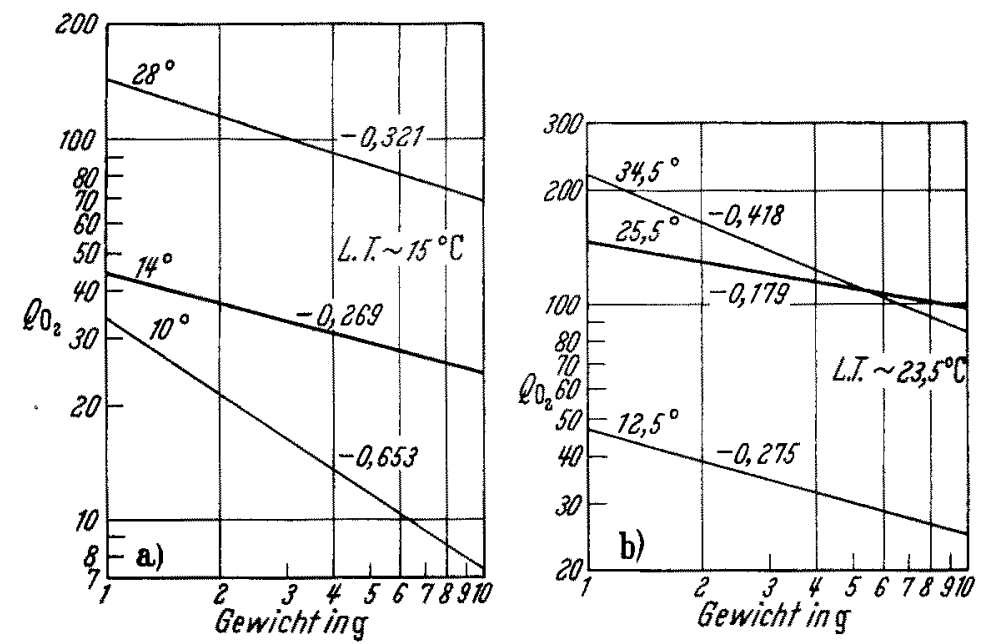

Abb. 12: Die Beziehung des Oz-Verbrauchs der Krabbe Uca pugnax zur Körpergröße. Tiere aus zwei verschiedenen Lebenstäumen. a) North Carolina; b) Florida. Bei Ubereinstimmung der Untersuchungstemperatur mit der Durchschnitts-Temperatur des Lebensraumes (L. T. $\sim 15^{\circ} \mathrm{C}$ bei a; $\sim 23,5^{\circ} \mathrm{C}$ bei $\mathrm{b}$ ) ist die Neigung der Regressionsgeraden am geringsten. Ordinate: $\mathrm{Q} 02$ (ml Ö/g Frischgewicht), Abszisse: Körpergewicht. (Nach Locker 1961b unter Verwendung der

Daten von R. E. TAshian, 1956, und F. J. VernBerg, 1959; kombiniert und vereinfacht)

kurz zu sprechen kommen werden, verändert sich in Abhängigkeit von Untersuchungsbedingungen und Umweltparametern. Bei Übereinstimmung der Untersuchungstemperatur mit der durchschnittlichen Biotoptemperatur ist sie jedoch (zumindest bei Wirbellosen) am geringsten (LOCKER 1961b) (Abb. 12); übrigens auch bei aquatilen Wirbellosen bei Übereinstimmung des Salzgehalts des Mediums mit dem Salzgehalt des Biotops (RAO 1958).

14 Vergleiche hierzu die Resultate von ROBERTS (dieses Symposion).

15 Wahrscheinlich nimmt von diesem Optimum auch der Temperaturadaptationsvorgang seinen Anfang; er scheint es möglichst zu verbreitern (ROBERTs, dieses Symposion). 
Aktivierung und Ausgangslage in der Pharmakologie

Da sich die Pharmakologie mit Reaktionen von Systemen gegenuiber Beeinflussung beschäftigt, hat auch in ihre Grundvorstellungen das Problem der Ausgangslage Einzug gehalten und besitzt hier, im Gegensatz zum ARndT-Schulzschen Gesetz, erfreulicherweise positive Bedeutung. Eine der enzymkinetischen analoge Betrachtung hat ebenfalls Anklang gefunden (Ariens et al.1956, van Rossum \& HurKmans 1962); sie verwendet die Gleichungen der Enzymkinetik, jedoch unter Wandlung der Terme $E$ und $S$ in $R$ (Rezeptor) und A (Aktor). In dem zitierten Ansatz wird kein Bezug auf das Ogston-Latdler-Modell genommen und damit der Weg zur Behandung von Aktivierungsphänomenen verbaut. Nach CLARK (1937) nimmt die auf EHRLICH zurückgehende Rezeptor-Theorie an, daß jeder Effekt der Anzahl der besetzten Rezeptoren direkt proportional und ein maximaler Effekt bei 100\% Rezeptorenbesetzung erreicht wird. Die Vorstellungen, die demgegenüber Stepuenson (1956) in Weiterbildung der Rezeptor-Theorie entwickelt hat, lassen sich gut zur Interpretation von Aktivierungsvorgängen heranziehen und stimmen in ihren Grundzügen mit dem Ogston-LAidler-Modell überein. Es wird von der Annahme ausgegangen, daß sich auch durch geringere als 100\%ige Rezeptorenbesetzung eine maximale (oder volle) Wirkung erzielen läßt und außerdem postuliert, daß zur gleichen Wirkung differente Rezeptorenbesetzung führen kann. Dadurch schwinder der scharfe Gegensatz zwischen Agonist (Synergist) und Antagonist, den übrigens auch LoEwe (1959) ablehnt. Auch ein schwacher Agonist kann zu einem Antagonisten eines stärkeren werden, wenn er schon vorher zufolge seiner geringeren Wirksamkeit eine größere Anzahl von Rezeptoren besetzen mußte. Diese Vorstellung läßt sich durch die Überlegung ergänzen, daß zwei (oder mehrere) Agonisten mit verschiedener Wirksamkeit sich zu einer maximalen Wirkung addieren können, wenn jeder für sich nur eine mittlere Wirkung zu erzielen vermag.

\section{MIT DEN REIZ-REAKTIONS-GESETZEN IM ZUSAMMENHANG STEHENDE PHANOMENE}

\section{Einige Konstanz-Phänomene}

Nach diesem Ưberblick über die wichtigsten Reiz-Reaktions-Gesetze in metabolisierenden Systemen wollen wir uns einigen Phänomenen zuwenden, die mit ihnen im Zusammenhang stehen. Wir wollen sie Konstanz-Phänomene nennen, weil sich in ihnen die Aufrechterhaltung (oder Wiederherstellung) des Fließgleichgewichts dokumentiert und sie auch häufig (unter Nullsetzung des Zeitparameters) tatsächlich als numerische (summative oder multiplikative) Konstanten aus zwei oder mehr Vorgängen beschrieben werden können ${ }^{16}$.

16 Nidht nur an dieser Stelle unserer Betrachtung, sondern auch an vielen anderen wird die Möglichkeit offenbar, sie gleichwertig unter dem Gesichtspunkt der Regelkunde zu führen. 
Nicht immer ist bei Zunahme der Dosis (oder Konzentration) eine Zunahme der Wirkung festzustellen; schon früher haben wir "polyphasische Wirkungskurven“ erwähnt, die in komplexen Mitochondriensystemen zur Beobachtung kommen (STANBURY \& MUdGe 1954). Ein direkt paradoxes Verhalten ist gegeben, wenn trotz Erhöhung der Dosis Verringerung der Wirkung (oder umgekehrt) eintritt. In der Mikrobiologie ist das Zonenphänomen (EAGLE 1948) bekannt, wonach trotz Konzentrationserhöhung von Antibiotika oder Chemotherapeutika die Hemmwirkung auf das Wachstum abnimmt. Dieses als paradox beschriebene Verhalten kann unschwer mit dem Ausgangslagengesetz in Verbindung gebracht werden. Nicht so leicht werden manche andere Effekte auf Reiz-Reaktions-Gesetze zurückgeführt werden können, obwohl grundsätzlich auch kein Gegensatz zu ihnen besteht; ein Beispiel ist die Erhöhung der Körpertemperatur von Säugern unter Einwirkung sogenannter hypothermisierender Substanzen bei höheren, tneist über einem kritischen Wert $\left(\sim 35^{\circ} \mathrm{C}\right)$ liegenden Umgebungstemperaturen (SCHMIDT 1963).

\section{Der Komplettierungseffekt}

Läßt sich in stoffwechselnden Systemen durch bestimmte Einflüsse ein maximaler Effekt erzielen, dann kann dieser auch durch Addition von Teileinflüssen hervorgerufen werden. So wird an der Gärung der Bierhefe durch $4 \mathrm{M} \mathrm{NaCl}$ eine maximale Steigerung bewirkt (Hotrz et al. 1948), aber auch die Wirkungen von $1+3 \mathrm{M}$ oder $2+2 \mathrm{M}$ ergänzen sich genau zu diesem Effekt.

\section{Regulationen}

Da auch bei der Befruchtung des Seeigeleis Atmungssteigerung und aerobe Glykolyse auftritt, vermuteten DRuCKREY et al. (1938), daß der Befruchtungsstoffwechsel eine Form des Schädigungsstoffwechsels wäre. Das war eine von einem Einzelbefund ausgehende, nicht stichhaltige, Verallgemeinerung, der gegenüber sich durch Untersuchung des Stoffwechsels des Eies vieler mariner Wirbellosen vor, während und nach Befruchtung zeigen läßt (BRACHET 1947), daß die zunächst stark divergierenden Atmungswerte auf ein für viele Spezies weitgehend gemeinsames Niveau gebracht werden. Hierbei wird ein zunächst hoher $\mathrm{O}_{2}$-Verbrauch gesenkt, ein tiefer gesteigert und ein mittlerer nicht verändert ${ }^{17}$. Eine solche Erscheinung läßt sich wohl angemessener „Regulationsstoffwechsel ${ }^{\text {" }}$ als "Schädigungsstoffwechsel" nennen.

Im Zellstoff wechsel lassen sich einige Kontrollpunkte mit einer Art Schlüsselfunktion aufzeigen (meist Quotienten wie ATP/ADP + anorganisches Phosphat zur Energiekontrolle, DPN/DPN $\cdot \mathrm{H}_{2}$ zur Brennstoffkontrolle und CoAS $\sim \mathrm{R} / \mathrm{CoA} \cdot \mathrm{SH}$ zur

17 Bedingt sein mag der ähnliche Stoffwechsel des befruchteten Eies bei vielen Spezies durch Ahnlichkeit in der Größe, in der chemischen Zusammensetzung und in den nach der Befruchtung einsetzenden biochemischen Mechanismen. 
Baustoffkontrolle; OpITz \& LüBBERs 1957); von ihnen geht eine Steuerung, Kontrolle oder Regulation aus. Hierher gehören auch die seit langem bekannten Erscheinungen des Pasteur-Effekts, der Hemmung der Glykolyse durch die Atmung, und des umgekehrten PASTEUR-Effekts oder CRABTREE-Effekts, der Hemmung der Atmung durch Glykolyse beziehungsweise der endogenen Atmung durch die Glucoseveratmung. Diese Phänomene sind in den letzten Jahren zum Gegenstand von Fließgleichgewichtsbetrachtungen genommen worden (Hess 1963).

\section{Kompensation}

Ohne Eingehen auf die biochemischen Umsätze ist auch die Kompensation des Ausfalls einer Reaktion durch das verstärkte Eintreten einer anderen (gekoppelten) nicht leicht verständlich. So wird die bei länger dauernden Reizen oder Schädigungen eintretende Anderung im Bestand gewisser Enzyme als Kompensation für den Ausfall

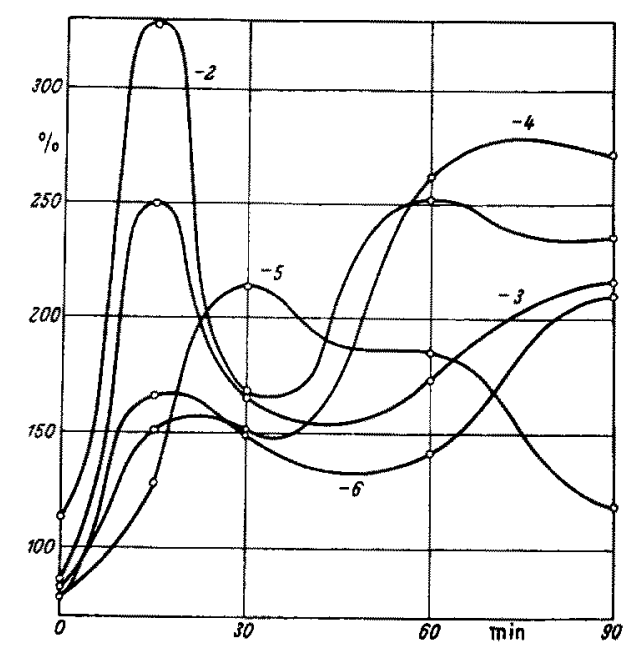

Abb. 13: Verlauf der prozentuellen Abweichungen der Kohlenhydrat-Veratmung der Rattenleber nach Zusatz von Diamox bestimmter Konzentrationen $(-2$ bis $-6: \log$. mol. Konz.) 1 Std. nach Versuchsbeginn. Ordinate: \% \% Aktivität, Abszisse: Zeit nach Zusatz. (Nach Locker et al. 1956d)

anderer angesehen, durch die es zur Aufrechterhaltung einer normalen Aktivität (also auch synthetischer Reaktionen) kommen soll (VILLA et al. 1957). Interpretationen dieser Art, die ja schon Enzymsynthesen einschließen, sind wahrscheinlich nicht unproblematisch. Aber bei jeder Vorstellung von Kompensation wird ein gewisser Normbegriff vorangestellt: Dies triff für die WARBURgsche Theorie der Krebsentstehung zu: Kompensation des Atmungsausfalls durch die (das ungehemmte Wachstum ermöglichende) aerobe Glykolyse, ebenso für die Annahme, daß die durch die Entkopplung energetisch weniger ergiebig gewordene Atmung sich notgedrungen erhöhen muß, damit wieder ausreichend Energie gewonnen und in Phosphatestern gespeichert werden kann 
(LAMPRECHT et al. 1957). In diesen Vorstellungen werden die meßbaten Aktivitäten $z w e i e r$ Vorgänge zu einem als konstant angenommenen Produkt vereinigt.

\section{Das Phänomen der Erbolung}

\section{Übergänge als Rückkehrdes Systems zum Normalzustand}

Erholungsvorgänge, Rückkehr des Systems zum Normalzustand, können nur zeitabhängig adäquat erfaßt werden; hierher gehören die schon früher erwähnten Übergangsphänomene. Sie werden auch sehr deutlich an kurzdauernden in vitroEinflüssen der Gewebsatmung, wobei gleichzeitig ein gewisser Aufschluß über die Reaktivität des Systems zu erhalten ist. So läßt sich durch Zusatz des SulfonamidDiureticums Diamox zu Leberschnitten hungernder Ratten (LOCKER et al. 1956d) (Abb. 13) eine Schwingung als der konzentrationsabhängigen Kohlenhydratmobilisation und eine weitere als dem konzentrationsunabhängigen Quellungszustand des

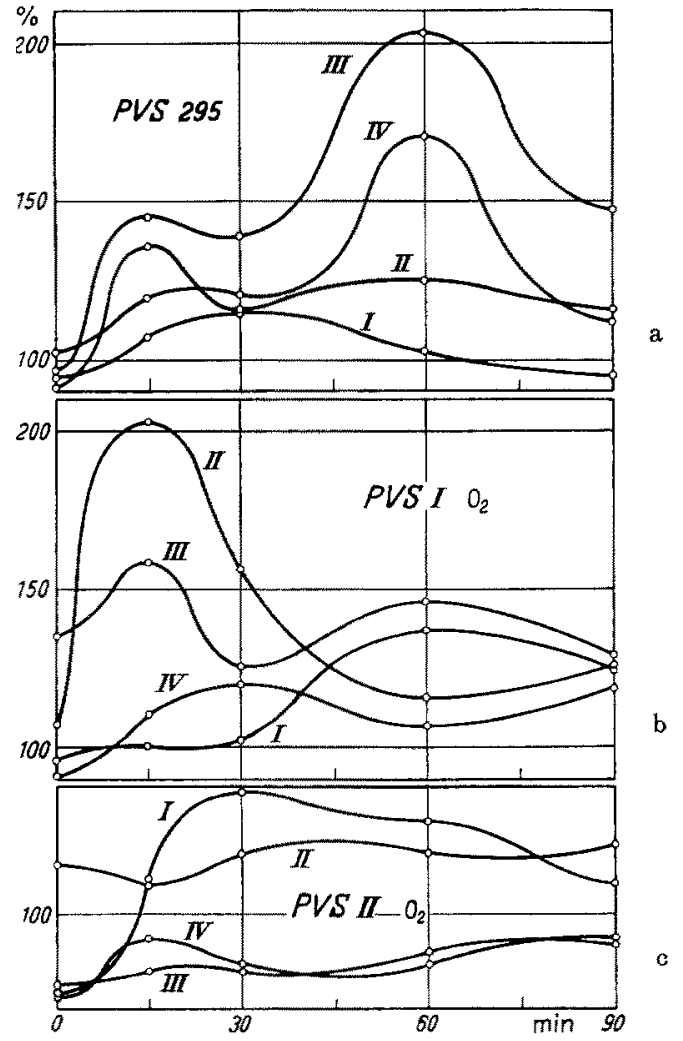

Abb. 14: Reaktionen der Gewebsatmung (in KkaBs-Bikarbonat-Ringer) nach Zusatz von Protoveratrin PVS 295, PVSI und PVSII (1 Std. nach Versuchsbeginn). Ordinate: $0 / 0$-Normalatmung, Abszisse: Zeit nach Zusatz I-IV: verschiedene molare Konzentrationen. (Nach LockER et al. 1954d) 
Gewebes zugehörig identifizieren. Verschiedene Reaktivität von Einzelreaktionen offenbarende multiple Übergangserscheinungen finden sich auch unter dem Einfluß von anorganischem Jod (LOCKER \& SIEDEK 1954) und von Veratrin-Abkömmlingen (LoKKER et al. 1957d) (Abb. 14). Diese Schwingungen deuten insofern Erholungsvorgänge an, als sie allmählich verschwinden und das System den Ausgangszustand wieder erreicht.

\section{Eigentliche Erholung}

Bei länger dauernden Einflüssen, die sich in vivo realisieren lassen, kommt es zu prinzipiell gleichen Erscheinungen, nämlich mehrfachen Übergängen. Erst bei stark protahiertem Einfluß, der sich als eine einzige, durch kleinere (frequentere) Schwingungen nicht unterbrochene schwingungsartige Reaktion äußert und eine entsprechende "Gegenschwingung" hervorruft, sprechen wir von Erholung. Sie ist allerdings in vielen Fällen auch wieder nicht einfach Rückkehr auf den ursprünglichen Zustand, sondern überschießend. Dieses fand sich beispielsweise bei verschiedenen CholinesteraseInhibitoren aus der Gruppe der Alkylphosphate (LOCKER \& SIFDEK 1952), nach deren Hemmphase der Cholinesterasegehalt von Serum und Organen des Meerschweinchens vorübergehend erhöht war ${ }^{18}$.

Als Beispiele für eine Erholungsatmung seien der $\mathrm{O}_{2}$-Verbrauch des Nerven im Zusammenhang mit der Wiederherstellung des Ionenungleichgewichts (CoNNelry 1959) und des Skelettmuskels nach 'Tätigkeit als Ausdruck der Elimination eines Oxygen-Debt genannt. Als ein Oxygen-Debt wird von PiсноткA (1957) auch das Ansteigen des $\mathrm{O}_{2}$-Verbrauches nach Beatmung von Säugetieren mit $\mathrm{O}_{2}$-armen Gasgemischen (Beatmungs-Hypoxie) angesprochen, bei welchem es gleichzeitig zu einem (exponentiellen) Absinken der Körpertemperatur kommt.

\section{Adaptation (Repression und Induktion)}

Nicht immer vermag das stoffwechselnde System sofort auf eine Beeinflussung zu reagieren; es benötigt bisweilen eine Zeit der Anpassung an diesen Einfluß, die zu Reaktionen füht, die schließlich die Beseitigung des Einflusses oder die Wiederherstellung der ursprünglichen Aktivität mit sich bringt. Nach der heute allgemein angenommenen Vorstellung vom fließenden Übergang zwischen sogenannten konstitutiven und adaptiven Enzymen (Mandelstam 1952) kann jedoch eine solche Adaptation (die auch Induktion genannt wird) sehr schnell (fast instantan) erfolgen. Dies läßt sich unter anderem an dex Penicillin-Inaktivierung durch atmende Leberschnitte demonstrieren (Locker \& SpItzy 1956b): Nicht nur, daß, wie theoretisch begründbar, der

${ }^{18}$ Dem Phänomen der Erholung ähnlich ist das der Entgiftung, das quantitativ nicht leicht verfolgbar ist. Hier kann man auch Uberraschungen erleben; so haben wir (LOCKER \& SIEDEK 1952b) den damals verschiedentlid, erhobenen Befund, daß ein bestimmtes Alkylphosphat (Pestox III) in der Leber (dem Hauptorgan für Entgiftungsvorgänge) in ein toxischeres Produkt umgewandelt wird, nicht bestätigen können. Neuere Untersuchungen wiesen jedoch eindeutig das Bestehen dieses Phänomens („Giftung") nach (O'BRIEN 1963). 
Inaktivierungsvorgang S-förmigen Verlauf nimmt, er zeigt auch Beziehung zum Atmungsvorgang (Abb. 15), welcher offenbar im Zusammenhang mit Verschiebungen zwischen konstitutiven und adaptiven Enzymen schwingungsartig reagiert.

Uber Anpassungsvorgänge wird auf diesem Symposion noch ausführlich gesprochen werden. Soweit wir aus bisherigen Befunden über den Vorgang der Adaptation an Umgebungstemperaturen entnehmen (JASPER et al. 1958), verlaufen die Reaktionen der Gewebsatmung des Warmblitters bei Anpassung an tiefe und hohe Umgebungstemperaturen praktisch gleich. Erstaunlich ist demgegenüber, daß sich bei länger dauernder Wärmeadaptation (zum Unterschied von der Kälteadaptation) der Gesamtstoffwechsel
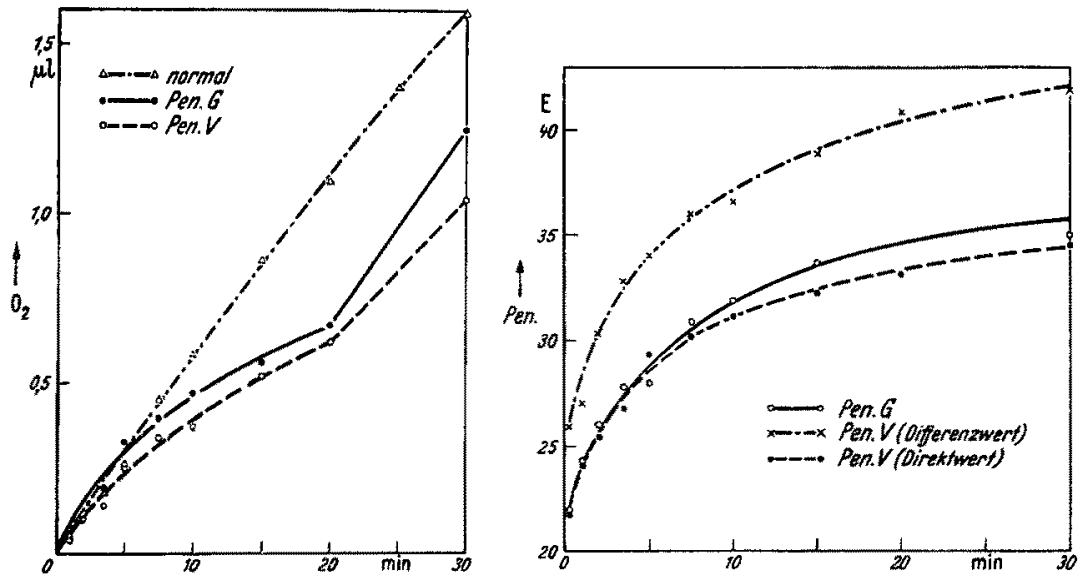

Abb. 15: Verlauf der Gewebsatmung (li) unter Einfluß zweier Penicilline und Verlauf der Penicillin-Inaktivierung (re) in den ersten 30 min. (Nach LOCKER \& SPITZY 1956b)

vermindert (KIBLER 1960). Besondere Erwähnung verdient außerdem hier die Vorstellung, die neuerdings über Induktion und Repression bei Bakterien gebildet worden ist (Jасов \& Monod 1961). Die Kinetik der Enzym-Induktion und der Enzym-Repression, also der Unterdrückung der Enzymsynthese (auch negative Adaptation genannt), ist sehr ähnlich. Sie erfordert, zum Unterschied von den früher genannten Formen der Hemmung der einzelnen Enzym-Aktivität, die Annahme einer Enzym-Sequenz. Repression und Induktion sind hochspezifisch; als Repressor kommt in der Regel ein Reaktionsprodukt in Frage, als Induktor ein Substrat. Heinmetz \& Herscrman (1960) haben ein auf dem Boden der Fließgleidngewichtstheorie stehendes kinetisches Schema der Induktion und Repression entworfen. Wie unsere schon länger zurückliegenden Versuche ïber Inaktivierung von Antibiotika (Penicillin, Aureomycin, Achromycin) durch Lebergewebe in vitro wahrscheinlich machen (Locker \& Spr'tzY 1955a, b) (Abb. 5), dürfte Induktion (und wohl auch Repression) nicht auf Bakterien beschränkt sein, sondern eine generelle Eigenschaft metabolisierender Systeme darstellen. 


\section{Empfindlichkeit - Resistenz - Interferenz}

Die Reiz-Reaktionsgesetze bringen auch eine selbstverständliche Eigenschaft des Stoffwechsels zur Geltung: er ist um so resistenter, je geringer die Intensität ist und um so empfindlicher, je höher sie ist. Zur Erklärung der allgemeinen Toxizität von Pharmaka (als $L D_{50}$ ) läßt sich infolge ihrer verschiedenen Angriffspunkte und ihrer differenten "Wirkungsmechanismen" keine einfache Beziehung zur Stoffwechselhöhe geben (mit Ausnahme jener, die wir oben bereits in bezug auf Kalt- und Warmbluter genannt haben). Bei ionisierenden Strahlen dürtte es leichter möglich sein, die $L_{50}$ der Totalbestrahlung (angegeben in Röntgen-Einheiten) und die Stoffwechselhöhe zueinander in Beziehung zu bringen. Bei kleinen Tieren (wie der Maus) mit höherem Stoffwechsel ist die $\mathrm{LD}_{50}$ höher als bei größeren (z. B. dem Esel) (SACHER 1958); bei vergleichbaren Tieren (wie den kleinen Nagern) ist sogar das Verhältnis von $\mathrm{LD}_{50} \mathrm{zu}$ Stoffwechselhöhe annähernd konstant (LOCKER 1964b) ${ }^{19}$.

Besonders interessant ist die Erscheinung der Interferenz, die sich darin äußert, daß der gemeinsame Effekt zweier Substanzen, etwa Parafuchsin plus Euflavin, auf die Atmung von Trypanosomen (Schefr \& Hassko 1936) geringer ist als die Wirkung jeder Substanz allein. Hier handelt es sich möglicherweise um das Reagieren beider Substanzen mit dem gleichen Rezeptor und ihre gegenseitige (sterische) Behinderung. Die Grenze dieser Erscheinung zu einem Antagonismus, der sich als gegensätzliche Wirkung auf einzelne Enzyme entpuppt, wie etwa von Thiouracil und DNOC auf das Cytochromsystem und die dadurch bewirkte Verminderung der DNOC-bedingten Atmungssteigerung (Locker et al. 1950), ist schwer zu ziehen.

Eine Form von Interferenz ist die Verhinderung der Wirkung von Lebergitten durch Antibiotika (EGER 1955). Von beiden Stoffen kann, wie von vielen anderen auch, ein Einfluß auf die oxydative Phosphorylierung und Zerstörung von energiereichen Phosphatestern angenommen werden. Bei einer so allgemeinen Wirkung hängt es vielleicht davon $a b$, durch welchen der (im System einander entgegenwirkenden) Stoffe sie zuerst ausgelöst wird. Werden nach der ersten Einwirkung die energiereichen Phosphatester zerstört, kann gegenüber dem nachfolgenden Eingriff, der den gleichen Effekt auslösen soll, Resistenz auftreten, weil die den Eingriff ermöglichenden Rezeptoren (Phosphatester) vorübergehend fehlen.

\section{Stoffwechsel-Alter - Körpergröße}

\section{Stoffwechselintensität und Lebensdauer}

Die Ursachen für die bekannte Erscheinung, daß sich der Stoffwechsel mit dem Alter vermindert (SHOCK 1955), sind zahlreich, unter anderem relative Vermehrung stoffwechselinerten Materials im Verhältnis zum eigentlich aktiven Protoplasma. Rein

19 Wie sehr nicht nur die somatische Anfälligkeit gegenüber ionisierenden Strahlen yom Stoff wechsel abhängt (was die Möglichkeit mit sich bringt, durch Hypothermie [WEIss 1961] oder Anoxie [LINDop \& RotBLAT 1960] zu schützen), sondern auch die genetische, beweist der "O2-Effekt" (Thoday \& READ 1947), der erstmals als Schutz gegenüber Chromosomenaberrationen (und Mutationen) beschrieben wurde. 
quantitativ zeigt sich, nicht nur bei Poikilothermen (BOURLIÈre 1954), sondern auch bei Säugetieren, daß die Lebensdauer um so kürzer, je höher der (gewichtsbezogene) Stoffwechsel ist (Mrischer 1955). Diese reziproke Beziehung, die erstmals RuBner erkannt hat und die deshalb Zweites RubNersches Gesetz genannt wird, deutet wieder auf die Existenz einer eigentümlichen biologischen Konstante hin. Der Mensch allerdings fällt aus dieser allgemeinen Beziehung heraus; ein Hinweis auf seine auch biologisch fundierte Sonderstellung. Bei Wirbellosen dïrte die Beziehung etwas anders sein und eine der ARrHenrusschen Formel ähnliche Verbindung zwischen Stoffwechselhöhe und Lebensdauer bestehen.

\section{Die sogenannte Stoffwechselreduktion}

Eine weitere Biokonstante ist durch die Verminderung des Stoffwechsels mit der Körpergröße gegeben, welche von der Altersabnahme des Stoffwechsels zu unterscheiden ist, die auch bei gleich schweren, aber verschieden alten Tieren eintritt. Von experimentellen Bedingungen abgesehen, ist die Stoffwechselreduktion sowohl von ontogenetischen wie phy!ogenetischen Phasen ("Cyclen") abhängig, was sich im intraspezifischen

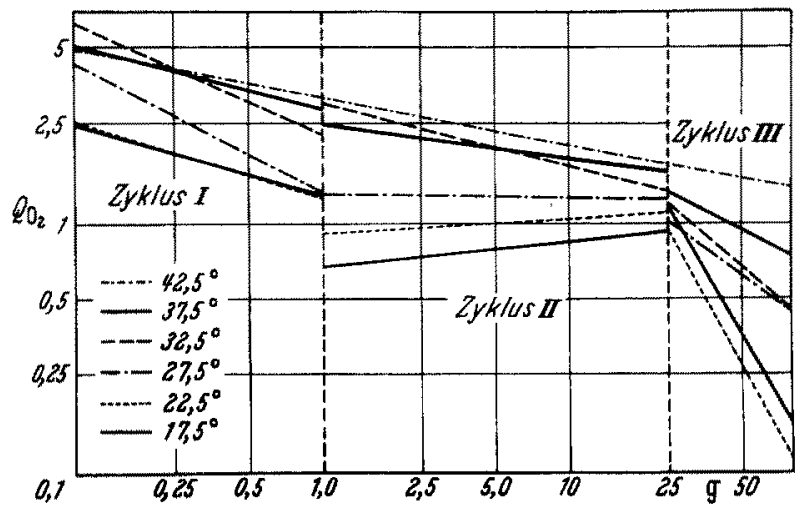

Abb. 16: Vorkommen von drei Zyklen an der Beziehung der Gewebsatmung des Winterfrosches zur Körpergröße bei verschiedenen Temperaturen in vitro. (Nach LockER, Z. vgl. Physiol. 41, 249-266, 1958)

Vergleich (für die Atmung der Froschleber; Abb. 16) wie im interspezifischen Vergleich (an der Atmung der Leber verschiedener Säuger; Abb. 17) demonstrieren läßt. Der Einfluß der experimentellen Variablen und solcher Cyclen führt zur Erkenntnis, daß sie nicht ohne wreiteres durch das Oberflächengesetz (das Erste Rubnersche Gesetz) interpretiert wird. Allerdings führen Erwägungen über den Aufbau von Zellen und Geweben aus Untereinheiten und die durch diese morphologischen Gegebenheiten bestimmte Oberflächenbegrenzung vieler Stoffwechselvorgänge zu einem neuen Aspekt des Oberflächengesetzes (LOCKER 1961b).

Bei einem Vergleich der Stoffwechselreduktion des Gesamtstoffwechsels mit derjenigen der Organe konnte bei Sommer- und Winterfröschen die Beobachtung gemacht 


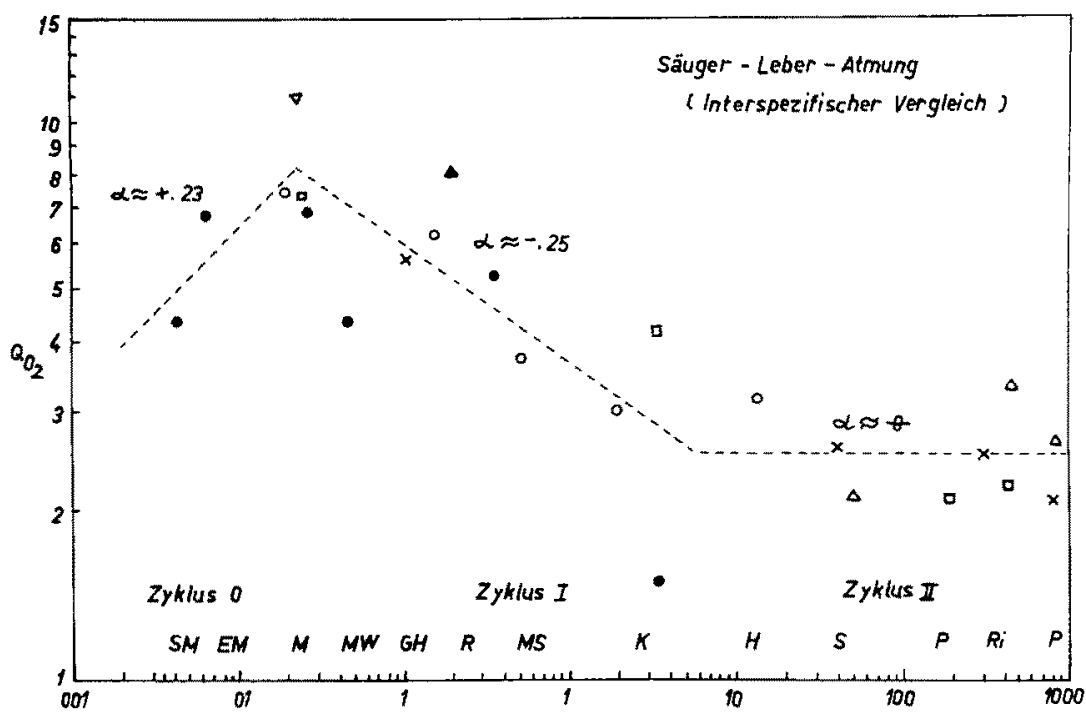

Abb. 17: Auftreten von Zyklen der Leberatmung im interspezifischen Vergleich ihrer Beziehung zur Körpergröße. $\alpha$ : Regressionskoeffizient. SM: Spitzmaus, EM: Erntemaus, M: Maus, MW: Maulwurf, GH: Goldhamster, R: Ratte, MS: Meerschweinchen, K: Kaninchen, H: Hund, S: Schaf, P: Pferd, Ri: Rind. Zusammenstellung nach Werten der Literatut (Locker, unpubl.)

werden (Locker 1963b), daß erstere im Bereich der jeweiligen saisonabhängigen Lebensraumtemperatur am ausgeprägtesten ist. Dieser Befund steht im Gegensatz zu den oben (p. 60) erwähnten Ergebnissen an Wirbellosen und verdient eine Aufklärung.

\section{SPEZIELLE EXEMPLIFIZIERUNG DER REAKTIVITAT METABOLI- SIERENDER SYSTEME AM PROBLEMKREIS DER LEBERSCHADIGUNG}

\section{Aufbau und Reaktionen des Leber-Histions}

Histosysteme allgemein betrachtet

In dem Bemihen, unsere bisherige Betrachtung speziell an Reaktionen der Leber zu veranschaulichen, soll vor allem des Werkes meines Lehrers EPPINGER gedacht werden $^{20}$. Bei höheren Organismen genügt es nicht, neben den intrazellulären Systemen (Enzymen und ihren strukturierten Trägern) Zellen und Gewebe beziehungsweise Organe zu unterscheiden, von denen ohne weiteres zum Gesamtorganismus übergegangen werden könnte. Entsprechend einem einfachen kinetisch interpretierbaren und uns vielfach als Modellsystem dienenden Enzymsystem existiert auch im Gewebe

2n Am Tage dieses Vortrags, dem 25. September 1963, jährt sich der Todestag Eppingers zum 17. Male. Die anzustellende Betrachtung, wiewohl Epprngers Größe und Bedeutung unangemessen, sei seinem Gedächtnis gewidmet. 


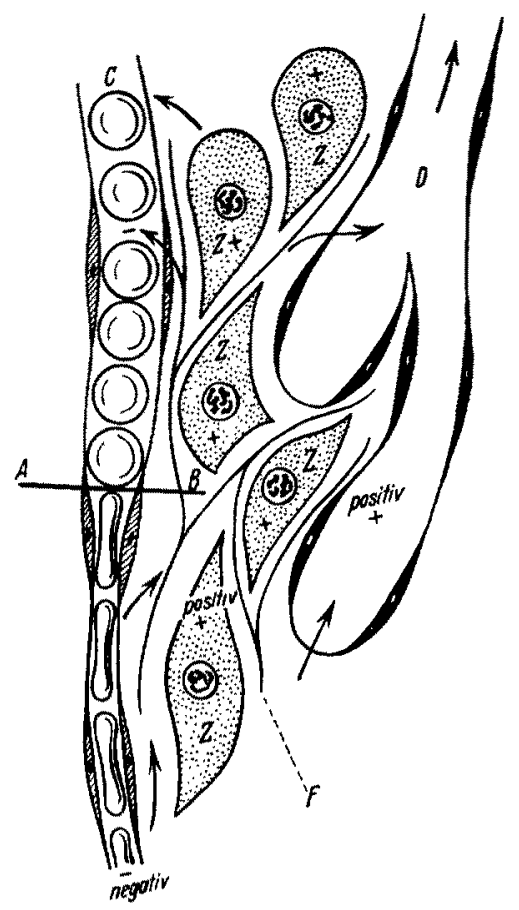

Abb. 18: Schematische Darstellung der Beziehungen zwischen Blut, Gewebsräumen, Parenchymzellen, Bindegewebe (und Lymphkapillaren). A-B: Theoretische Grenze zwischen arterieller und venöser Kapillare, C: Blutkapillare, D: Lymphkapillare, Z: Parenchymzelle, F: Bindegewebsfibrille. (Nach EPpinger 1937)

ein einfachstes System, an welchem sich bereits alle seine Stoffwechseleigenschaften demonstrieren lassen: das $\mathrm{H}$ istion. Es wird definiert durch die morphologische und funktionelle Verbindung zwischen Zelle, Interzellularraum (Interstitium) und Kapillare (bzw. Sinusoid). Diese kleinste Wirkeinheit (Zelle - Interstitium - Kapillare) hat noch verschiedene andere Bezeichnungen erhalten wie Dreikammer-System (SCHADE 1935) oder Synergide; EPPINGER $(1937,1949)$ nennt sie einfach „Betriebsgemeinschaft“ (Abb. 18). Wirkeinheiten dieser Art schließen sich zu höheren Einheiten mit charakteristischen funktionellen und morphologischen Differenzierungen zusammen, dem Histosystem oder Histion zweiter Ordnung, das in der Leber auch Hepaton genannt wird $^{21}$. In ihm stehen Aufbau, Funktion und Reaktivität in innigster Wechselbeziehung. Im Leberhistion wird diese Trias weitgehend durch den Blutstrom von der Peripherie zum Zentrum (mit abnehmendem Oz-Gehalt) bestimmt. Dadurch entsteht eine Gliederung in ein sogenanntes peripheres und zentrales Funktionsfeld (EGER 1954), in zwei Bereiche also, die sich durch Anordnung von Speicherstoffen (Fett, Glykogen) ebenso wie durch den Gehalt und die Aktivität von Enzymen voneinander unterscheiden (Kettler 1954, Holre 1955). Die Funktion der Leber ist, wie seit langem bekannt, rhythmisch (BARNUM et al. 1958).

21 Histosysteme anderer Organe werden Nephron, Myon, Perzeptron (für Zapfen-Stäbchen-Einheit der Netzhàut) etc. genannt. 

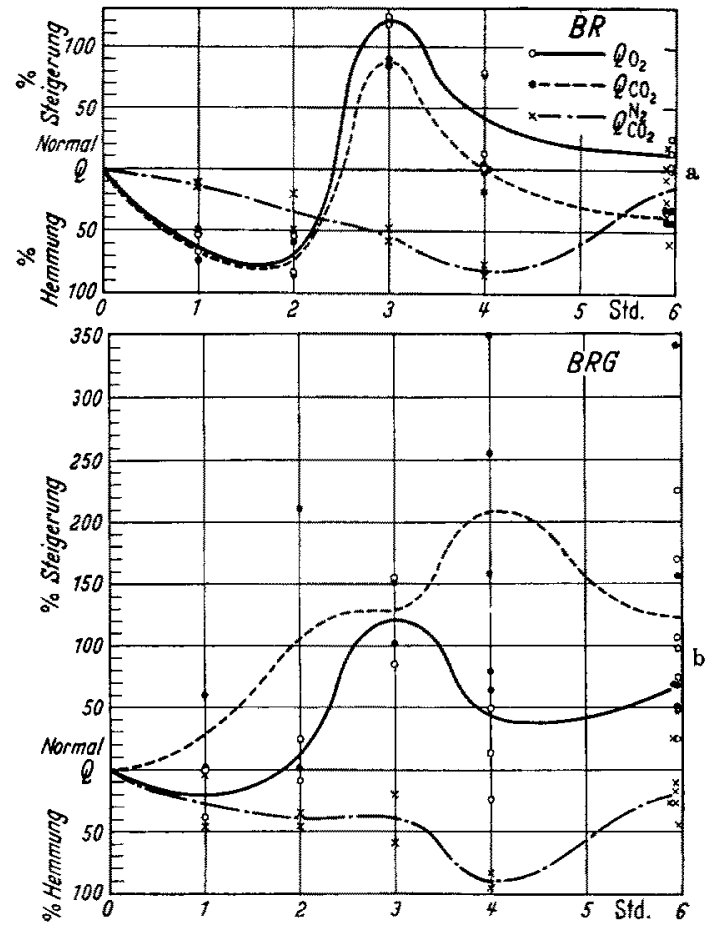

Abb. 19: Unterschiedliche Reaktionen der Leberatmung und anaeroben Glykolyse im glucosefreien (BR) und glucosehältigen (BRG) Medium nach $50 \mathrm{mg} / \mathrm{kg}$ Allylformiat bei hungernden Ratten. (Nach LOCKER et al. 1951a)

\section{Stoffwechselreaktionen bei chemischer Beeinflussung}

In dem Bestreben, eine „Permeabilitätspathologie als Lehre vom Krankheitsbeginn" aufzubauen, wandte sich EppINGers Interesse besonders der Serösen Entzündung zu, einer bestimmten Störung in der Verbindung von Zelle und Kapillare, bei der es zum Durchtritt von Bluteiweiß durch letztere und zu einem auch lichtmikroskopisch feststellbaren Spalt (dem Drsseschen Raum) kommt22. KaunITz \& SELzer (1937) untersuchten als erste den Leberstoffwechsel bei Seröser Entzündung, die sich besonders gut mit Allylformiat hervorrufen läßt. Zunächst von FLEckenstein (1944), später von uns (Locker et al. 1951a), wurde jedoch gefunden, daß es unter Allylformiat-Einfluß nicht nur (wie ursprünglich von EPPINGER angenommen) zu alleiniger Kapillarschädigung, sondern vor allen zu Parenchym(=Zell)schädigung kommt ${ }^{23}$. Nach Allylformiat finden sich im Leberstoffwechsel nicht nur Dosisabhängigkeit und

22 Lange Zeit umstritten, ist die Existenz des Drsse-Raumes auch im Normalzustand jetzt elektronenmik roskopisch eindeutig erwiesen.

$\because$ Auch die Stoffwechseleffekte, die sich unter Einfluß von Allylverbindungen (Allylsenföl, Allylalkohol, Allylformiat) an der Leber in vitro ergeben, sprechen für direkte Angriffe im Zellstoffwechsel (Locker et al. 1951c). 
Zeitabhängigkeit (von der Geschwindigkeit der Giftresorption), sondern wieder Phasen: Hemmung (als Ausdruck schwerer Zellschädigung) und Anstieg (als Anzeichen einer gewissen Erholung) (Abb. 19). Bei mit anderen Gitten hervorgerufener sich vor-

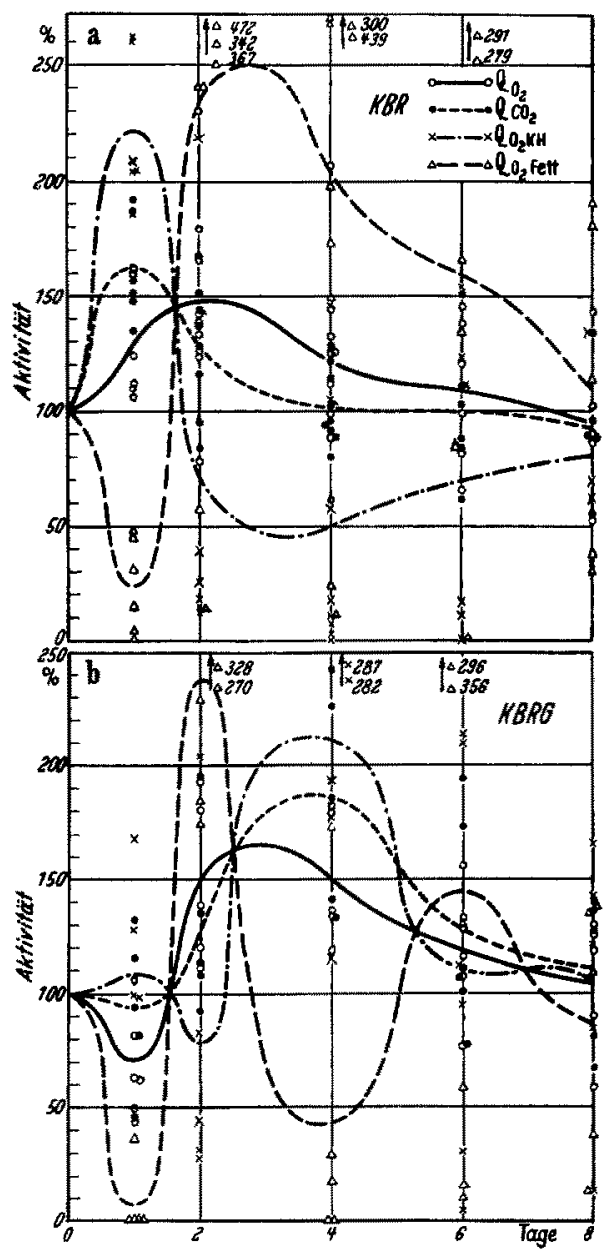

Abb. 20: Verlauf des Sauerstoffverbrauchs sowie der Kohlenhydrat- und Fettverbrennung in glucosefreier (KBR) und glucosehältiger (KBRG) KREBs-Bikarbonat-Ringerlösung nach Tetrachlorkohlenstoff in vivo-Einfluß bei der Ratte. Ordinate: Aktivität in \% $\%$, Abszisse: Zeit in Tagen. An der endogenen Atmung zeigt sich zuerst eine Kohlenhydrat-, anschließend Fettverbrennung. (Nach LockeR et al. 1956c)

wiegend als Seröse Entzündung manifestierender Schädigung ließ sich zeigen, daß die Stoffwechselerhöhung mit dem Auftreten der Serösen Entzündung zeitlich genau koinzidiert (Locker et al. 1951b).

Die prinzipielle Gleichartigkeit der Befunde in vivo ließ sich beim Leberstoffwechsel ${ }^{24}$ während des anaphylaktischen Schocks (Locker et al. 1954a) beobachten,

24 Übrigens auch am Gehirnstoffwechsel (Locker \& KölBL 1954). 
auch dann, wenn durch Cortisonbehandlung eine Glykogenanreicherung erzielt wird (LOCKER et al. 1954c), ferner nach Tetrachlorkohlenstoff (LOCKER et al. 1956c) (Abb. 20) oder bei Fettleber, hervorgerufen entweder durch chronische Behandlung mit Thiosemikarbazon (Locker \& BENDA 1954) (Abb. 21) oder durch fortgeführte Phosphoröl-Injektionen (Locker et al. 1956a) (Abb. 22).

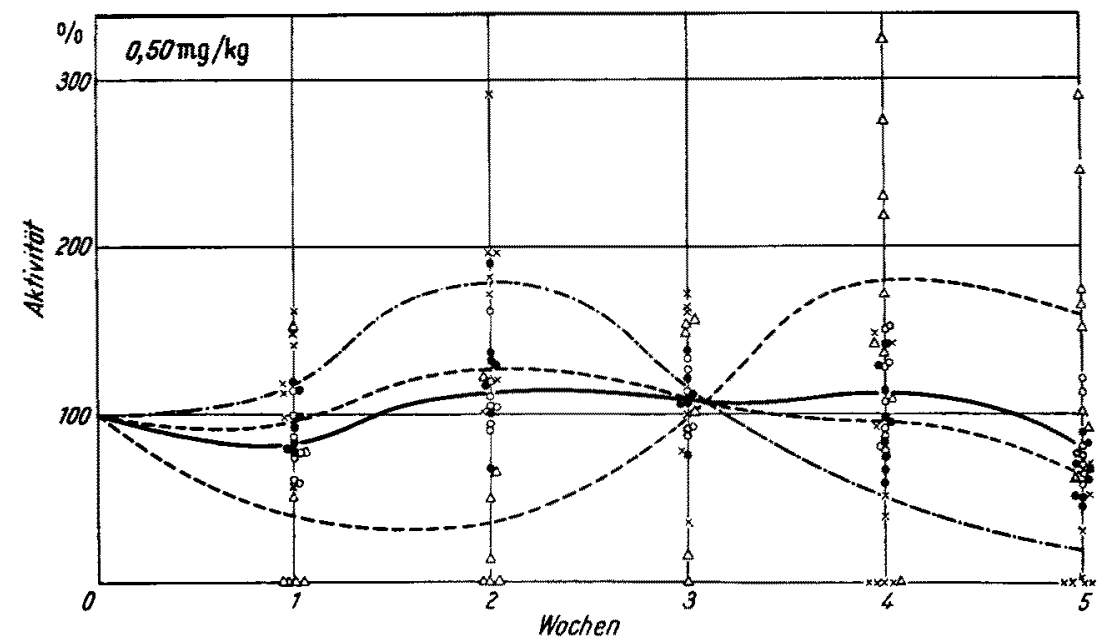

Abb. 21: Leberstoff wechsel $\left(\mathrm{O}-\mathrm{O}_{2}\right.$-Verbrauch, - -.- CO2-Bildung, $\times$-..- Kohlenhydrat-, $\triangle$--- Fettverbrennung) bei chronischer oraler TB I-Verabreichung an der Ratte (Schwingung sehr niedriger Frequenz). (Nach Locker \& BENDA 1954)

\section{Leberstoffwechsel nach physikalischer Beeinflussung}

Den Prototyp einer physikalischen Beeinflussung stellt die Hypoxie (in unseren Untersuchungen Unterdruck-Hypoxie) dar, welche zu charakteristischen Reaktionen führt. Die Abbildung 23 demonstriert, wie es in der Meerschweinchenleber während einer Hypoxiedauer von 3 Stunden im Glucose-freien Medium zu einer Herabsetzung des $\mathrm{O}_{2}$-Verbrauchs, dagegen im glucosehältigen besonders gegen Ende der Hypoxie zu einer Erhöhung kommt (LOCKER et al. 1952); sie ist vielleicht schon Ausdruck einer gewissen Reversibilität des Vorgangs. Werden die Versuchstiere nach 2 Stunden Hypoxie wieder in Luft gebracht, wird der zur Erholung führende Einfluß von Glucose besonders deutlich (Locker et al. 1954b) (Abb. 24). Unmittelbar nach Aussetzen der Hypoxie ist der $\mathrm{O}_{2}$-Verbrauch im glucosefreien Medium noch vermindert, während er im glucosehältigen bereits stark gefördert wird. Infolge der während der Erholung einsetzenden Glykogenzunahme kehrt sich der Kurvenverlauf um: Jetzt wird die exogene Gewebsatmung gesteigert, die endogene erreicht Normalausmaß. In diesen Fällen wechselseitiger Beeinflussung von exogenem und endogenem Substrat drückt sich möglicherweise eine Art Substratkompetition um die Initialreaktion aus.

Ahnliche Beobachtungen werden gemacht, wenn Leberschnitte in vitro einer verschieden lang dauernden Anoxie, einer anaeroben Glykolyse, ausgesetzt werden (LOCKER 1955) (Abb. 25). Nach nur kurzer Anoxie findet sich in glucosefreier Ringer- 


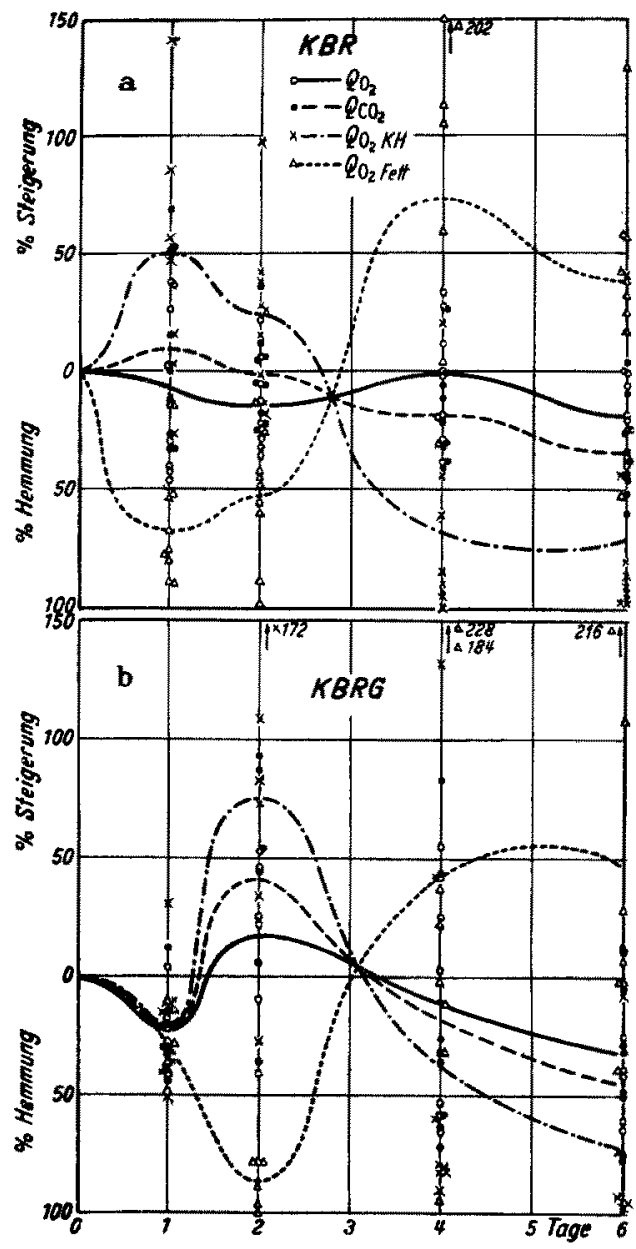

Abb. 22: Leberstoffwechsel während der Entwicklung einer Fettleber nach täglicher Verabreichung von Phosphoröl. (Nach LoCKER et al. 1956a)

lösung eine Zunahme der Atmung bei unveränderter Atmung im Glucosemedium. Nach 30 Minuten Anoxie kehrt sich auch hier das Bild um; dies ist durch Abnahme des zelleigenen Kohlenhydrats während der Anoxie erklärt, die schließlich zur Abhängigkeit der Reaktion vom exogenen Substrat führt. Die nach 60 Minuten dauernder Anoxie in beiden Medien eintretende Verminderung der Gewebsatmung, auf welche die Substrate keinen Einfluß mehr ausüben, beruht auf einer Enzyminaktivierung.

Gegenüber einer anderen Form von in vivo-Beeinflussung physikalischer Natur, nämlich Röntgenstrahlen, erweist sich die Leber der Maus unter allen Geweben als das nahezu am geringsten reagierende (LOCKER 1964b). 

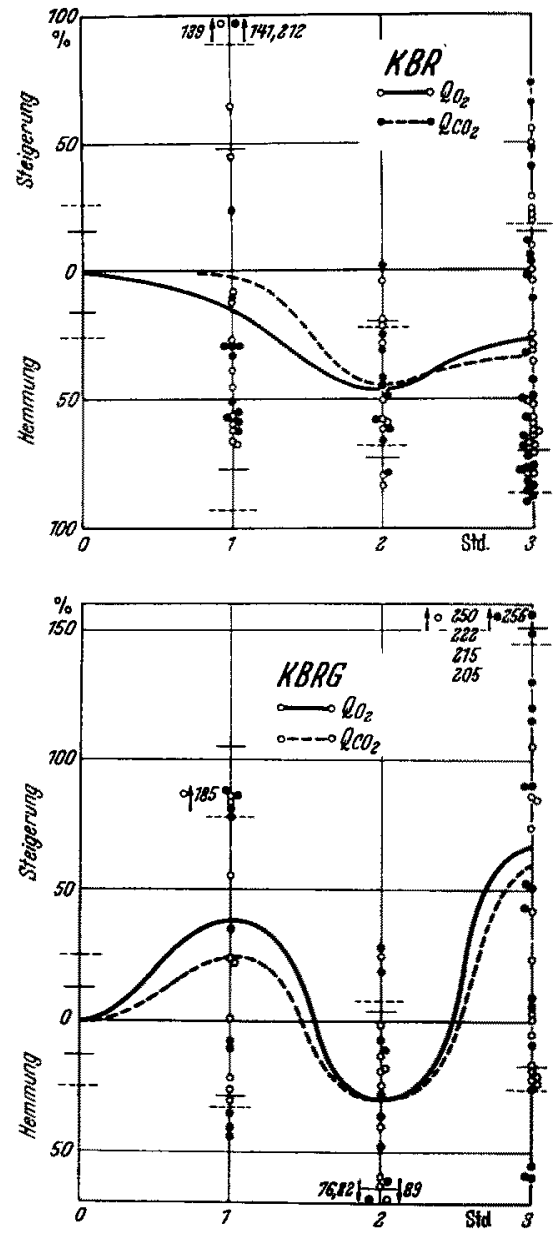

Abb. 23: Reaktionen der Leberatmung während Unterdruckhypoxie $(180 \mathrm{~mm} \mathrm{Hg})$ beim Meerschweinchen. KBR, KBRG: s. Abb. 20. Ordinate: \%/-Reaktion, Abszisse: Dauer der Hypoxie in Std. (Nach Locker et al. 1952)

\section{Der Stoffwechsel in Verbindung mit der Histionstruktur}

Besonders unter Hypoxie in vivo, aber auch nach Tetrachlorkohlenstoffeinwirkung und nach anaphylaktischem Schock finden sich in den zentralen um die Lebervene liegenden Anteilen des Hepatons Nekrose beziehungsweise hochgradige Vakuolisation, während die peripheren Partien unbeteiligt erscheinen oder geringe Veränderungen zeigen. Diese Verschiedenartigkeit der Reaktion spricht für die Gültigkeit der Vorstellungen vom peripheren und zentralen Funktionsfeld auch unter pathologischen Bedingungen; vor allem aber wird an ihr wieder die Systemgesetzlichkeit des Reagierens offenbar. Tatsächlich rufen die bis jetzt bekannten etwa 100 Lebergifte stets die gleichen morphologischen Veränderungen hervor (KETTIER 1954) und es ist 
anzunehmen, daß bei allen diesen Giften auch die metabolischen Reaktionen jenen gleichen, die wir mit insgesamt etwa 10 Substanzen erzielt haben. Werfen wir noch einmal einen Blick auf die Ergebnisse unserer Untersuchung mit Tetrachlorkohlenstoff (Abb. 20). Nicht nur, daß die Wirkung (nach einer bestimmten einmaligen Dosis)
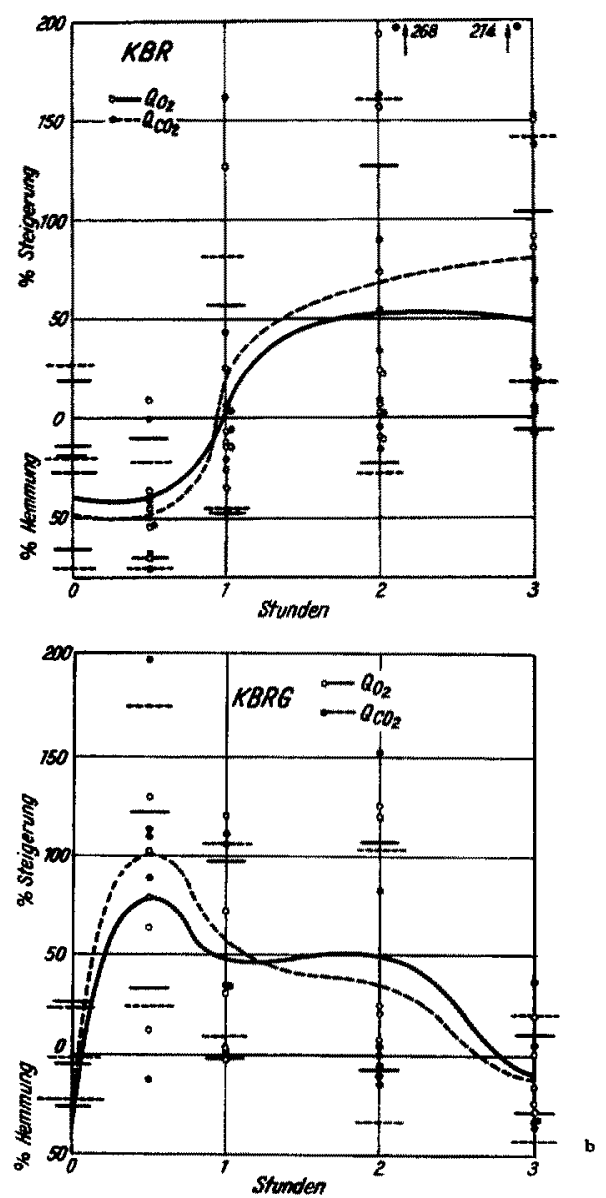

Abb. 24: Verlauf der Erholungsatmung (nach 2 Std.-dauernder Hypoxie) der Meerschweinchenleber. (Nad Locker et al. 1954b)

reversibel ist, daß die Reaktionen in beiden Medien nicht gleich sind und die Auftrennung des Gesamt- $\mathrm{O}_{2}$-Verbrauchs des Gewebes in die Substratfraktionen ein Vorangehen der Kohlenhydratveratmung (als Folge der Substratmobilisation; HolTZ et al. 1948) und ein Nachfolgen der Fettverbrennung zeigt. Im Zusammenhang mit den morphologischen Veränderungen muß die Stoffwechselsteigerung bereits als Reparationsstoffwechsel angesprochen werden, welcher von der Peripherie besorgt, die im nekrotischen Zentrum verminderte Atmung kompensiert. Wäre diese Untersuchung nicht an einem die Histionstruktur aufrechterhaltenden Gewebsschnitt, sondern an 
einem Homogenat oder einer Mitochondrienpräparation vorgenommen worden, wäre wie in der Arbeit von Zöllner \& Groebl (1952) ein solches Resultat nicht zustandegekommen. Die zahlreichen mit der Tetrachlorkohlenstoffeinwirkung auf die Leber beschäftigten Untersuchungen (die Hemmungen an verschiedenen Enzymen, z. B. des

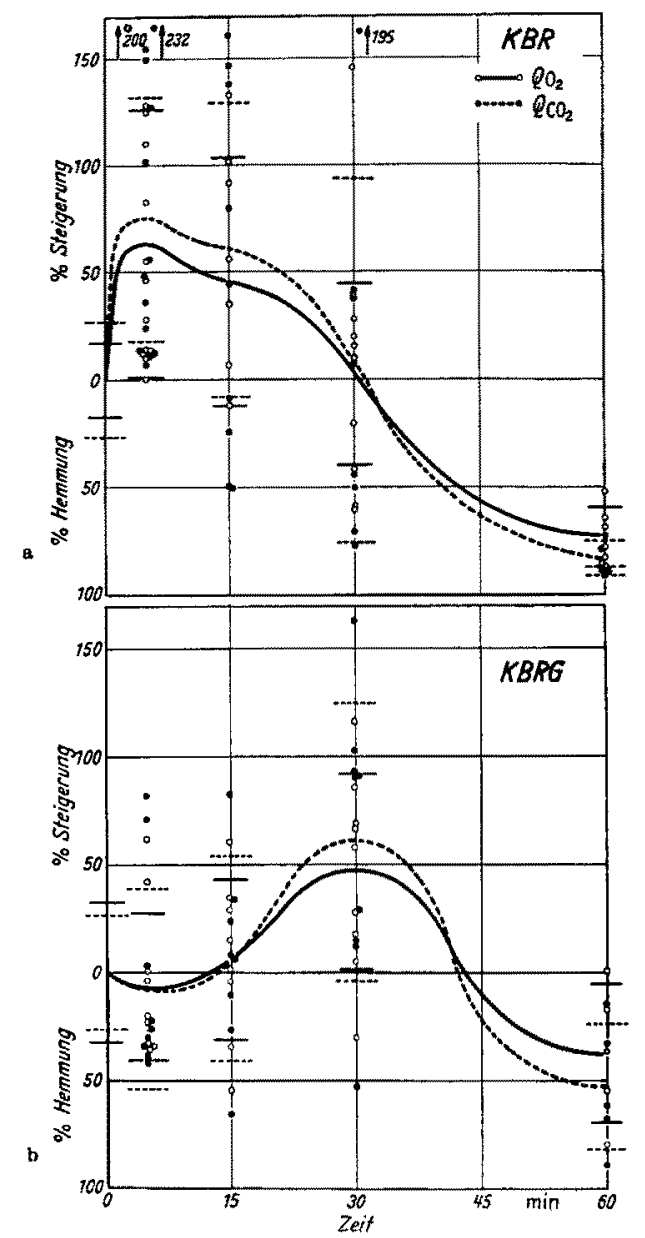

Abb. 25: Verlauf der Gewebsatmung der Meerschweinchenleber nach Anoxie in vitro in glucosefreier (a) und glucosehältiger (b) KREBS-Bicarbonat-Ringerlösung. Ordinate: \% (Steigerung oder Hemmung), Abszisse: Zeitdauer der Anoxie in vitro (min). (Nach LocKER 1955)

Citronensäurecyclus oder Verminderung des Gehalts an Coenzym A oder DPN etc. zeigen und die ich im einzelnen nicht aufführen kann) gehen an dem Entscheidenden vorbei, nämlich dem Aufzeigen der Reaktionsmöglichkeit des Histions und der tatsächlichen Reaktionsverläufe. 
Kriterien der Unterscheidung von Reiz und Schädigung

Schon früher haben wir davon gesprochen, daß uns die Möglichkeit in die Hand gegeben ist, Reiz von Schädigung zu unterscheiden. Sie geht wieder auf das im OGston-LAIDLER-Modell gegebene Verhalten zurück, in welchem durch Kopplung von Reaktionen Förderung der einen mit Zurückbleiben der anderen verbunden ist. Demgemäß können wir definieren, daß dort noch einfache Aktivierung (ohne Schädigung) vorliegt, wo der Normalbereich einer Funktion (Reaktion) trotz Beschleunigung der mit ihr gekoppelten nicht über-(oder unter-) schritten wird24a. So kann eine geförderte

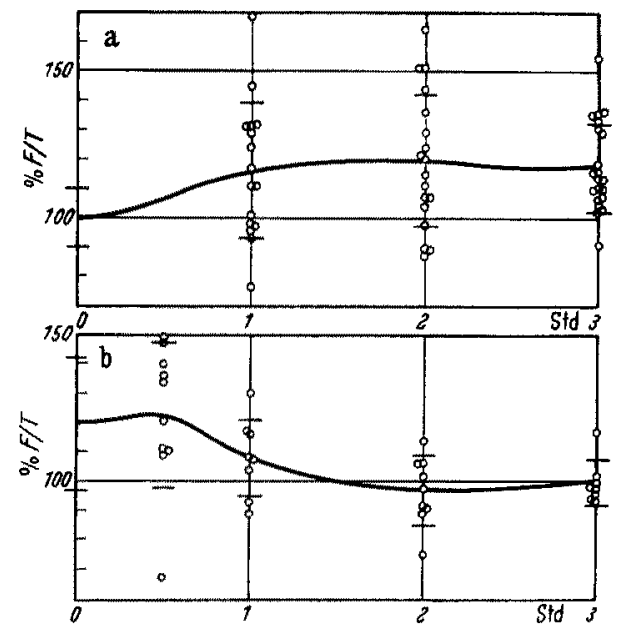

Abb. 26: Verlauf der Veränderungen des Wassergehaltes der Leber von Meerschweinchen während der Unterdruckhypoxie (a) (vgl. mit Abb. 23) und während der Erholung nach Aussetzen dieser (b) (vgl mit Abb. 24). Ordinate: 0/0-Feuchtgewicht/Trockengewicht, Abszisse: Zeit in Std. Trotz erhöter Atmung 1-3 Std. nach Etholung liegt normaler Wassergehalt vor. (Nach LockER 1956)

$\mathrm{O}_{2}$-Aufnahme bei normal hohem (absoluten) Phosphat-Verbrauch (trotz verminderten $\mathrm{P} / \mathrm{O}$-Quotienten) noch als aktivierte, ungeschädigte Atmung aufgefaßt werden. Entsprechend kann auch bei Reaktionen der Leber dort Reiz von Schädigung unterschieden werden, wo trotz erhöhter Gewebsatmung (z. B. nach Unterdruckhypoxie) der Wassergehalt des Gewebes normal hoch ist (Abb. 26) (LockER 1956). Ist die Gewebsatmung dagegen vermindert und bestehen zugleich schwere Strukturveränderungen, dann braucht des eindeutig für Schädigung sprechenden Befundes wegen dieses Kriterium gar nicht mehr herangezogen zu werden.

24a Hier wird der Normalbereich bereits als ein statistischer aufgefaßt. Sobald allerdings bei Stimulation einer Funktion eine (direkt oder indirekt) mit dieser gekoppelte unter den Normalbereich sinkt, wird die Beurteilung des Vorliegens von einfacher Aktivierung oder von Schädigung bereits schwierig. 


\section{Leberstoffwechsel und Karzinogenese}

Konstanz-Phänomene und Ubergänge

Durch chronische Verfütterung des Leberkarzinogens Buttergelb (Dimethylaminoazobenzol, $\mathrm{DAB})$ wird der Stoffwechsel der Rattenleber $\left(\mathrm{O}_{2}-\right.$ Verbrauch und aerobe bzw. anaerobe Glykolyse) nach einer längeren Periode scheinbaren Normalzustandes innerhalb kurzer Zeit sozusagen "plötzlich" in den typischen Krebsstoffwechsel umgewandelt, der durch die besonders von WARBURG herausgestellte hohe aerobe (und anaerobe) Glykolyse charakterisiert ist (Druckrey et al. 1958). Fiala \& Fiala (1959) wiesen nach, daß die zugleich eintretende Verminderung des $\mathrm{O}_{2}$-Verbrauchs nicht auf Hemmung bestimmter Enzymreaktionen, sondern auf die Abnahme der Mitochondrienanzahl in der Leberzelle zurückgeht. Da sich beim Wachstumsprozeß des Karzinoms (der auf wenige Tage beschränkt sein kann) die Zellzahlen exzessiv erhöhen (LAIRD \& BARTON 1959), liegen zwei gegenläufige Prozesse vor: der eine (nämlich der Wachstumsvorgang) kann als Kompensation für den anderen, nämlich die Verminderung der eigentlichen atmungs- und funktionsfähigen Elemente der Zelle (Mitochondrien und Ribosomen) aufgefaßt werden (LAIRD \& BARTON 1961).

In unseren Untersuchungen (LOCKER 1964c) ${ }^{25}$ ließ sich auch bei sehr langer Dauer der kontinuierlichen Verfütterung von DAB (an Wistar-Ratten) und hohen, die Mortalitätsrate stark beeinflussenden Gesamtdosen, kein Leberkarzinom erzeugen; dagegen fanden sich wieder schwingungsartige Reaktionen des Leberstoffwechsels und eine allmähliche Zunahme der aeroben und anaeroben Glykolyse. Durch den „DNOC-Test" (Locker \& Sptтzy 1951) ließ sich feststellen, daß keine im gewöhnlichen Sinn geschädigten Zellen vorlagen. Es wurde daher angenommen, daß der Prozeß der Karzinogenese stark protrahiert in Aktion tritt und nicht zur kompletten Ausbildung von Hepatomherden, aber doch zum Auftreten von Krebszellen führt. Übrigens spielt bei der Leberkarzinogenese auch die funktionelle Auftrennung des Leberhistions eine Rolle: nach Büchner (1961) und Grundmann \& Sieburg (1962) geht die Transformation von Normal- zu Hepatomzellen (verbunden mit schwingungsartigem Oszillieren zwischen diploiden und polyploiden Zuständen) vom Läppchenzentrum aus.

\section{Weitere quantitative Stoffwechselbefunde beim Karzinom}

Da wir schon vom Karzinomstoffwechsel sprechen, wollen wir einige quantitative Befunde anschließen, die sich nicht auf die Leber beziehen. Auch der Atmungsabfall des Tumorgewebes in vitro kann entsprechend dem an Lebergewebe und leukämischen Leukozyten angewendeten kinetischen Verfahren (Locker \& SPITZY 1956a, Locker \& Geyer 1958) als formal monomolekulare Reaktion beschrieben werden. An Platten-

25 Diese Untersuchungen wurden in den Jahren 1954 und 1955 auf Anregung meines fruheren Chefs, Professor E. V. LAUDA, ausgeführt, der sich von ihnen vor allem einen Einblick in den Ubergang von Normalleber uber Zirrhose zu Karzinom versprach. Außere Gründe verhinderten ihre fruhere Veröffentlichung. 
epithelkarzinomen von einheitlichem Malignitätsgrad wurde dies auch unter dem Einfluß von DNOC, das am Tumorgewebe den gleichen Effekt wie an Normalgewebe ausübt, gezeigt (Locker \& Weghaupt 1958). Die aerobe Glykolyse, die ohne DNOC

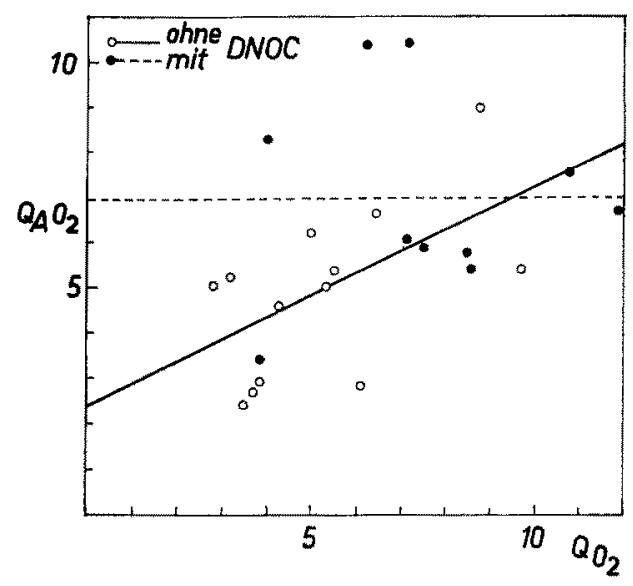

Abb. 27: Verhältnis von aerober Glykolyse (Ordinate) zum Sauerstoffverbrauch (Abszisse) ohne und mit DNOC bei menschlichen Plattenepithelkarzinomen. Die ohne Beeinflussung bestehende Korrelation verschwindet unter Einfluß von DNOC. (Nach LOCKER \& WEGHAUPT, unpubl.)

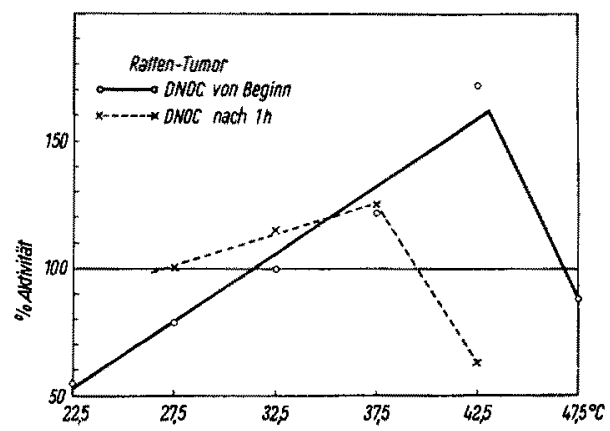

Abb. 28: Einfluß von DNOC (10 $\left.10^{-5} \mathrm{M}\right)$ auf den $\mathrm{O}_{2}$-Verbrauch eines experimentellen Rattentumors bei verschiedenen Temperaturen. Zunahme der prozentuellen Aktivität bei Temperatursteigerung. (Nach LOCKER. \& HOFER 1958)

eine positive Korrelation zur Höhe des $\mathrm{O}_{2}$-Verbrauchs zeigt, wird so verändert, daß die Korrelation verschwindet (Abb, 27); das bedeutet das Hinzutreten einer Schädigungsglykolyse zur Tumorglykolyse.

Bei Untersuchung des Stoff wechsels von Tumorgewebe (durch 9,10-Dimethyl-1,2benzanthrazen erzeugtes Spindel-Sarkom der Ratte) unter dem Finfluß von DNOC 
und verschiedenen. Temperaturen findet sich mit Temperaturerhöhung ein Anstieg des zusätzlichen $\mathrm{O}_{2}$-Verbrauchs (Locker \& Hofer 1958) (Abb. 28). Ein ähnlicher Befund ist auch von CLowes et al. (1958) an der Milchsäureproduktion von Ascitestumorzellen erhoben worden. Er wird verständlich bei der noch vor uns liegenden Behandlung der Stoffwechselunterschiede zwischen Kalt- und Warmblïtern. Zunächst sei noch eine kurze Betrachtung eingefügt.

Kurze Betrachtung über die Probleme Entzündung und Karzinom

Sie ist dem morphologischen Aspekt gewidmet, aber notwendig, weil auch zwischen Morphologie (Struktur) und Physiologie (Funktion) analoge (komplementäre) Beziehungen, die unsere Betrachtung leiten, bestehen. Wie in der Zelle Kompartimente, nämlich M-Raum (Mitochondrien) und C-Raum (Cytoplasma), vorliegen, so auch im Histion („Drei-Kammer-System“); wie im Enzym-Modell Enzym und Substrat unlösbar zusammengehören, so im Histion Parenchym und Stroma (bzw. Mesenchym: Interstitium plus Kapillare). Die Rolle, die beim Vorgang der Aktivierung im EnzymModell (und höheren funktionellen Systemen) dem Substrat zukommt, wird im Histion bei seiner (strukturell-funktionellen) Aktivierung, nämlich der Entzündung, vom Mesenchym ubernommen. Aber bei dieser kann die Kapillare, infolge ihres niederen Stoffwechsels (Locker et al. 1956), keine Führungsrolle innehaben. In ihr sind gewiß Rezeptoren vorhanden, durch die sie mit den auf dem Blutwege angebotenen Stoffen reagiert; die Reaktion des Histions aber wird von den Parenchymzellen bestimmt, welche ihrer Stoffwechselhöhe entsprechend die wesentlichen Rezeptoren tragen (LoKKER \& BENDA 1955). Erst die Zerstörung des Parenchyms läßt, gemäß dem WeIGERTKalluUsschen Gesetz, das Mesenchym zur Führung kommen, die sich bis zur Ausbildung einer Fibrose oder Zirrhose (über)steigern kann. Beim Karzinom dagegen, und $z$ war dem der Leber liegt, wie besonders durch die neuen Untersuchungen mit $\mathrm{Di}^{-}$ äthylnitrosamin sichergestellt ist, kein Parenchymuntergang vor, sondern nur die Umwandlung in metabolisch minderwertigere, aber wachstumsaktivere Zellen.

Die Probleme Entzündung und Karzinom, wie weit sie auch immer voneinander differieren können, verschaffen dennoch der Systembetrachtung gewisse Geltung. Entgegen der überspitzten Haltung Rickers (1924), der den Entzündungsbegriff überhaupt verwerfen wollte ${ }^{26}$, muß mit RoEssLe (1923) an ihm festgehalten werden, weil nur er einem Gesamtkomplex gesetzmäßig verbundener Reaktionen, also einem System, Rechnung trägt. In ganz ähnlicher Weise könnte ein Karzinom vom Detailvorgang her (z. B. Enzymreaktionen oder -konzentrationen) nicht als solches erkannt werden; wie es ja tatsächlich bisher nicht gelungen ist, auf biochemischem Niveau einen qualitativen Unterschied zum Normalgewebe nachzuweisen (ReID 1962).

26 Zugleich befruchtete er aber durch Formulierung des Rickerschen Gesetzes die Auffassung der Entzündung als eines gesetzmäßigen Vorgangs. Nach ihm reagieren die kleinen Gefäße (sowohl bei Persistenz eines Reizes als bei Intensitätszunahme des Reizes ohne Berücksichtigung des Zeitparameters) mit Fluxion $\rightarrow$ Ischämie $\rightarrow$ Fluxion $\rightarrow$ Stase. Die Entsprechung mit dem ARNDT-Schulzschen Gesetz ist deutlich! 


\section{RUHE- UND AKTIVITATSSTOFFWECHSEL}

\section{Allgemeine Gesetzmäßigkeiten}

Wieder kehren wir nunmehr zum Problem der Ausgangslage zurück. Sie hängt insofern mit dem Aktivitätszustand zusammen, als sich in ihr bereits eine gewisse Grundaktivität darstellt, der sich eine weitere, experimentell induzierte, aber in ihrem Ausmaß von ihr abhängige Aktivität superponiert. Demgemäß gibt es für jede Aktivitätshöhe eine bestimmte Stoffwechselaktivität; zwischen Ruhe- und Maximalstoffwechsel können alle Abstufungen verwirklicht sein. Besonders deutlich ist die Innigkeir der Beziehung zwischen Stoffwechsel- und Aktivitätshöhe aufzuzeigen, wenn es sich um motorische Aktivität handelt: dann stehen diese (wie Schwimm-, Flug- oder Laufgeschwindigkeit) und der Stoffwechsel (des Tieres) oft in linearer Bezichung zueinander (Wyndham et al. 1962, Margaria et al. 1963).

Bereits yom kinetischen Standpunkt ist die Frage zu behandeln, ob und in welcher Weise sich der Aktivitätsstoffwechsel vom Ruhestoffwechsel unterscheidet; der energetische Aspekt möge in unserer Betrachtung in den Hintergrund treten. Die Bedeutung

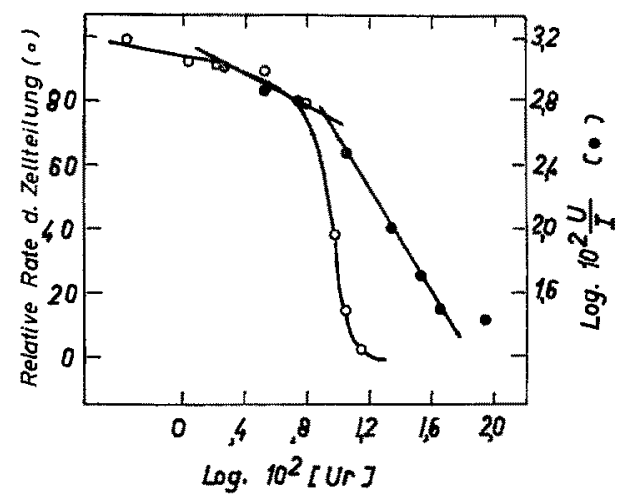

Abb. 29: Wirkung verschiedener Konzentrationen von Urethan auf die Zellteilung (offene Kreise) und den $\mathrm{O}_{z}$-Verbrauch (solide Kreise) des befruchteten Seeigeleis. U: Ungehemmter, I: gehemmter $\mathrm{O}_{2}$-Verbrauch. Bei Hemmung der Zellteilung: Auftreten einer neuen Beziehung $z$ wischen U/I und Urethan-Konzentration. (Nach FisHer \& HENRY 1944; umgezeichnet)

limitierender Glieder erhellt aus der Notwendigkeit, Fließgleichgewichte zu beherrschen, das heißt, sie unter bestimmten Erfordernissen in umgekehrter Richtung ablaufen zu lassen, und Metabolitmuster für unter Umständen plötzlich geforderte Aktivitäten in der Ruheperiode vorzubereiten (Bücher \& Rüssmann 1963). Nach Hess (1963) lassen sich (in Ascites-Tumorzellen) zwei typische Zustände definieren: de $\mathrm{r}$ in a $\mathrm{k}$ i ive Zustand als Quasi-G leichge wich $\mathrm{t}$ mit Fast-Stillstand des Elektronenflusses zum Sauerstoff, relativem Mangel an ADP und anorganischem Phosphat und ATP-Öberschuß und der aktive $Z$ ustand als Fließgleichgew ich t mit raschem Elektronenfluß in Richtung zum Sauerstoff, Oberschuß an ADP und anorganischem Phosphat und ATP-Synthese. Im Glykolyse-System ist der Úbergang ž wischen beiden Zuständen durch beschleunigte $\mathrm{O}_{2-}$ und Glucoseaufnahme, der aktivierte Zustand durch Hemmung $\operatorname{der} \mathrm{O}_{2}$ - und Glucoseaufnahme gekennzeichnet. 
Schon aus der älteren Literatur lassen sich Aussagen über die Unterschiede zwischen Aktivitäts- und Ruhestoffwechsel gewinnen. Wie Abbildung 29 zeigt, ist an der Atmung und Zellteilung von Seeigeleiern unter dem Einfluß von Urethan folgendes feststellbar (FiSHER \& HENRY 1944): Die Atmung wird entsprechend einer bestimmten Konzentrations-Wirkungsbeziehung gehemmt; gleichzeitig erfolgt eine zunehmende Einschränkung der Zellteilung. Sistiert die Zellteilung vollständig, tritt eine andere Konzentrations-Wirkungsbeziehung der Atmungshemmung auf. Die gleiche Erscheinung findet sich unter anderem an der Aktivierungsatmung des elektrisch erregten Nervs (BRINK 1957) oder des durch Koffein zur Kontraktion gebrachten Muskels (STANnard 1939; weitere Beispiele bei Johnson 1954). Stets ist der Aktivitätsanteil empfindlicher und wird durch Substanzen (wie in den genannten Beispielen Azid) in niedrigeren Konzentrationen und entsprechend einer anderen Konzentrations-Wirkungsbeziehung gehemmt als die Ruheatmung.

\section{Die besondere Bedeutung der limitierenden Bedingungen}

$$
\text { Der Sauerstoffgehalt }
$$

Die höhere Empfindlichkeit der Aktivitätsatmung ist nichts anderes als ein Ausdruck dafür, daß sie unter schärferen und engeren Bedingungen steht als die Ruheatmung. Dies läßt sich mit den wichtigsten Parametern gut demonstrieren. So ist die Aktivitätsatmung von Fischen und Krebsen schon durch geringere Herabsetzung der $\mathrm{O}_{2}$-Konzentration zu vermindern als die Ruheatmung (SHEPARD 1955, EGUSA 1961), wie es Abbildung 30 schematisch zeigt; der kritische $\mathrm{O}_{2}$-Druck liegt bei ihr höher. Man

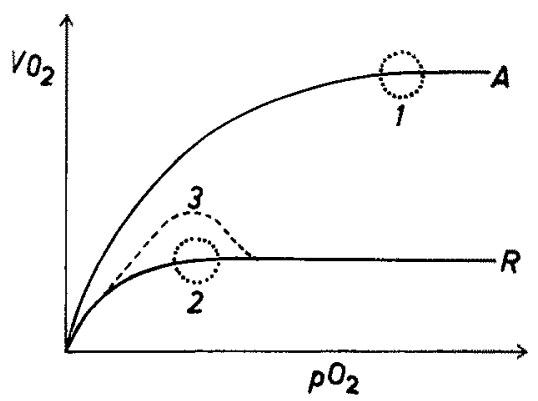

Abb. 30: Schematische Darstellung der Veränderungen des Ruhestoffwechsels (R) und Aktivitätsstoff wechsels (A) bei Änderung der $\mathrm{O}_{2}$-Spannung im Medium. 1: Inzipientes Grenzniveau, 2: Inzipientes Letalniveau, 3: Hypoxisches Paradox. Ordinate: Sauerstoffverbrauch ( $\mathrm{VO}_{2}$ ), Abszisse: $\mathrm{O}_{2}$-Spannung $\left(\mathrm{pO}_{2}\right)$

unterscheidet am Einfluß des $\mathrm{O}_{2}$-Drucks (bzw. der $\mathrm{O}_{2}$-Spannung) ein inzipientes Grenzniveau (FRY 1947), an dem sich der Aktivitätsstoffwechsel vermindert, der Ruhestoffwechsel aber noch ungehindert ist, von einem inzipienten Letalniveau, welches bereits letzteren gefährdet.

In diese Problematik spielt auch die in Geweben, namentlich im Gehirn, studierte Beziehung zwischen $\mathrm{O}_{2}$-Partialdruck, Stoffwechsel und Aktivität hinein. Entgegen 
früheren Anschauungen (OPITZ \& SCHNEIDER 1950) ist heute die Entscheidung zugunsten der "Anoxie-Hypothese" gefallen. Nicht die bloße Verminderung im Sinne der „Hypoxie-Hypothese", sondern an bestimmten Stellen (den kritischen Ecken) tatsächlich vorhandene Anoxie führt zu Atmungsverminderung und Bewußtseinsverlust und verursacht bei Überschreiten des Reversibilitätsbereichs Dauerschädigung (THEws 1960). Das Durchschreiten dieses Bereichs (der beim intakten Organismus dem inzipienten Letalniveau entspricht) kann bisweilen durch das "hypoxische Paradoxon", eine auf Durchblutungsförderung zurückgehende Erhöhung des $\mathrm{O}_{2}$-Verbrauchs, gekennzeichnet $\operatorname{sein}^{27}$.

\section{Substratgehalt und Durchblutung}

Nachdem Aktivität ( $\mathrm{z}, \mathrm{B}$. motorischer Art) mit gleichzeitiger permanenter Aktivierung des Stoffwechsels im Zusammenhang steht, letztere aber durch Substratmobilisation zustande kommt, muß die limitierende Funktion des Substrats besonders groß sein. Das ist die Ursache dafür, daß vor allem für den Stoffwechsel bei langdauernden Aktivitäten auf ein schon vorhandenes (in Speicherform vorliegendes) Substrat zurückgegriffen wird, nämlich auf Fett (z. B. beim Vogel-oder Insektenflug).

Die Verfügbarkeit des Substrats und des Sauerstoffs steht in engster Abhängigkeit von der Durchblutung. Diese wird zur vorherrschenden limitierenden Bindung bei Leistungs- oder Maximalstoffwechsel. Die absolute Höhe des Aktivitätsstoffwechsels im Vergleich zum Ruhestoffwechsel („scope of activity nach FRY 1947) differiert außerordentlich und reicht von 10 bis $30 \%$ bis zu einigen $100 \%$ (v. DöBeLn 1956, Wyndham et al. 1959). Dieser Zunahme muß die Durchblutung entsprechen; in den Geweben, etwa in der Leber (Wakim \& ManN 1942), wird im Ruhezustand nur ein Teil der möglichen Durchblutung realisiert. Der Vorgang der Kapillarisierung (des Offnens der Kapillaren) ist zuerst von KroGH (1924) studiert worden. Zwischen dem Ausmaß der Kapillarisierung des Muskels und der Höhe des $\mathrm{O}_{2}$-Debt nach Beendigung der Leistung besteht eine Beziehung (CoffmaN 1963).

Der Zusammenhang der Durchblutung mit der Sauerstoffversorgung und damit der "scope of activity " wird außerdem bestimmt von der Lungenventilation oder der Kiemenventilation, von der Leistungshöhe des Herzmuskels, vom Hämoglobingehalt etc. Er steht natürlich schon in Abhängigkeit von der genuinen Aktivität (d. h. der Ausgangslage der Aktivität), die sich beispielsweise bei Fischen bis in die Höhe der Gewebsatmung verfolgen läßt (VERNBERg \& GRAY 1953).

\section{Weitere Bedingungen}

Die durch Aktivität bedingte Stoffwechselsteigerung steht selbstverständlich auch in Abhängigkeit von experimentellen Bedingungen, zum Beispiel der Umgebungstemperatur (Abb. 31). Vor längerer Zeit ist die Vermutung ausgesprochen worden (Fox

${ }^{27}$ Siehe unsere spätere Diskussion des Wirkungsmechanismus von Strahlenschutzstoffen (Locker, dieses Symposion). 
1936), daß für gleiche Aktivitäten (etwa gleiche Schwimmgeschwindigkeiten oder gleiche Pleopodenschlagfrequenz) jeweils die gleichen Stoffwechselintensitäten erforderlich wären, und zwar sowohl bei verschiedenen Arten einer Gattung als auch bei verschiedenen Temperaturen innerhalb einer Art. Die Stoffwechselunterschiede, die bei verschie-
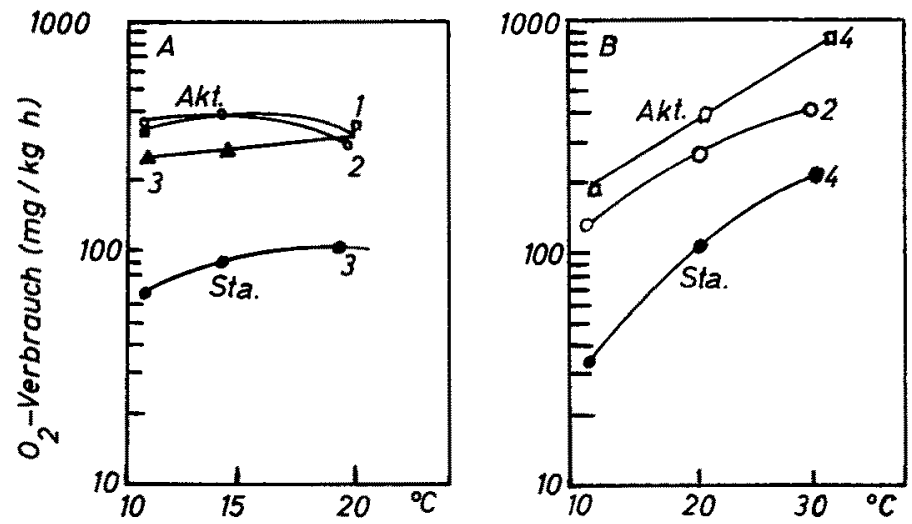

Abb. 31: Aktivitäts- und Standard-Stoffwechsel (Akt. bzw. Sta) bei Fischen: li: Salvelinus jontinalis, re: Ameiurus nebulosus. (Nach verschiedenen Autoren: 1. GraHam 1949, 2: JoB 1955, 3: BAsU 1959, 4: PAUL \& FRY 1940). Ordinate: Sauerstoffverbrauch (log), Abszisse: Temperatur. Standard-Rate: hier minimale Ruheatmung. (Nach BASU 1959; umgezeichnet)

denen Temperaturen oder in verschiedenen Biotopen auftreten, würden dann vor allem die Ruheatmung betreffen müssen; der Aktivitätsbereich wäre von ihr unabhängig und immer gleich. Ein Blick auf die Abbildung 31 (entnommen der Arbeit von BAsU 1959) überzeugt vom Gegenteil dieser Vorstellung.

Weitere auch beim Aktivitätsstoff wechsel sich Geltung verschaffende Bedingungen sind - besonders bei Poikilothermen - die Jahreszeit (bei Fröschen entspricht die Winterruhe mehr einem Basalstoffwechsel, die Sommeraktivität einem Aktivitätsstoffwechsel) oder die Ernährung. Erinnern wir uns, was letztere betriff, an die prämigratorische Hyperphagie bei Zugvögeln, die eine in direkter Beziehung zur Flugdistanz stehende Zunahme der Körperfettmenge mit sich bringt (ODum et al. 1961). Durch die Verflechtung des Aktivitätsstoffwechsels mit den genannten und vielen anderen Parametern wird einsichtig, daß wieder nur unter bestimmten Gesichtspunkten (oder bei eindeutig definierten Aktivitäten) scharf zwischen Ruhe- und Aktivitätsstoffwechsel unterschieden werden kann. In vielen Fällen bestehen zwischen beiden, in Abhängigkeit von einwirkenden Faktoren, fließende Übergänge.

\section{STOFFWECHSELUNTERSCHIEDE ZWISCHEN KALT- UND WARMBLUTTERN}

Das Problem von Ruhe und Akrivität erfährt eine besondere Spezifizierung, wenn wir die Formen von Aktivitäten betrachten, durch die sich Warmblüter von Kaltblütern unterscheiden. Im allgemeinen kann (besonders unter Bedachtnahme der Energie- 
leistung des Insektenfluges, der sich freilich die des Kolibrifluges annähert) nicht behauptet werden, daß die Aktivität beim Wirbeltier (oder Säugetier) stets höher als die beim Wirbellosen ist. Aber innerhalb des Wirbeltierstammes dürfte es außer Frage stehen, daß die allgemeine Aktivität von Warmblütern der von Kaltblütern schon allein durch ihre Unabhängigkeit von den Schwankungen der Tagestemperatur überlegen ist (wenn wir vom Winterschlaf, der echten Poikilothermie der Chiropteren und dem Hitzetorpor absehen). Die Frage der Thermoregulation ist sicher auch die eines komplexen Regelmechanismus. Schon früh ist jedoch die Vermutung geäußert worden (ADOLPH 1951), daß die Thermoregulation Voraussetzungen auf dem Gewebsniveau besitzt. 'Tatsächlich ist die Höhe der Gewebsatmung und des Gesamtstoffwechsels vom Warmblüter (z. B. Maus oder Ratte) um den Faktor 2,5-10 höher als die des Kaltblüters (repräsentiert durch den Frosch). Der Frage nach den Ursachen dieser Erscheinung kann durch verschiedene Untersuchungen nahegekommen werden; vor allem durch Betrachtung der Beziehung zwischen Stoffwechsel und Temperatur. Dazu seien einige Vorfragen kurz erörtert.

\section{Zur Wirkung der Temperatur auf Stoffwechselvorgänge}

Für die Biologie ist es bis heute ein nicht befriedigend gelöstes Problem, auf welche Weise die Beziehung eines Lebensvorgangs zur Temperatur am besten beschrieben werden kann. Der Beitrag Herrn Krügers erscheint in diesem Zusammenhang so wertvoll, weil er, abgesehen von der hier nicht zur Debatte stehenden mathematischen Formulierung, erstmals eine Beziehung zwischen Temperaturfunktion und Wachstumsprozeß aufzeigte, wodurch die erstere in einen umfassenderen Zusammenhang gestellt wird. Die formale Ähnlichkeit der Beschreibung kann ein Hinweis auf die Ahnlichkeit zugrunde liegender Mechanismen sein. Nachdem Wachstum, materiell gesehen, ein chemischer Prozeß ist, der durch einen gegenläufigen Vorgang fortlaufend eingeschränkt wird, würde das darauf hindeuten, daß auch die Temperaturwirkung als eine chemische angesprochen werden kann. Damit würde sie in den Zusammenhang eingeordnet, den wir für unsere Betrachtung geltend gemacht haben und erst unter Berïcksichtigung der allgemeinen Eigenschaften des reagierenden Systems, von Reiz-Reaktionsgesetzen, allgemeinen Bedingungen etc., ihre wahre Bedeutung enthüllen.

Haben wir also in Fließgleichgewichtssystemen unter dem Einfluß verschiedenster Wirkfaktoren Ubergangsphänomene zu erwarten, so auch unter dem der Temperatur. Diese werden tatsächlich beobachtet (GRAingER 1956). Wird die Gewebsatmung der Froschleber eine gewisse Zeit einer hohen (supramaximalen) Temperatur $\left(47,5^{\circ} \mathrm{C}\right.$ ) ausgesetzt, dann zeigen sich bei Rückführung in die Maximaltemperatur $\left(37,5^{\circ} \mathrm{C}\right)$ typische "over-shoots" (Locker 1958a) (Abb. 32). Wird die Substratatmung (von Pyruvat plus Succinat) bei verschiedenen Temperaturen untersucht (LOCKER 1958b), so zeigt sich (Abb. 33) mit Erhöhung der Temperatur eine Verminderung des substratbedingten Inkrements. Hier wiederholt sich eine schon früher beobachtete Erscheinung (RUBENSTEIN \& GERARD 1934, KORR 1941), nämlich, daß höhere Atmung nur mehr geringer gesteigert werden kann; dies ist ein Hinweis auf die Gültigkeit des Ausgangslagengesetzes. Eine noch innigere Verbindung der Temperaturwirkung mit den Eigenschaf- 


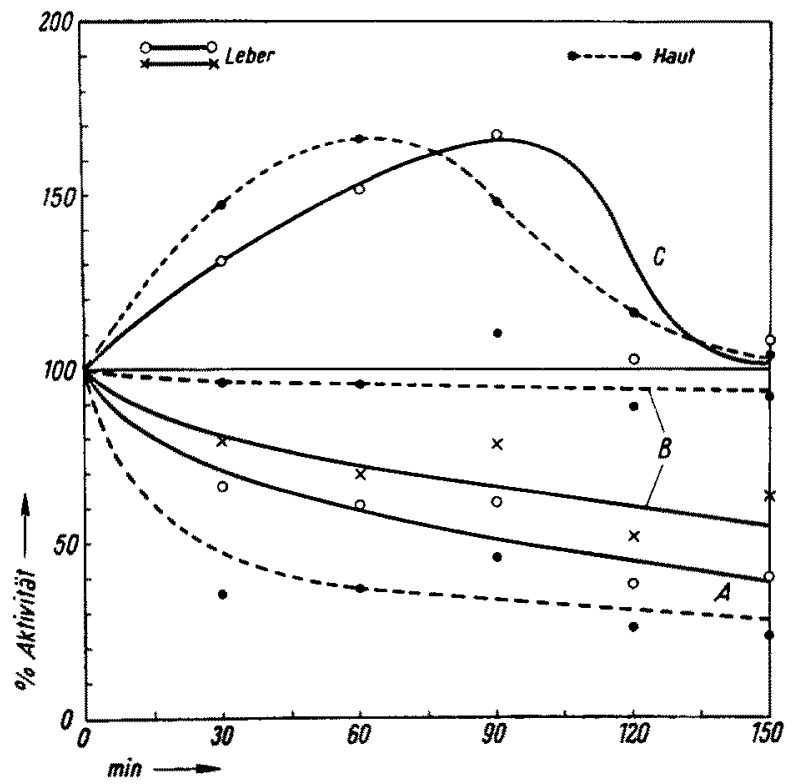

Abb. 32: Prozentuelle Aktivität (Ordinate) der Gewebsatmung der Leber und Haut des Frosches nach Inkubation bei $47,5^{\circ} \mathrm{C}$. A: Durchschnittliche Erholungsatmung im Vergleich zur Normalatmung bei $37,5^{\circ} \mathrm{C}$; B: Durchschnittliche Erholungsatmung im Vergleich zur. Atmung bei $47,5^{\circ} \mathrm{C}$; C: Prozentuelle Änderung der Gewebsatmung unmittelbar nach Temperaturwechsel gegenüber dem vorher gemessenen Niveau („overshoot ${ }^{\star}$ ). Abszisse: Inkubationsdauer. (Nach LOCKER 1958a)

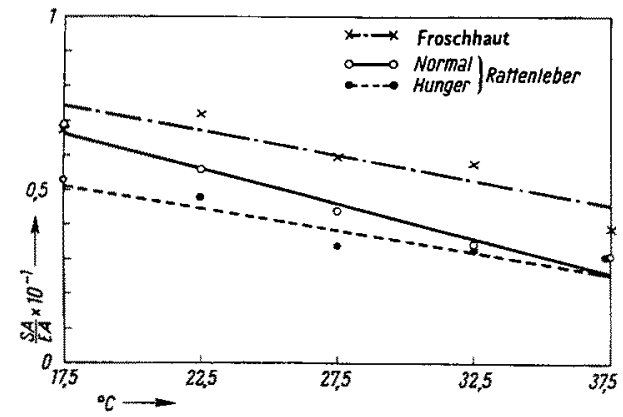

Abb. 33: Relative Aktivität der Substratatmung (SA/EA) im Temperaturbereich $17,5-37,5^{\circ} \mathrm{C}$. (Nach LOCKER 1958b)

ten metabolisierender Systeme wird in dem Maße zutage treten, in dem die Systembetrachtung an Raum gewinnt ${ }^{28}$. Soll aber mit Hilfe der Temperaturwirkung eine Untersuchung zur Aufdeckung der Stoffwechselunterschiede zwischen Kalt- und Warmblütern vorgenommen werden, so verlangt die gegenwärtige Situation immer noch die

28 Wo Mechanismen interferierender Arr in Erwägung gezogen werden, handelt es sich eigentlich schon um Systembetrachtung, so, wenn KüHNELT (1950) eine Diskrepanz zwischen $\mathrm{O}_{\mathrm{z}}$-Bedarf und Leistungsfähigkeit der Atmungsorgane annimmt. 
Verwendung problematischer Terme (wie der $\mathrm{Q}_{10^{-}}$oder $\mu$-Werte), die akzeptiert werden darf, wenn das Temperaturintervall, für das sie gelten, stets genannt wird. Unter dieser Voraussetzung wollen wir uns dem eigentlichen Problem zuwenden.

\section{Die Befunde und die Möglichkeit ibrer Interpretation}

Wir finden zunächst, daß bei den Geweben von Kalt- und Warmblütern der $\mu$-Wert weitgehend, wenn auch nicht vollkommen, von der Höhe der Gewebsatmung unabhängig ist und daß zumindest bei Warmblütergeweben (vielleicht auch bei Kalt-
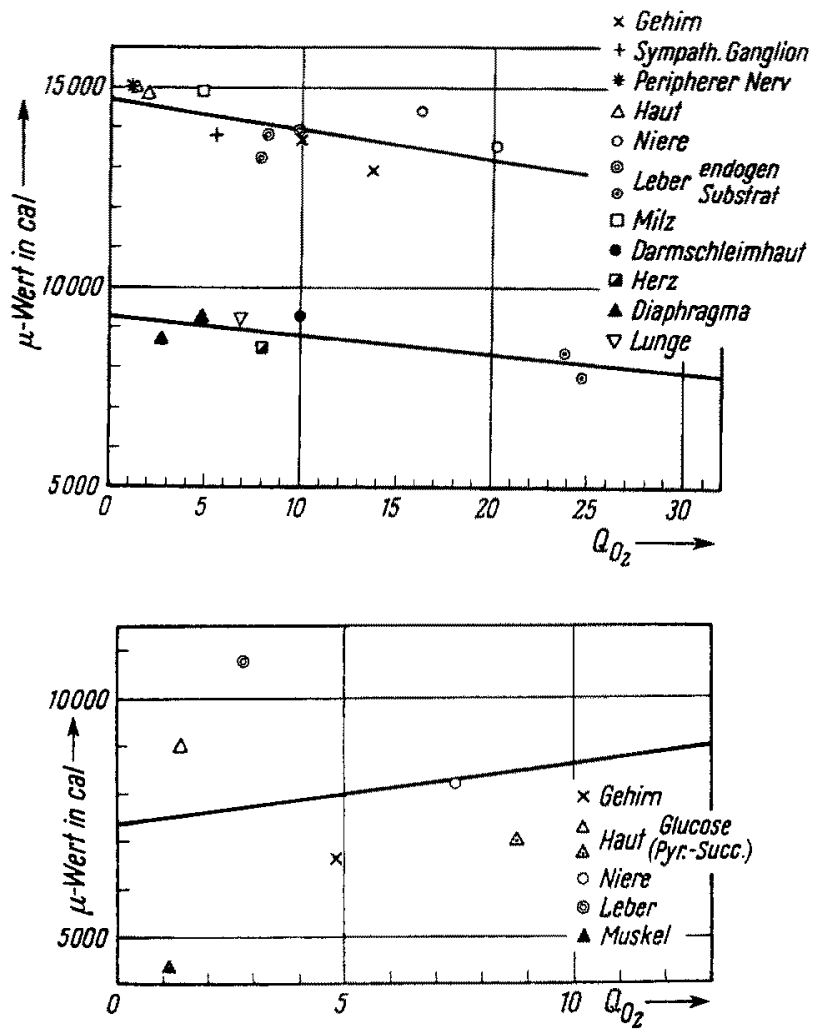

Abb. 34: Die Beziehung zwischen der Aktivierungsenergie ( $\mu$-Wert) (Ordinate) und der Gewebsatmung (Abszisse) bei verschiedenen Geweben der Ratte (oben) und des Frosches (unten). Beide Regressionsgeraden der oberen Abbildung sind etwa parallel, nur die untere schwach signifikant von Null unterschieden; Regressionskoeffizient der unteren Abbildung nicht signifikant. Am Säugetier sind 2 Gruppen von $\mu$-Werten, am Frosch (wahrscheinlich) nur eine Gruppe erkennbar. $\mu$-Werte für Temperaturintervall von $17,5^{\circ}$ bis $37,5^{\circ} \mathrm{C}$ bestimmt, Gewebsatmung bei $37,5^{\circ}$ gemessen. (Nach LOCKER \& LOCKER 1961)

blütergeweben) zwei Gruppen von $\mu$-Werten unterschieden werden können (LockER \& LOCKER 1961) (Abb. 34). Die absoluten Beträge zeigen dagegen Unterschiede und sind beim Warmblütergewebe etwa um 5000 cal oder mehr höher. Die Gewebe mit höheren $\mu$-Werten (Gehirn, Leber, Herz) sind jene, die sich durch höheren Mitochondriengehalt 
auszeichnen (MILLER et al. 1959). An diesen Geweben wird noch ein weiterer Unterschied zwischen Maus und Frosch erkennbar, und zwar unter Einfluß von DNOC bei verschiedenen Temperaturen (Locker 1958, 1962a). Im Gegensatz zu den übrigen Kaltblütergeweben und sämtlichen Warmblütergeweben zeigt sich unter dem kombinierten Einfluß von DNOC und Temperatur mit Erhöhung letzterer nur an diesen Geweben eine Zunahme der relativen Steigerung des $\mathrm{O}_{2}$-Verbrauchs. Sie ist besonders ausgeprägt an der Leber (Abb. 35). Bedeutungsvoll ist, daß zum Unterschied vom Herzmuskel, sich der Skelettmuskel bei Kalt- und Warmblütern gleich verhält; wieder können wir dies mit dem Mitochondriengehalt in Verbindung bringen, der beim Skelettmuskel 5 bis 50\% des Herzmuskels beträgt (Paul \& SPERLing 1952).
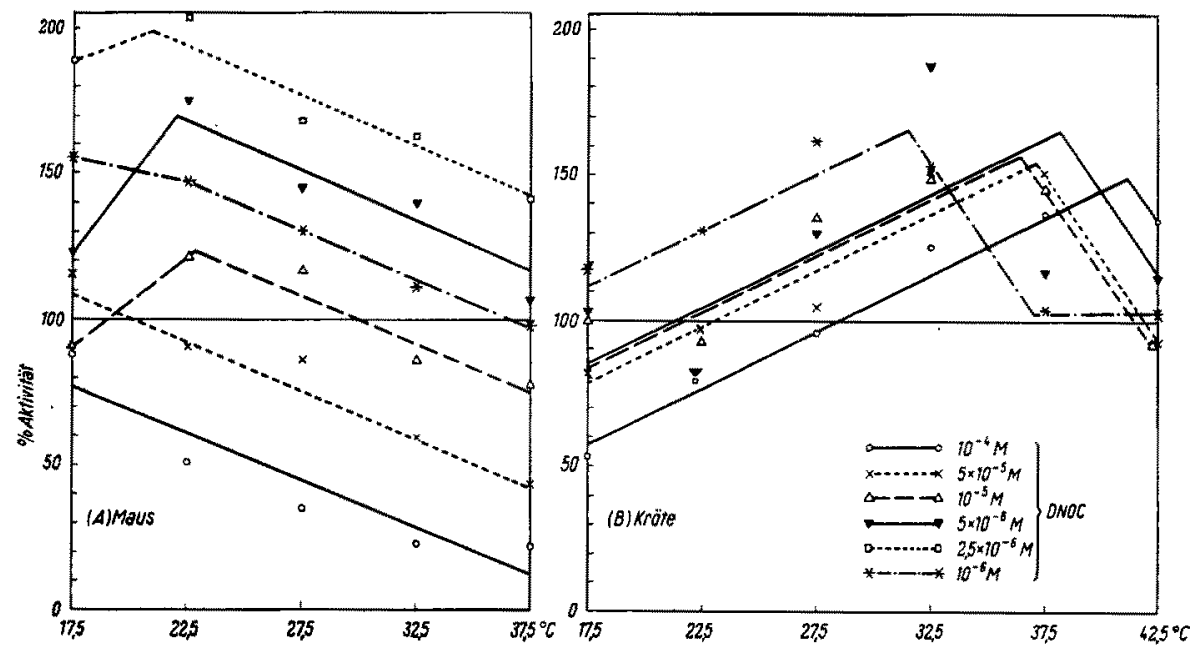

Abb. 35: Prozentuelle Aktivität der Gewebsatmung der Leber von Maus (Warmblüter) und Kröte (Kaltblüter) unter Einfluß von DNOC verschiedener Konzentrationen bei Temperaturen von $17,5^{\circ}$ bis $37,5^{\circ} \mathrm{C}$ (bzw. $42,5^{\circ} \mathrm{C}$ ). (Nach Locker 1958c)

Eine kinetische Interpretation unserer Befunde wurde auf der Basis der Theorie JoHnsons (1954) versucht. Nach dieser bestehen $z$ wischen dem aktiven und inaktiven Zustand von Enzymen reversible Gleichgewichte, welche sich mit Temperaturerhöhung zur inaktiven Seite verschieben; über dem Maximum wird die Verschiebung irreversibel. Auf Grund experimenteller Daten gelangt JoHnson zur Charakterisierung von 3 Hemmtypen. Beim Hemmtyp 1 wirkt der Hemmstoff (I) auf aktives und inaktives Enzym unter Bildung eines Enzym-Hemmstoffkomplexes:

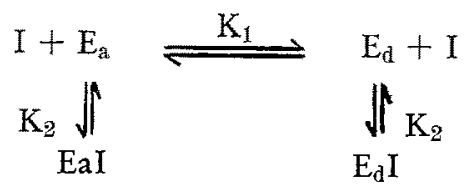

$K_{1}$ stellt die Gleichgewichtskonstante zwischen aktivem $\left(E_{a}\right)$ und denaturiertem $\left(E_{\mathrm{d}}\right)$ 
Enzym dar, $\mathrm{K}_{2}$ die zwischen Enzym und Enzym-Hemmstoffkomplex. Beim Hemmtyp 2 wirkt der Hemmstoff ausschließlich auf denaturiertes Eiweiß:

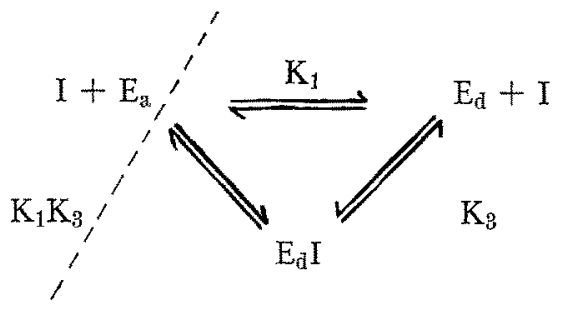

Das Gleichgewicht zwischen denaturiertem Enzym plus Inhibitor und dem entsprechenden Komplex hängt von der Konstanten $K_{3}$ ab. Der Komplex $E_{d} I$ tritt auch ein, wenn der Inhibitor, entsprechend dem Hemmtyp 3, zunächst ausschließlich auf aktives Enzym wirkt und unter seinem Einfluß die Denaturierung des Enzyms zunimmt. Die für das nunmehr eingetretene Gleichgewicht verantwortliche Konstante wird zum Produkt aus $\mathrm{K}_{1}$ und $\mathrm{K}_{3}$. Durch die gestrichelte Linie soll zum Ausdruck gebracht werden, daß beide Fälle (Wirkung auf $\mathrm{E}_{\mathrm{a}}$ und $\mathrm{E}_{\mathrm{d}}$ ) nicht zugleich eintreten können. Infolge des gleichen Endprodukts läßt sich in der kinetischen Analyse Hemmtyp 2 von 3 nicht unterscheiden. Beim Hemmtyp 1 ist die Bindung des Inhibitors vom Denaturierungszustand des Enzyms unabhängig; bei Temperaturzunahme führt die Dissoziation des Enzym-Substratkomplexes zur Verringerung der Hemmung. Auch

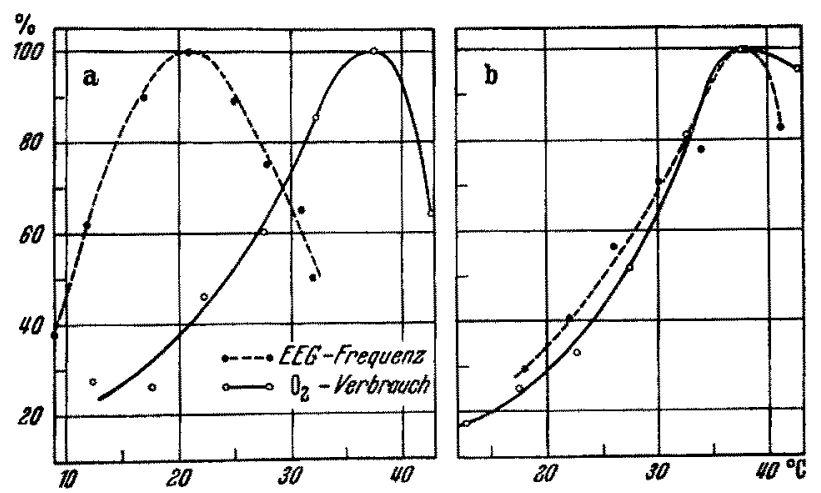

Abb. 36: Vergleich der Gewebsatmung der Gehirne von Frosch (a) und Maus (b) (eigene Ergebnisse) mit der Ruhe-EEG-Frequenz von Frosch (a) und Ratte (b). (Nach LeMarTrE 1954). Die Aktivitätsmaxima beider Funktionen sind gleich 100 gesetzt. Ordinate: Prozentuelle Aktivität, Abszisse: Temperatur. (Nach LOCKER 1962a)

bei Typ 2 und 3 tritt unter Temperaturerhöhung verstärkte Dissoziation des EnzymInhibitor-Komplexes ein; sie wird dadurch aufgewogen, daß der Inhibitor mit Temperaturerhöhung das Enzym immer stärker denaturiert, was zu der für Typ 2 beziehungsweise 3 charakteristischen Zunahme der Hemmung führt.

Bei Wirkung von DNOC auf den $\mathrm{O}_{2}$-Verbrauch von Gehirn, Herz und Leber treten somit verschiedene Hemmtypen zutage. Wenn ein und derselbe Stoff scheinbar nach zwei Hemmtypen wirkt und die Umwandlung eines Hemmtyps in einen anderen ausgeschlossen werden kann, muß angenommen werden, daß die Wirkung von DNOC 
dem Typ 1 entsprechend zugleich auf aktives und inaktives Enzym gerichtet ist. Im Gewebe des Poikilothermen kommt sie dadurch zur Geltung, daß sich beide Enzymformen größenordnungsmäßig entsprechen; beim Gewebe des Homoiothermen kann erscheinungsmäßig nur dann ein anderer Hemmtyp imponieren, wenn eine extreme Verschiebung des Gleichgewichts auf eine Seite erfolgte; es ist anzunehmen, daß es die des aktiven Enzyms ist. Bei Verbindung der kinetischen Interpretation mit den Mitochondriengehalten, wie sie für Gehirn, Herz und Leber möglich ist, wird auch der an Tumorgewebe erhobene Befund verständlich ( $\mathrm{Abb}, 28$ ), nämlich seine Entsprechung zum mitochondrienarmen Kaltblütergewebe. In der Tumorzelle ist der Mitochondrien-. gehalt wesentlich niedriger (FIALA \& Frala 1959).

Ein ausgeprägter Unterschied im Stoffwechselverhalten von kalt- und warmblütigen Tieren wird bei Gegenüberstellung von energieliefernden und energieverbrauchenden Reaktionen gefunden (LOCKER 1962a). Die Abbildung 36 demonstriert, daß bei Ratte und Maus unter Temperaturzunahme EEG-Frequenz und Gehirnatmung sich konkordant erhöhen, beim Froschgehirn aber auseinanderstreben, so daß zum Unterschied vom Warmblïter das Maximum der EEG-Frequenz (vielleicht als Ausdruck einer energieverbrauchenden Reaktion) tiefer zu liegen kommt. Die gleiche Erscheinung wird unter anderem an der Herzschlagfrequenz, der HCl-Produktion der Magenschleimhaut und dem Phosphatverbrauch im Verhältnis zum $\mathrm{O}_{2}-$ Verbrauch gefunden (Literatur bei Locker 1962a): Stets sind beim Warmblüter diese Prozesse konkordant (haben gleiche $\mu$-Werte), beim Kaltblüter nicht. In gewissem Sinne bedeutet dies auch, daß die Leistung des letzteren geringer ist.

\section{ABSCHLIESSENDE BEMERKUNGEN}

\section{Die Möglichkeit formaler Betrachtungen}

\section{Beziehungen $z$ wischen determinierten und stochastischen Prozessen}

Wenn wir im bisher Dargebotenen eine allgemeine (formalisierte) Theorie zur Grundlage unserer Betrachtung nahmen und schon bekannte Reiz-Reaktions-Gesetze auf ihrem Boden neu fundierten, war bei all dem bewußt, daß dadurch die Beschreibung des Mechanismus von Einflüssen auf Biosysteme nicht erschöpft wurde. Das WEBER-Fechnersche Gesetz beispielsweise kann zwar, wie dargelegt, aus dem allgemeinen Ansatz eines Fließgleichgewichts abgeleitet werden, aber auch anders, nämlich als Integral einer Normalverteilung interpretiert werden (DE RUDDER 1943), dessen mittlerer Anteil innerhalb enger, für biologische Fragen aber bisweilen ausreichender Grenzen mit einer linearen Funktion zusammenfällt ${ }^{29}$. Mit dieser Interpretation des

29 Dies wird besonders dann möglich, wenn bereits durch logarithmische Auftragung der Abszissenwerte eine schiefe Verteilung in eine Normalverteilung übergefüht wurde, deren Summenkurve (praktischerweise in Prozent ausgedrückt) dem WeBER-FECHNERschen Gesetz entspricht. 
Weber-Fechnerschen Gesetzes ist nicht ein Gebiet auf ein anderes zurückgeführt, sondern das Gesetz nur als in einem allgemeinen Zusammenhang stehend dargelegt, der in der Fließgleichgewichtstheorie vorwiegend deterministisch ist, aber unter anderem Gesichtswinkel auch ein stochastischer sein kann. Diese Ableitbarkeit darf nicht zur Negation der Gesetzesnatur führen. Tatsächlich wird (in bezug auf das WiLdersche Gesetz) auf Grund korrelations-statistischer Untersuchungen eine solche Ablehnung vertreten (PolAK \& KNoBloch 1957); damit ist eine Betrachtungsweise unzulänglich verabsolutiert und das System, innerhalb dessen sie allein gültig ist, vernachlässigt worden ${ }^{30}$.

Die Möglichkeit, ein Gesetz mit so weiter Anwendung wie das WEBER-FechNERsche Gesetz im stochastischen Sinne zu interpretieren, öffnet den Blick für eine Arbeitsrichtung, die gerade beim Problem des Reizes eine fruchtbare Erweiterung zu werden verspricht, und zwar nicht nur in der Sinnesphysiologie, in der die Reizquantelung eine Rolle spielt (BAUMGARDT 1952). Es muß jedoch Klarheit darïber bestehen, daß grundsätzlich eine stochastische Betrachtung eine deterministische nicht ersetzen, sondern bloß in gewissem Sinne erweitern und ergänzen kann. Die Voraussetzung muß akzeptiert werden, daß der determinierte (kausale) Prozeß die Grundlage bleibt ${ }^{31}$. Auch hier wird also eine Systembetrachtung vorangehen müssen, nur kann das System sozusagen aus determinierten und indeterminierten „Bereichen" bestehend aufgefaßt werden (WIESER 1959). Je nachdem, auf welchem von beiden das Hauptgewicht der Betrachtung liegt, wird der Normalzustand ein bloß statistischer oder ein streng determinierter.

In die Enzymkinetik (WILKINSON 1961) und in die theoretische Pharmakologie (JUNG 1952) hat diese Betrachtungsweise bereits Einzug gehalten. So wird von JuNG erkannt, daß beim Hineinwirken statistischer Verteilungen einzelner Reaktanten in einen Funktionszusammenhang einfache Massengleichgewichte zur Beschreibung von Dosis-Wirkungskurven nicht ausreichen ${ }^{32}$. Durch CHRISTIANSEN (1958) ist gezeigt worden, wie schon auf dem enzymkinetischen Niveau spontan-rhythmische Vorgänge erklärt werden können: Am ES-Komplex können periodisch nach der Zeit variierende Verteilungen angenommen werden; der Mittelwert wird in der usuellen "steady-state" Kinetik allein verwendet. Daß für rhythmische Vorgänge, ständiges Schwanken zwischen Ruhe- und Aktivitätsniveau, stochastische Prozesse von Bedeutung sein können, wird bei niedrigem "scope of activity" oder niedriger Reizschwelle verständlich. Vergegenwärtigen wir uns schließlich, daß nach ZEMANEK (zit. nach WIESER 1959) die Informationsuibertragung im Nervensystem stochastischer Natur ist, werden wir nicht fehl gehen in der Vermutung, diesen Medanismus auf viel basaleren Organisationsstufen wiederzufinden. So werden vielleicht derartige Mechanismen auch für die Steuerung

30 Ubrigens gelangt WINNE (1963) durch Berücksichtigung von Mehrfach-Korrelationen zum gegenteiligen Resultat.

31 WIESER (1959) diskutiert diese Frage im Zusammenhang mit der Unvorhersagbarkeit von Verhaltensyorgängen in elektrischen Analog-Modellen, die einen bestimmten Komplikationsgrad aberschritten haben.

${ }_{32}$ Auch von KIESE (1950) wird die Bedeutung der stochastischen Interpretierbarkeit des Weber-Fechnerschen Gesetzes zugestanden, obwohl er mit experimentellen Daten befriedigender übereinstimmende Kurven findet, wenn die Wirkung als einfache Potenzfunktion der Dosis beschrieben wird. Dods diese Darstellung bedeutet keinen prinzipiellen Gegensatz, zumal das WeBER-FechNersche Gesetz (als psycho-physisches Gesetz) auch von Plateau als Potenzfunktion beschrieben wurde. 
von Enzymsynthesen (der Impuls-Ubertragung vom Induktor-Repressor-System uber messenger-RNS- Transfer-RNS bis zur Aminosäure), die ja zeitweise schon informationstheoretisch dargestellt werden (WITTMANN 1963), von Bedeutung sein.

\section{Treffertheorie und allgemeine stochastische Wirktheorie}

In der Treffertheorie, der Vorstellung, daß an Biosystemen auftretende Wirkungen zufälligen Treffern zu verdanken sind, werden seit langem stochastische Gesichtspunkte vertreten. Allerdings trug sie auch lange Zeit hindurch dem von biologischer Seite (Clark 1937) erhobenen Einwand, die Variabilität zu wenig zu berücksichtigen, nicht genügend Rechnung und verlor in Biologenkreisen an Ansehen. Eine Wendung verspricht diese Einstellung durch die Untersuchungen von Hug \& KELLERER (1963) zu erfahren, die unter Rückgriff auf verschiedene Untersuchungen nachweisen konnten, daß sich beide Aspekte - Trefferwahrscheinlichkeit und biologische Variabilität - zu einer allgemeinen stochastischen Wirktheorie vereinen lassen. Bei dieser werden für Prozesse (die als solche Fließgleichgewichts- oder Kommunikationssystemen analog gesetzt werden könnten) Wahrscheinlichkeiten für Übergänge (von einem bestimmten $\mathrm{zu}$ einem anderen Zustand) angegeben, die schließlich zu einem Endeffekt führen.

\section{Typologische und dynamische (deterministische oder indeterministische) Betrachtung}

Wenn ein System aus verschiedenen Komponenten (Reaktanten) mit unterschiedlichen Verteilungen besteht und in stochastische Prozesse verwickelt ist, wird es unmöglich, irgendwelche Reaktionen als typisch anzugeben. Die Fragwürdigkeit einer typologischen Betrachtung sei an der Untersuchung von MEIER et al. (1955) über sogenannte Reaktionstypen gegenüber bestimmten Stoffklassen dargelegt. Der Blick auf einige Typen, die an der Atmung und Gärung der Bäckerhefe erhoben wurden (Abb. 37),
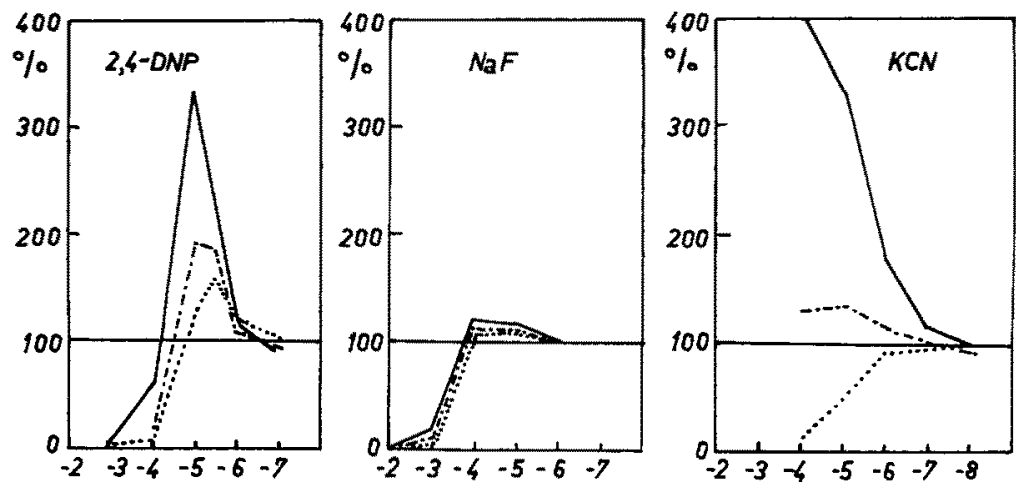

Abb. 37: Überblick über einige sogenannte Wirkungstypen der Atmung (...), des Gesamt-COz $(-\cdots)$ und der Gärung (-) der Bäckerhefe. Ordinate: $\%$-Aktivität, Abszisse: Effektive Konzentration. (Nach Mrier et al. 1955; umgezeichnet) 
zeigt im wesentlichen nur Reaktionen nach dem ARNDT-SCHulzschen Gesetz, zwischen denen keine anderen als quantitativen Unterschiede bestehen. Dies ist für DNP und $\mathrm{NaF}^{33}$ sofort klar, kann aber selbst für $\mathrm{KCN}$ behauptet werden, bei dem ein Hemmbereich der Gärung fehlt. Möglicherweise beruht dies auf dem Mangel an für einen schwachwirksamen Stoff erforderlichen Rezeptoren; das ist aber vorwiegend eine Eigenschaft des Systems und nicht die des Stoffes.

Die Abhängigkeit der Reaktionen allein vom System kann bis zu einer analogen Behauptung, zur in der Neurophysiologie geläufigen Feststellung: "Alles ist mit allem verbunden", geführt werden: „Alles vermag alles." Obwohl unsere Darstellung die Gültigkeit dieses Satzes unterstreicht, sei ein Beispiel noch einmal herausgegriffen: die Karzinogenese, für welche übrigens auch eine stochastische Theorie formuliert wurde (ARLEY 1960). Wie erwähnt, kann eine etwa durch Tetrachlorkohlenstoff herbeigeführte Leberschädigung durch Sulfonamide und Antibiotika verhindert werden. Nicht nur, daß bei chronischer Verabreichung der Tetrachlorkohlenstoff (der bei einmaliger Applikation eine flüdhtige Wirkung entfaltet; vgl. Abb. 20) hepatokarzinogen wird (RudaLI \& Mariani 1950), auch Sulfonamide sind karzinogen (Hansen \& Bichel 1952) ${ }^{34}$. So wird man vielleicht sogar bei Karzinogenen verschiedene Grade der Spezifität annehmen müssen. Bei den hochspezifischen Karzinogenen ist die Dosis-Wirkungskurve von außerordentlicher Steilheit (DRUCKREY \& SCHMÄHL 1962); es wäre interessant zu wissen, ob sie bei weniger spezifischen Karzinogenen, wie beim Tetrachlorkohlenstoff, die gleiche Neigung hat.

\section{Uber quantitative und qualitative Betrachtung in der Biologie}

In unseren Ausfuihrungen war von quantitativer Biologie die Rede, deren Anliegen am speziellen Problem der Reaktionen stoffwechselnder Systeme aufgezeigt werden sollte. Abschließend sei jedoch unterstrichen, daß quantitative Biologie mit Biologie als solcher niemals gleichgesetzt werden kann. In der Biologie existieren nämlich Bereiche, die einer quantitativen (formalisierbaren) Betrachtung prinzipiell unzugänglich sind. Erzwingt sich diese ihre Berechtigung dort (als Methode und Ziel), wo die Komplexität von Prozessen nach einer Vereinheitlichung in der Darstellung drängt, so gelangt sie mit Notwendigkeit auch wieder an eine Grenze. Diese ist nicht etwa dadurch gegeben, daß ein in sich quantifizierbarer Gegenstand infolge seiner Komplexität bloß vorläufig als unanalysiert hingenommen und dadurch nur scheinbar von qualitativer Natur wird. Die Grenze ist gezogen, sobald erkannt wird, daß (analog zur Beziehung von stochastischer zu deterministischer Betrachtung) die quantitative Betrachtung durch die qualitative bedingt wird. Das impliziert, daß das Qualitative nicht bloß als Vorläufiges etwa so lange stehen gelassen, bis es einer Quantifizierung zugänglich wird (wie es der Einstellung der quantitativ orientierten Naturwissenschaft entspricht, die dadurch das Qualitative stets aus ihrem konkreten Arbeitsgebiet ver-

33 Von BoREr (1942) ist mit Fluorid am gleichen Objekt (Bäckerhefe) eine ansehnliche Steigerung der Atmung erzielt worden.

${ }_{34}$ Eine mögliche karzinogene Wirkung von Antibiotika wurde meines Wissens noch nicht untersucht. 
treibt). Es bedeutet, daß das Qualitative als solches anerkannt, freilich damit ein Standpunkt eingenommen wird, den nicht jedermann teilen kann.

Das Qualitative äußert sich durch Bezug auf eine gegebene Wirklichkeit, nämlich den Organismus, ja noch mehr, wird durch diesen repräsentiert. Damit setzt es erst die Möglichkeit, daß an diesem (bzw. in der Welt der Organismen zwischen diesen) Beziehungen (letztlich formalisierbarer Natur) aufgedeckt werden können. Morphologie und Systematik, die Schwerpunkte der qualitativen Forschung in der Biologie, müssen daher nicht die Befürchtung hegen, etwa durch eine sogenannte Gestaltmathematik (FrIEDMANN 1948, RASHEVSKY 1960) oder überhaupt durch eine quantitative Biologie ihre eigene Domäne zerstört zu sehen. Die überspitzte Devise: „Morphologie ist, was sich noch nicht in Physiologie hat auflösen lassen", hat keine Berechtigung. Halten wir daher daran fest, daß immer erst eine qualitative Biologie eine quantitative ermöglicht, wobei letztere auch in ihrer Gesamtheit (z. B. als Systemtheorie oder Gestaltmathematik) der ersteren höchstens analog sein kann. Auch eine durchgehende mathematische Formulierung des analogen Systems (von der wir eingangs sprachen) kann über diese Voraussetzung nicht hinweg; das Qualitative bleibt ihr unangreifbar. Es stellt gleichsam die Einheit dar, die vor und über der quantitativ auflösbaren Vielfalt steht. Wird letztere auch in einer perfekten Theorie zusammengefaßt, so bleibt diese dennoch analog und dependent. Übrigens haben wir auch von der Stellung der Biochemie etwas Ahnliches anzunehmen: sie liefert qualitativ-stoffliche wie strukturelle Gegebenheiten als Voraussetzung für eine Quantifizierung.

Mit dieser Feststellung könnten wir uns begnügen und abbrechen. Wir scheuen uns aber nicht, hinzuzufügen, daß Qualitatives mehr ist als bloße Bedingung des Quantitativen: es bringt eine andere Seinsweise zum Ausdruck, die als Metaphysik (oder Ontologie) im Sinne KanTs die Voraussetzung der Naturwissenschaft überhaupt ist.

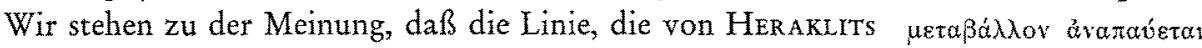
(für welches wir GoETHEs Wort von der "Dauer im. Wechsel“ setzen können) über Leibnizs Monadologie ${ }^{35}$, Doutremonts (1798) „Dissertatio de materiae physicomedicalis perpetua vicissitudine" bis zu v. BERTALANFFYs $(1955,1962)$ allgemeiner Systemtheorie führt, reinste Metaphysik, doch Grundgedanken der uns leitenden Theorie offener Systeme enthält, wie um die metaphysische Voraussetzung naturwissenschaftlicher Theorien zu demonstrieren. Vermochte die moderne Naturwissenschaft vorïbergehend den quantitativen Gesichtspunkt allzusehr in den Vordergrund zu stellen, so zeichnet sich heute bereits eine Entwidklung ab, die FISCHER (1933) vorhergesagt hat und die auch junge Naturwissenschaftler, die etwa als theoretische Physiker in der Mathematik zu Hause sind, des quantitativen Formalismus überdrüssig sein und diesen lediglich als Methode, nicht mehr als Ziel der Naturwissenschaft empfinden läßt. Diese Entwicklung wird mit Sicherheit zur Wiedererwedkung der Philosophie im Bewußtsein der Naturwissenschaftler führen. Für den bescheidenen Rahmen unserer Betrachtung soll als Gewinn die Forderung gezogen werden, sich nicht ausschließlich einer quantitativen Betrachtung hinzugeben und damit den Bezug auf eine Wirklichkeit, die als solche letztlich niemals ganz verstehbar, sondern nur annehmbar ist, zu verlieren.

\$n In ihr heißr es unter $\$ 70$ : "Alle Körper sind in fortwährendem Fluß, wie Ströme, und ständig treten "Teile ein und aus." 


\section{ZUSAMMENFASSUNG}

1. Die Grundlagen einer quantitativen Biologie werden an Hand der Reaktionen stoffwechselnder Systeme auf experimentelle Beeinflussung, Reiz und Schädigung erörtert. In die Darstellung geht mit Notwendigkeit die Berücksichtigung des Systems (vor den Einzelreaktionen) ein.

2. $\mathrm{Zu}$ den Begriffen Wirkungsmechanismus und spezifische Wirkung wird einleitend Stellung genommen.

3. Die Reaktionen metabolisierender Systeme äußern sich in Übergängen („transition-states"); sie können schon am Modellsystem der Enzymkinetik dargestellt werden, in welcher die Fließgleichgewichtsbetrachtung immer mehr" an Raum gewinnt. Limitierende Glieder (das Master-Prinzip) stehen mit den Eigenschaften des Gesamtsystems in Wechselwirkung. Die Übergänge können zu multiplen Schwingungen werden; von diesen sind spontan-rhythmische Vorgänge abzugrenzen.

4. Allgemeine Reiz-Reaktionsgesetze, wie das WEBER-Fechnersche Gesetz, das ARNDT-SCHUIzsche Gesetz und das WidDERshe Ausgangslagengesetz, lassen sich aus der Theorie stoffwechselnder Systeme ableiten. Schon im Bereich der Enzymkinetik, besonders im sogenannten Ogston-LaIDLERschen Modell, können diese Gesetze verifiziert werden.

5. Neben Hemmungserscheinungen werden ausfuhrlich Aktivierungsvorgänge betrachtet, die die Gültigkeit des (von der Pharmakologie irrtümlich abgelehnten) Arndt-Schulzschen Gesetzes unter Beweis stellen.

6. Für das Problem der Ausgangslage erweist sich die Diskussion experimenteller Bedingungen als notwendig. Die Frage einer "physiologischen" Ausgangslage wird erörtert.

7. Auch einige sogenannte Konstanz-Phänomene, die mit den Reiz-Realtrionsgesetzen im Zusammenhang stehen und sich oft als (summative oder multiplikative) Konstanten aus zwei oder mehr Vorgängen ergeben, werden behandelt: paradoxe Reaktion, Komplettierung, Regulation, Kompensation, Erholung, Adaptation, Empfindlichkeit, Interferenz und die Beziehung des Stoffwechsels zu Alter und Körpergröße.

8. Auf dem Gebiete der experimentellen Leberpathologie wird eine besondere Exemplifizierung gegeben, und zwar bei den Reaktionen des Stoffwechsels nach chemischer und physilkalischer Beeinflussung und ihren Verbindungen zu morphologischen Veränderungen. Kriterien zur Unterscheidung von Reiz und Schädigung werden erwogen; zu den Problemen der experimentellen Karzinogenese und zu Entzündung und Krebs wird Stellung genommen.

9. Auch der Aktivitätsstoffwechsel stell eine spezielle Exemplifizierung der Gesetzmäßigkeiten stoffwechselnder Systeme dar; bei ihm verschaffen sich limitierende Bedingungen (wie Or-Gehalt, Substratgehalt, Durchblutung etc.) besonders stark Geltung.

10. Stoffwechselunterschiede zwischen Kalt- und Warmblütern treten unter Beeinflussung der Gewebsatmung in vitro mit 4,6-Dinitro-o-kresol bei verschiedenen Temperaturen zutage, und zwar an Gehirn, Leber und Herz, den mitochondrien- 
reichsten Geweben. Die Unterschiede werden audh auf der Basis der Theorie JoHnsons kinetisch interpretiert. Hier wird zum Problem der biologischen Temperaturwirkung kritisch Stellung genommen.

11. Abschließend wird das Problem der Beziehung der deterministischen zur indeterministischen Betrachtung in der Biologie erörtert. Es wird auf die Anerkennung stochastischer Abhängigkeiten in der Enzymkinetik, theoretischen Pharmakologie und Treffertheorie hingewiesen; sie deuten die Möglichkeit einer Erweiterung der Betrachtung der Reaktionen metabolisierender Systeme an. Eine typologische Auffassung wird der Fülle der Erscheinungen und der dynamischen Ubergänge zwischen ihnen nicht gerecht. Auch die quantitative Betrachtungsweise gelangt an eine Grenze, sobald die Notwendigkeit qualitativer Gesichtspunkte anerkannt wird.

\section{ZITIERTE LITERATUR}

Adolph, E. F., 1951. Some differences in responses to low temperatures between warm-blooded and cold- blooded vertebrates. Am. J. Physiol. 166, 92-103.

AERr, H., 1952. Uber die chemische und morphologische Natur der Stickstoffabgabe von Gewebsschnitten im Warburg-Versuch. Biochim. biopbys. Acta 9, 443-456.

ALBERT, A., 1951. Selective toxicity with special reference to chemotherapy. Methuen \& Co., New York, 228 pp.

Alberty, R. A., 1959. Mechanisms of enzyme action. Rev. mod. Phys. 31, 177-184.

Ariens, E. J., Rossum, J. M. van \& Simonis, A. M., 1956. A theoretical basis of molecular pharmacology. Arzneimittel-Forsch. 6, 282-293, 611-621, 737-746.

ARLEY, N., 1960. Theoretical analysis of carcinogenesis. Proc. 4 th Berkeley Symp. Math. Statist. Probability, Univ. of Calif. Pr., Berkeley, p. 1-18.

Barnum, C. P., Jardetzky, C. D. \& Halberg, F., 1958. Time relations among metabolic and morphologic 24-hour changes in mouse liver. Am. J. Physiol. 195, 301-310.

BASU, S. P., 1959. Active respiration of fish in relation to ambient concentrations of oxygen and carbon dioxide. J. Fish. Res. Bd. Can. 16, 175-212.

BAUMGARDT, E., 1952. Sehmechanismus und Quantenstruktur des Lichts. Naturreissenschaften 39, 388-393.

BerTalanfFY, L. v., 1953. Biophysik des Fließgleichgewichts. Vieweg, Braunschweig, 56 pp.

- 1955. General system-theory. Main Curr. mod. Thought 11, 75-83.

- 1962. General system-theory; a critical review. Gen. Syst. 7, 1-20.

Blackman, F. F., 1905. Optima and limiting factors. Ann. Bot. 19, 281-295.

BOREI, H., 1942. Zur endogenen Atmung und Gärung der Oberhefe. 1. Verhalten der Atmung gegen Fluorid und Azid. Biochem. Z. 312, 160-187.

Brachet, J., 1947. Embryologie chimique. Masson \& Cie., Paris, 534 pp.

BrigGs, G. E. \& Haldane, J. B. S., 1925. A note on the kinetics of enzyme action. Biochem. J. 19, 338-339.

Brink, F., 1957. Ionic transfer in muscle and nerve. In: Metabolic aspects of transport across cell membranes. Edited by Q. R. Murphy, Univ. of Wisconsin Pr., Madison, p. 167-172.

Brock, N., 1938. Experimentelle Beiträge zum "Arndt-Schulzschen Gesetz". Arch. exp. Path. Pharmak. 190, 191-194.

BRONK, J. R., 1960. Some actions of thyroxine on oxidative phosphorylation. Biochim. biophys. Acta 37, 327-336.

BouRlik̀re, F., 1954. Einige Gesichtspunkte zur Physiologie des Alterns. Scbweiz. med. Wschr. 84, 1310-1313.

BüCher, Th. \& Rüssmann, W., 1963. Gleichgewicht und Ungleichgewicht in System der Glykolyse. Angew. Chem. 75, 881-893. 
BüCHNER, F., 1961. Die experimentelle Kanzerisierung der Parenchymzelle in der Synopsis klassischer und moderner morphologischer Methoden. Verh. Dit. Ges, Path. 45, 37-59.

Burton, A. Ch., 1936. The basis of the principle of the master reaction in biology. J. cell. comp. Physiol. 9, 1-14.

- 1939. The properties of the steady state compared to those of equilibrium as shown in characteristic biological behavior. J. cell. comp. Physiol. 14, 327-349.

Chateen, R. R. J., Hoch, F. L. \& Lyman Ch. P., 1961. Mitodondrial oxidative enzymes and phosphorylations in cold exposure and hibernation. Am. J. Physiol. 201, 29-32.

Chambers, R. \& Z ZEETFACH, B. W., 1947. Intercellular cement and capillary permeability. Pbysiol. Rev. 27, 436-463.

Chance, B., 1960. Analogue and digital representations of enzyme kinetics. J. biol. Chem. 235, $2440-2443$.

Christensen, H. N., 1962. Biological transport. Benjamin, inc., New York, 133 pp.

Christiansen, J. A., 1958. On oscillating enzymatic reactions and on a possible interpretation of spike-potentials in nerves. Z. Elektrochem. 62, 225-230.

Clark, A. J., 1937. General pharmacology. In: Handbuch d. exp. Pharmakologie. Hrsg. von W. Heubner \& J. Schüller, (Erg. Werk) Bd. 4, Springer, Berlin, 228 pp.

Cleland, W. W., 1963. The kinetics of enzyme-catalyzed reactions with two or more substrates or products. Biochim. biopbys. Acta 67, 104-137, 173-187, 188-196.

Clowes, G. H. A., Walters, C. P. \& Kedtch, A. K., 1958. Temperature-dependence of dinitrocresol-stimulation of aerobic and anaerobic lactate production in Ascites tumor cells. Proc. Soc. exp. Biol. 99, 415-418.

Coffman, J. D., 1963. Blood flow and oxygen debt repayment in exercising skeletal muscle. Am. J. Physiol. 205, 365-369.

Conneliy, C. M., 1959. Recovery processes and metabolism of nerve. Rev. mod. Phys. 31, 475-484.

Crozrer, W. J., 1924/25. On biological oxidations as a function of temperature. J. gen. Physiol. 7, 189-216.

DöbELN, W. von, 1956. Human standard and maximal metabolic rate in relation to fat free body mass. Acta physiol. scand. 37 (Suppl. 126), 1-79.

Dose, K., Bresciant, F. \& Rajewsisy, B., 1959. Über die Wirkung yon Röntgenstrahlen auf den Zellstoff wechsel. 1. Die Beeinflussung des Gasstoffwechsels und der Glykolyse von isoliertem Gewebe durch Röntgenstrahlen. Z. Naturf. 14b, 158-168.

Doudoroff, P., 1938. Reactions of marine fishes to temperature gradients. Biol. Bull. mar. biol. lab., Woods Hole. 75, 494-509.

Druckrey, H., 1936. Der Stoffwechsel des geschädigten Gewebes. Arch. exp. Path. Pharmak. 180, 231-250.

-, Bresciani, F. \& SCHNeider, H., 1958. Atmung und Glykolyse der Rattenleber während der Behandlung mit 4-Dimethylaminoazobenzol. Z. Naturf. 13b, 516-525.

--, Brock, N. \& Herken, H., 1938. Der Stoffwechsel des geschädigten Gewebes. 3. Beitrag zur Frage der Entwicklungserregung am Seeigelei. Arch. exp. Path. Pharmak. 188, 451-464.

- \& Küppmüller, K., 1949. Dosis und Wirkung. Beiträge zur theoretischen Pharmakologie. Pharmazie. Beih. 8, Erg.Bd. 1, 511-645.

- \& SсHмäHL, D., 1962. Quantitative Analyse der experimentellen Krebserzeugung. Naturwissenschaften $49,217-228$.

EAGLE, H., 1948. A paradoxical zone phenomen in the bactericidal action of penicillin in vitro. Science 107, 44-45.

EGER, W., 1954. Zur Pathologie des zentralen und peripheren Funktionsfeldes im Leberläppchen. Zbl. allg. Path. 91, 255-267.

- 1955. Beiträge zur experimentellen Lebernekrose, zu ihrer Entstehung und ihrer Verhütung. Acta bepat. 3, 57-75.

Equsa, S., 1961. Studies on the respiration of the „Kuruma" prawn, Penaeus japonicus Bate. 2. Preliminary experiments on the oxygen consumption. Bull. Jap. Soc. scient. Fish. 27, $650-659$. 
Epprnger, H., 1937. Die Leberkrankheiten. Allgemeine und Spezielle Pathologie und Therapie der Leber. Springer, Wien, 801 pp.

- 1949. Die Permeabilitätspathologie als Lehre vom Krankheitsbeginn. Springer, Wien, 755 pp.

Etrunger, L., 1957. Wirkungsmechanismus der Antibiotika. Antibiotica Chemother, 4, 46-68.

Ferguson, J., 1939. The use of chemical potentials as indices of toxicity. Proc. roy. Soc. Lond. (B) 127, 387-404.

FIALA, S. \& FialA, A. E., 1959. On the correlation between metabolic and structural changes during carcinogenesis in rat liver. Br. J. Cancer 13, 136-151.

Frscher, J. L., 1933. Über die Zukunft der europäischen Kultur. Drei-Masken Verl., München, $118 \mathrm{pp}$.

Frsher, K. C. \& Henry, R. J., 1944. The effects of urethane and chloral hydrate on oxygen consumption and cell division in the egg of the sea urchin, Arbacia punctulata. J. gen. Pbysiol. 27, 469-481.

- \& Needler, M. E., 1957. Spontaneous activity of the lemming Dicrostonyx groenlandicus Richardsoni MerRIam as indicated in 24-hour records of oxygen consumption. J. cell. comp. Physiol. 50, 293-308.

Fleckenstein, A., 1944. Beitrag zum Mechanismus der experimentellen serösen Entzündung nach Allylformiat. Arch. exp. Path. Pharmak. 203, 151-170.

Fleming, A., 1946. Penicillin, its practical application. Butterworth \& Co., London, $380 \mathrm{pp}$.

Fontarne, M., 1957. Diskussionsbemerkung zu S. M. Marshall \& A.P. Orr, Coll. Int. Biol. Mar. Station Roscoff. Année biol. 33, 224-225.

Fox, H. M., 1936. The activity and metabolism of poikilothermic animals in different latitudes. 1. Proc. zool. Soc. Lond. (A) 106, 945-955.

Friedmann, H., 1949. Wissenschaft und Symbol. Aufriß einer symbolnahen Wissenschaft. Biederstein, München, $502 \mathrm{pp}$.

FRIEDRICH, W., 1963. Biochemischer Wirkungsmechanismus der wichtigsten Antibiotika. Med. Welt 1963, 3-55.

Fromm, P. O. \& Johnson, R. E., 1955. The respiratory metabolism of frogs as related to season. J. cell. comp. Physiol. 45, 343-360.

FRY, F. E. J., 1947. Effects of the environment on animal activity. Publ. Ont. Fish. Res. Lab. $62,1-62$.

Grainger, J. N. R., 1956. Effects of changes of temperature on the respiration of certain crustacea. Nature. Lond. 178, 930-931.

Grundmann, E. \& Sieburg, H., 1962. Die Histogenese und Cytogenese des Lebercarcinoms der Ratte durch Diäthylnitrosamin in lichtmikroskopischen Bild. Beitr. path. Anat. 126, $57-90$.

Hansen, B. P. \& Bichel, J., 1952. Carcinogenic effect of sulfonamides. Acta radiol. 37, $258-265$.

Heinmets, F. \& Herschman, A., 1960. Quantitative analysis of metabolic processes. Phys. Med. Biol. 4, 238-252.

Hess, B., 1963. Koordination von Atmung und Glykolyse. In: Funktionelle und Morphologische Organisation der Zelle. Hrsg. v. P. Karlson, Springer, Berlin, p. 161-193.

Heusner, A., 1956. Métabolisme de repos du rat estimé à partir de la corrélation entre le métabolisme et l'activité. C. r. Séanc. Soc. Biol. 150, 421-424.

Hiestand, W. A., Stemler, F. W. \& Madden, R. F., 1956. Relative toxicity of certain chemical agents at low and room temperatures in a homeotherm (mouse) and a poikilotherm (frog). Am. Midl. Nat. 55, 321-325.

Hinshel wood, C. N., 1947. The chemical kinetics of the bacterial cell. Clarendon Pr., Oxford, $284 \mathrm{pp}$.

HoLIE, G., 1955. Die gegenwärtigen Vorstellungen über die gestaltliche und funktionelle Organisation der Leber. Acta Hepat. 3, 135-156.

Holtz, P., ExNER, M. \& SChÜMANN, H. J, 1948. Zellreiz und Zellschädigung. Untersuchung über die "Reizatmung" und "Reizgärung" der Hefezelle. Arch. exp. Path. Pharmak. 205, 243-275. 
Hosenn, E. A., Emblem, M., Rochon, S. \& Morch, S. E., 1962. Tissue slice respiration in the absence of suspension medium. Archs Biochem. 99, 414-417.

Hug, O. \& Kellerer, A., 1963. Zur Interpretation der Dosiswirkungsbeziehungen in der Strahlenbiologie. Biophysik 1, 20-32.

Huston, M. J. \& Martin, A. W., 1954. Rate of respiration of tissues in contact with oxygen. Proc. Soc. exp. Biol. Med. 86, 103-107.

Irving, Ch. C. \& Perkinson, J. D., 1960. Biochemical effects of internal irradiation. Radiat. Res. 12, 597-606.

JACOB, F. \& Monod, J., 1961. Genetic regulatory mechanisms in the synthesis of proteins. J. mol. Biol. 3, 318-356.

Jasper, R. L., Denison, M. E., Zarrow, M. X. \& Hiestand, W. A., 1958. Comparison of tissue respiration in mice exposed to heat and cold. Am. J. Physiol. 195, 285-287.

Johnson, F. H., Eyring, H. \& Polissar, M. J., 1954. The kinetic basis of molecular biology. Wiley, New York, 874 pp.

Jung, L., 1952. Die Bedeutung statistischer Faktoren für die Analyse biologischer Reaktionsabläufe. Arch. exp. Path. Pharmak. 215, 600-609.

Kaunitz, H. \& Selzer, L., 1937. Sauerstoffverbrauch von überlebendem Gewebe bei seröser Entzündung. Z. ges, exp. Med. 100, 764-774.

Kettrer, L. H., 1954. Parenchymschädigungen der Leber. Ergebn. allg. Path. path. Anat. 37. $1-206$.

KibLer, H. H., 1960. Oxygen comsumption in cattle in relation to rate of increase in environmental temperatures. Nature, Lond. 186, 972-973.

Kiese, M., 1947, 1950. Dosis und Wirkung. 1-2. Klin. Wschr. 24/25, 453-458 (1), 28, 385-388 (2).

KLExN, P., 1957. Bakteriologische Grundlagen der chemotherapeutischen Laboratoriumspraxis. Springer, Berlin, 210 pp.

KorR, I. N., 1941. Further analysis of the factors determining the temperature coefficients of cellular respiration. Am. J. Physiol. 133, 354-355.

Kristopfersson, R., 1961. Hibernation of the hedgehog (Erinaceus europaeus). The ATP and o-phosphate levels in blood and various tissues of hibernating and non-hibernating animals. Annls Acad. Sci. fenn. (Ser. A 4) 50, 1-45.

Krogh, A., 1924. Anatomie und Physiologie der Capillaren. Springer, Berlin, 232 pp.

KüHNELt, W., 1950. Bodenbiologie. Verl. Herold, Wien, 368 pp.

LAIDLER, K. J., 1956. General steady-state equations in enzyme and other catalyzed reactions. Trans. Faraday Soc, 52, 1374-1382.

Latrd, A. K. \& BARTon, A. D., 1959. Cell growth and the development of tumours. Nature, Lond. 183, 1655-1657.

-, - 1961. Cell proliferation in precancerous liver: relation to presence and dose of carcinogen. J. natn. Cancer Inst. 27, 827-839.

Lamprecht, W., Lamprecht, G. \& Hockerts, Th., 1957. Untersudungen über den Herzstoffwechsel. 3. Die Beeinflussung der Herzenergetik durch Strophanthin. Hoppe-Seyl. Z. $307,144-153$.

LEE, K. H. \& EILER, J. J., 1953. Studies in oxidative phosphorylation with radioactive phosphate. J. biol. Chem. 203, 705-717, 719-730.

LehMann, G., 1951. Das Gesetz der Stoffwechselreduktion in der höheren Tierwelt. Z. Naturf. $6 \mathbf{b}, 216-223$.

Lindop, P. J. \& Rotblat, J., 1960. Protection against acute effects of radiation by hypoxia. Nature, Lond. 185, 593-594.

Locker, A., 1955. Reaktive Veränderungen der Gewebsatmung nach Anoxie und Hypoxie in vitro. Z. ges. exp. Med. 126, 288-297.

- 1956. Anderungen des Wassergehalts der Leber bei experimenteller Schädigung. Z. ges. exp. Med. 127, 551-557.

- 1958a. Ein Beitrag zur irreversiblen Temperatur-Inaktivierung der Gewebsatmung. $E x$ perientia 14, 406-407.

- 1958b. Zur Temperaturaktivierung der Substratatmung tierischer Gewebe. Experientia 14, $407-408$. 
Locker, A., 1958c. Charakteristische Stoffwechselunterschiede zwischen Geweben homoiothermer und poikilothermer Tiere. Z. Naturf. 13b, 548-555.

- 1961a. Die Bedeutung experimenteller Variablen für die Abhängigkeit der Gewebsatmung von der Körpergröße. 2. Die Bezugsbasis. Pflügers Arch, ges. Physiol. 273, 345-352.

- 1961b. Das Problem der Abhängigkeit des Stoffwechsels von der Körpergröße. Naturwissenschaften 48, 445-449.

- 1962a. Uber Stoffwechselunterschiede zwischen den Geweben kalt- und warmblïtiger Tiere (Zugleich ein Beitrag zur Frage: Poikilothermie als Strahlenschutz). Pflïgers Arch. ges. Physiol. 275, 238-255.

- 1962b. Abhängigkeit der Thermoneutralitätszone der Maus vom Ernährungszustand. Naturwissenschaflen 49, 547.

- 1963a. Zum Wirkungsmedhanismus des Strahlenschutzes durch Olivenöl. Z. ges. exp. Med. 137, 587-596.

- 1963b. Neue Ergebnisse zum Problem der Stoff wedhselreduktion im Tierreich (Die summierte Gewebsatmung beim Frosch in Beziehung zur Körpergröße, Temperatur und Jahreszeit). Zool. Anz. Suppl. 27,606-628.

- 1964a. Reaktionen der Gewebsatmung der Maus nach Röntgenbestrahlung in vivo (im Druck).

- 1964b. Probleme der quantitativen Strahlenbiologie. 1. Schädigung und Erholung (im Druck).

- 1964c. Anderungen des Leberstoffwechsels der Ratte während dex Verfütterung von Buttergelb (im Druck).

- \& BENDA, L., 1954. Zur Frage der Leberschädigung nach TB I (nach Untersuchungen der Gewebsatmung). Z. ges. exp. Med. 124, 418-431.

-, - 1955. Die Funktion der Kapillare im Ablauf der Entzündung. In: Kapillare und Interstitium (Hamburger Symposion). Hrsg. von H. Bartelheimer \& H. Küchmeister, Thieme, Stuttgart, p. 150-157.

-, -, Engelhardt, H. \& Moser, K., 1956a. Zellstoffwechsel und Entzündung. 7. Die Gewebsatmung der Fettleber. Z. ges. exp. Med. 127, 313-324.

-, -, Rersetbauter, E. \& Rissel, E., 1952. Zellstoff wechsel und Entzündung. 3. Die Wirkung von Hypoxie in vivo auf die Gewebsatmung der Leber. Z. ges. exp. Med. 118, 583-592.

-, 一, \& RIssex, E., 1951a. Zellstoff wechsel und Entzündung. 1. Stoffwedhselveränderungen in der Leber nach Allylformiatvergiftung. Z. ges, exp. Med. 117, 519-538.

-, -, - 1951b. Zellstoffwechsel und Entzündung. 2. Gewebsatmung der Leber bei sogen. "Seröser Entzündung“. Z. ges. exp. Med. 117, 559-566.

,,$---1951 \mathrm{c}$. Die Wirkung von Allylverbindungen in vitro auf die Gewebsatmung. $M b$. Chem. 82, 1094-1103.

-, -, - 1954a. Zellstoffwechsel und Entzündung. 5. Die Gewebsatmung der Leber bei anaphylaktischem Schock. Z. ges. exp. Med. 124, 189-200.

-, -, - 1954b. Zellstoffwechsel und Entzündung. 4. Die Erholungsatmung der Leber nach Hypoxie in vivo. Z. ges. exp. Med. 123, 141-151.

-, -, - 1954c. Die Gewebsatmung bei anaphylaktischem Schock nach In-vivo-Behandlung mit Nebennierenrinden-Hormonen. Z. ges, exp. Med. 124, 390-403.

,,$---1956 \mathrm{c}$. Zellstoffwechsel und Entzündung. 6. Die Atmung der Leber nach Tetrachlorkohlenstoffeinwirkung in vivo. $Z$. ges. exp. Med. 126, 537-545.

-, - \& Moser, K., 1956b. Das Peritoneum als Kapillarmodell. Untersuchungen über die experimentelle Beeinflussung seines Stoff wechsels. Z. ges. exp. Med. 127, 345-353.

- \& DonefF, D., 1958. Der Einfluß der Temperatur auf die Abhängigkeit der Gewebsatmung der Froschleber vom Glykogengehalt. Z. vergl. Pbysiol. 41, 242-248.

- \& GeYer, G., 1958. Die Wirkung von Cortison auf die Atmung eosinophiler Leukocyten. Zugleich ein Beitrag zur quantitativen Erfassung einer Zellatmung mit starkem in vitroAbfall. Z. ges. exp. Med. 130, 34-40.

- \& Hofer, R., 1958. Die Wirkung von 4,6-Dinitro-o-kresol auf die Atmung eines experimentellen Rattentumors bei verschiedenen Temperaturen. Experientia 14, 225-226. 
Locker, A., Hofmann-Credner, D. \& Moser, K., 1956d. Die Wirkung von Diamox auf die Gewebsatmung. Z. ges. exp. Med. 126, 546-553.

- \& Kölbu H., 1954. Gehirnatmung und anaphylaktischer Schod. Z. ges. exp. Med. 124, 170-175.

- \& Locker, R.-M., 1961. Eigentümliche Beziehungen zwischen der Gewebsatmung und ihrer Aktivierungsenergie bei Kalt- und Warmblütern. Z. Naturf. 16b, 196-198.

-, Moser, K. \& Srtzzy, K. H., 1954d. Reaktionen der Gewebsatmung unter dem Einfluß von Protoverattin und Veratrin. Z. ges, exp. Med. 124, 371-389.

- \& SIEdek, H., 1952a. Über Aktivierung von Cholinesterasen durd Alkylphosphate in vivo. Experientia 8, 146-148.

-, - 1952b. Zur Frage der durch Lebergewebe bewirkten Umwandlung von Pestox III in einen aktiven Cholinesterase-Inhibitor. Mb. Chem. 83, 455-458.

,--1954 . Die Wirkung von elementarem und ionisiertem Jod auf die Gewebsatmung. Z. ges. exp. Med. 122, 431-445.

-, - \& SpזTZY, K. H., 1950. Zur Wirkung von Dinitrokresol und Thiouracil auf den Zellstoffwechsel. Arch. exp. Path. Pharmak. 210, 281-288.

- \& Sprtzy, K. H., 1951. Die Wirkung ron Dinitrokresol auf die Atmung normaler und geschädigter Zellen und Gewebe. Z. ges, exp. Med. 118, 155-168.

- - - 1955a. Über Beziehungen $z$ wischen Penicillininaktivierung und Gewebsatmung der Leber. Z. ges. exp. Med. 125, 100-115.

- - $-1955 \mathrm{~b}$. Beziehungen zwischen Gewebsatmung und Inaktivierung von Aureomycin und Achromycin in der Leber. Z. ges. exp. Med. 125, 445-454.

-, - 1956a. Die Atmung von Zellen und Geweben in vitro als physiologische Methode und als Modellvorgang. Z. ges. exp. Med. 127, 1-15.

- $-1956 \mathrm{~b}$. Weitere Untersuchungen uber die Inaktivierung von Penicillin durch atmendes Lebergewebe. Z. ges. exp. Med. 127, 300-312.

- \& WEGHAUPT, K., 1958. Atmung und aerobe Glykolyse des Tumorgewebes unter Einfluß von 4,6-Dinitro-o-kresol. Naturwissenschaften 45, 191-192.

LOEWE, S, 1959. Randbemerkungen zur quantitativen Pharmakologie der Kumulation. Arzneimittel-Forsch, 9, 449-456.

Mandelstam, J., 1952. Studies in biochemical adaptation. The „mass action“ theory of enzyme adaptation. Biochem. J. 51, 674-681.

Margaria, R., Cerretelli, P., Aghemo, P. \& Sassi, G., 1963. Energy cost of running. J. appl. Pbysiol. 18, 367-370.

MeIER, R., SCHULER, W. \& KRUEGer, R., 1955. Pharmakodynamische Bedeutung der Zellstoftwechselwirkung ,cytotoxischer" Stoffe. Arch. exp. Path. Pharmak, 224, 206-223.

Michaelis, L. \& Menten, M., 1913. Die Kinetik der Invertasewirkung. Biochem. Z. 49, 333-369.

Miescher, K., 1955. Zur Frage der Alternsforschung. Experientia 11, 417-429.

Mrller, A. T., Conoly, D. M., Gabriel, M. \& Handy, M. S., 1959. Mitochondrial regulation of tissue respiration. Am. J. Physiol. 197, 653-656.

MORIWAKI, K., 1958. Influence of temperature in altering the augmenting effect of sodium azide on the energy-rich phosphate content of the toad embryo. J. Fac. Sci. Univ. Tokyo (6) 8, $287-295$.

O'Brien, R. D., 1963. Organophosphates and carbamates. In: Metabolic inhibitors. Edited by R. M. Hochster \& J. H. Quastel, Acad. Pr. New York, Vol. 2, p. $205-241$.

Opum, E. P., Connell, C. E. \& Stondard, H. L., 1961. Flight energy and estimated flight ranges of some migratory birds. Auk 78, 515-527.

Ogston, A. G, 1955. Activation and inhibition of enzymes. Discuss. Faraday Soc. 1955, $161-167$.

Opıтz, E. \& Lüвbers, D., 1957. Allgemeine Physiologie der Zell- und Gewebsatmung. In: Handbuch d. allgem. Pathologie. Hrsg. von F. Büchner (u. a.). Springer, Berlin, Bd. 4, T. 2, $395-496$.

- 8x Schnerder, M., 1950. Über die Sauerstoffversorgung des Gehirns und den Mechanismus von Mangelwirkungen. Ergebn. Physiol. 46, 126-260. 
Paul, M. H. \& Sperling, E, 1952. Cyclophorase system XXIII: Correlation of cyclophorase activity and mitochondrial density in striated muscle. Proc. Soc. exp. Biol, N.Y. 79, $352-354$.

Peiss, C. N. \& Field, J., 1948. A comparison of the influence of 2,4-dinitrophenol on the oxygen consumption of rat brain slices and homogenates. J. biol. Chem. 175, 49-56.

Pichotra, J., 1957. Der Gesamtorganismus im Sauerstoffmangel. In: Handbuch d. allgem. Pathologie. Hrsg. von F. Büchner (u. a.). Springer, Berlin, Bd. 4, T. 2, II, 497-568.

Polak, F. \& KNobloch, F., 1957. Ist das Ausgangswertgesetz von Wilder ein Naturgesetz? Acta neuroveg. 15, 473-481.

Precht, H., 1955. Wechselwarme Tiere und Pflanzen. In: Precht, H., Christophersen, J. \& Hensel, H., Temperatur und Leben. Springer, Berlin, p. 1-177.

Quastler, H., 1953. Information theory in biology. Univ. of Illinois Pr., Urbana, 273 pp.

Rashevsky, N., 1960. Mathematical biophysics. Physico-mathematical foundations of biology. Dover Publ. Inc., New York, Vol. 1., 2., 488, 462 pp.

- 1962. Mathematical foundations of general biology. Ann. N.Y. Acad. Sci. 96, 1105-1116.

RAO, K. P., 1958. Oxygen consumption as a function of size and salinity in Metapenaeus monoceros FAB. from marine and brakish-water environments. J. exptl Biol. 35, 307-313.

REES, E. D., 1960. Respiration of epithelial component of mammary gland slices. Am. J. Physiol. 199, 1067-1069 (1960).

REID, E., 1962. Significant biochemical effects of hepatocarcinogens in the rat (A review). Cancer Res. 22, 398-430.

Ricker, G., 1924. Pathologie als Naturwissenschaft. Relationspathologie. Springer, Berlin, $391 \mathrm{pp}$.

Rössı́, R., 1923. Referat über Entzündung. Verh. dtsch. Path. Ges. 19, 18-68.

Rossum, J. M. van \& Hurkmans, J. A. T. M., 1962. Molecular pharmacology and enzymology. Acta physiol. pharmac. néerl. 11, 173-194.

Rothschun, K. E., 1959. Theorie des Organismus. Bios-Psyche-Pathos. Urban \& Schwarzenberg, München-Berlin, $330 \mathrm{pp}$.

RubenstenN, B. B. \& GerARd, R. W., 1934. Fertilization and the temperature coefficients of oxygen consumption in eggs of Arbacia punctulata. J. gen. Physiol. 17,677-685.

Rudali, G. \& Mariani, P. L., 1950. Sur la production de tumeurs du foie, chez la souris XVII Ivry à l'aide du tétrachlorure de carbone. C. r. Séanc. Soc. Biol. 144, 1626-1627.

RudDer, B. DE, 1943. Über ein allgemeines Reiz-Reizantwort-Gesetz in der Biologie. Naturwissenschaften 31, 577-584.

SACHER, G. A., 1958. Reparable and irreparable injury: A survey of the position in experiment and theory. In: Radiation, biology and medicine. Edited by W. D. Claus, Addison-Wesley, Reading, Mass., p. 283-313.

Schade, H., 1935. Die Molekularpathologie der Entzündung. Steinkopff, Dresden, 100 pp.

SchefF, G. \& Hassro, A., 1936. Einfluß einiger Chemotherapeutika auf den Stoff wechsel der Trypanosomen mit Rüdksicht auf das Interferenzphänomen. Zbl. Bakt. 136, 420-424.

Schmidr, J., 1963. Die Abhängigkeit der Temperaturbeeinflussung von Ratten durch biogene Amine von der Applikationsart und der Umgebungstemperatur. Acta biol. med. germ. 10, 350-356.

SCHULER, W, 1947. Uber den Wirkungscharakter verschiedener Antibiotika in vitro. Experientia 3, 110-111.

SHEPARD, M. P., 1955. Resistance and tolerance of young speckled trout (Salvelinus fontinalis) to oxygen lack, with special reference to low oxygen acclimation. J. Fish. Res. Bd. Can. 12, $387-446$.

Sноск, N. W., 1961. Current concepts of the aging process. J. Am. med. Ass. 175, 654-656.

SieberT, G., 1954. Biochemie der normalen und der malignen Zelle. In: Grundlagen und Praxis chemischer Tumorbehandlung. Hrsg. von J. Pirwitz, Springer, Berlin, p. 82-97.

Smith, R. E. \& Fairhurst, A. S., 1958. A mechanism of cellular thermogenesis in cold-adaptation. Proc. natn. Acad. Sci., Wash. 44, 705-711.

Spiegelman, S. \& Reiner, J. M., 1945. A note on steady-states and the Weber Fechner law. Psychometrika 10, 27-35. 
StAnbury, S. W. \& Mudge, G. H., 1954. Polyphasic response of respiration and aerobic glycolysis to 2,4-Dinitrophenol. J. biol. Chem. 210, 949-964.

STANNARD, J. N., 1939. Separation of the resting and activity oxygen consumption of frog muscle be means of sodium azide. Am. J. Physiol. 126, 196-213.

Stephenson, R. P., 1956. A modification of receptor theory. Br. J. Pharmac, Chemother. 11, 379-393.

THews, G., 1960. Die Sauerstoffdiffusion im Gehirn. Ein Beitrag zur Frage der Sauerstoffversorgung der Organe. Pflügers Arch. ges. Physiol. 271, 197-226.

Thoday, I. M. \& ReAd, J., 1947. Effect of oxygen on the frequency of chromosome aberrations produced by X-rays. Nature, Lond. 160, 608-610.

VERNBERG, F. J. \& GRAY, I. E., 1953. A comparison of the respiratory metabolism of excised brain tissue of marine teleosts. Biol. Bull. mar. biol. Lab., Woods Hole 104, 445-449.

Viaud, J., Mandel, P. \& Fontaine, R., 1958. Etude expérimentale, chez le rat, de la consommation d'oxygène des téguments après un traumatisme artificiel. Semaine Hôpitaux 1958, 29-34.

Villa, L., Polli, E. \& Dioguardr, N., 1957. Experimentelle Leberinsuffizienz. Sci. med. ital. 5, $402-439$.

WAKIM, K. G. \& MaNN, F. C., 1942. Intrahepatic circulation of blood. Anat. Rec. 82, 233-236.

Warburg, O., GaWenn, K. \& Gerssler, A. W., 1957. Manometrie der Körperzellen unter physiologischen Bedingungen. Z. Naturf. 12b, 115-118.

WeIss, L., 1961. Sensitivity of hypothermic mammals to X-irradiation. Br. med. Bull. 17, 70-73.

WIESER, W., 1959. Organismen-Strukturen-Maschinen. Fischer, Frankfurt a. M., 167 pp.

Wilbrandr, W', 1963. Probleme des aktiven Transports (Transportmechanismen und Pharmakologie). Arch. exp. Path. Pharmak. 245, 28-47.

WILDER, J., 1958. Zur Kritik des Ausgangswert-Gesetzes. Klin. Wschr. 36, 148-151.

Widminson, G. N., 1961. Statistical estimations in enzyme kinetics. Biochem. J. 80, 324-332.

WINNe, D., 1960. Bemerkungen zum Wilderschen Ausgangswertgesetz. Klin. Wschr. 38, 1233 bis 1235 .

WitTManN, H. G., 1963. Ubertragung der genetischen Information. Naturwissenschaften 50, 76-88.

Wyndham, C. H., Strydom, N. B., Maritz, J. S., Morrison, J. F., Peter, J. \& Potgieter, J. U., 1959. Maximum oxygen intake and maximum heart rate during strenous work. J. appl. Physiol. 14, 927-936.

-, 一, Williams, C. C, \& Rahden, M. van, 1962. A physiological basis for the "optimum" level of energy expenditure. Nature, Lond. 195, 1210-1212.

ZIMNY, M. L. \& GREGORY, R., 1958. High energy phosphates during hibernation and arousal in the ground squirrel. Am. J. Physiol. 195, 233 236.

Zöllner, N, \& Groebl, H., 1952. Die Aktivität der Bernsteinsäuredehydrogenase bei experimenteller Leberschädigung. Hoppe-Seyl. Z. 290, 177-180.

\section{Diskussion im Anschluß an den Vortrag Locker}

VON BERTALANFFY: I wish to congratulate Locker on his excellent presentation. The wealth of viewpoints presented is so large that comments are difficult. One important aspect, $\mathrm{I}$ believe, is the fact that many laws in physiology and pharmacodynamics result from the conception of the organism as an open system. This was already apparent from investigations by WERNER, DRUCKREY and others, but LOCKER's work, covering a broad field, gives reason to hope for unification and conceptualization of a wide realm which hitherto was often in the nature of unconnected observations and disputed generalizations. LOCKER's work should give fresh impulse to the conception of regulation as dynamic interaction of processes, which is nowadays somewhat overshadowed by the "homeostatic" viewpoint, that is, to look at the organism as a feedback- and servomechanism. One specific question: As far as I know, it is easy enough to obtain increase of both total and tissue metabolism by administering thyroxine in vivo by 
injection, but to my knowledge no one has been able to reproduce this effect in vitro by adding thyroxine or a related compound to the medium in Warburg determinations. We have made considerable efforts to obtain such an effect but were also unable to do so. Would you comment on this question?

LOCKer: Daß an der Gewebsatmung in vitro unmittelbar nach Zusatz von Thyroxin keine Wirkung eintritt, mag von mehreren Faktoren abhängen. Einerseits muß berücksichtigt werden, daß im euthyroiden Organismus bereits der Stoffwechsel aller Gewebe unter Thyroxineinfluß steht, der im Normalzustand eher regulatorisch als stimulierend sein wird. Andererseits darf vielleicht vermutet werden, daß dieses in den Geweben vorhandene Thyroxin in freier und in gebundener Form (etwa in Verbindung mit einer Eiweißkomponente als Thyreoglobulin) vorliegt. Dies ist zwar für die peripheren Gewebe meines Wissens noch nicht experimentell bewiesen, aber wahrscheinlich, weil es für eine Anzahl anderer Wirkstoffe zutriff, so für Gewebshormone von Peptidnatur (Renin-Angiotensin-System etc.), biogene Amine (Histamin, Serotonin), Acetylcholin, Heparin etc. In einem solchen Fall würde das Bestehen eines relativ stabilen Gleichgewichts zwischen freier und gebundener Form angenommen werden müssen, das erst bei entsprechender quantitativer Veränderung einer Komponente (des freien oder des gebundenen Hormons) zu einer Stoffwechselsteigerung führt. Dies mag die Ursache dafür sein, daß erst bei länger dauernder Einwirkung von Thyroxin in vitro ein Stoffwechseleffekt auftritt. Insofern unterscheidet sich die Reaktion des Gewebsschnittes gar nicht prinzipiell von der des gesamten Organismus unter Einfluß von Thyroxin in vivo. Das System Hypophyse-Schilddrüse, verbunden durch Thyrotropin, und die Peripherie, der Gewebsstoffwechsel vor allem der Muskulatur und der Leber, ist im euthyroiden Organismus ebenfalls sehr stabil, so daß der "rebound-effect" (die Einschränkung der endogenen Hormonproduktion durch exogene Hormonzufuhr) ebenso wie die Stoffwechselsteigerung nur schwer zu erzielen sind. Erst wenn durch Thyroidektomie dieses System zerstört wird und eine Stoffwechselverminderung eintritt, kann nach Thyroxinzufuhr eine Stoff wechselsteigerung zustandekommen, die auf Werte der $\mathrm{O}_{2}$-Aufnahme führt, die wesentlich höher als die des euthyroiden (unbehandelten) Tieres sind (LINDBERG et al. 1962, Nature Lond. 193, 1059). Da die Verminderung des Gesamtstoff wechsels nach Thyreoidektomie auf die der Gewebe zurïckgeht (Whaley et al. 1959, Am. J. Physiol. 196, 1268), ist es sehr wahrscheinlich - aber, soweit ich informiert bin, noch nicht untersucht - daß hier durch Thyroxin in vitro die Gewebsatmung sofort auf die Höhe normaler Gewebe gebracht werden könnte.

PRECHT: Welche konkreten Hinweise gibt es für eine Wirkung der Schilddrüsenhormone in vitro?

Locker: Die von mir zitierte Arbeit (Bronk 1960) ebenso wie die genau das gleiche findende von Dallam \& Howard $(1960$, Biochim. biopbys. Acta 37, 188) beziehen sich auf Mitochondrien-Atmung beziehungsweise oxydative Phosphorylierung. Aber auch diese Befunde scheinen mir für die entwickelte Vorstellung zu sprechen. Die Mitochondrien werden vor der Atmungsund Phosphorylierungsmessung gewaschen, möglicherweise wird durch die Präparation das endogen gebundene Thyroxin (das die Außerung des exogen zugeführten bestimmt) vollkommen entfernt, so daß eine schnelle und unmittelbare Reaktion auf Zusatz von Thyroxin möglich wird. - Ein Wort vielleicht noch zur Kälteadaptation, bei der ja eine besondere Rolle von Thyroxin angenommen wird. Da auch thyreoidektomierte Ratten (mit minimalen sub-substituierenden Thyroxingaben) zur Kälteadaptation bzw. zu dieser entsprechenden Stoffwechselsteigerung gebracht werden können und auch thyreoidektomierte kurarisierte Ratten Kältereaktionen zeigen, vermutet HarT $(1958, F e d$. Proc. 17, 1045), daß eigentlich Nor-Adrenalin für den kalorigenen Effekt verantwortlich sei. Es ist mir nicht bekannt, ob ähnliche Befunde auch an kaltadaptierten poikilothermen Wirbeltieren erhoben worden sind, aber wahrscheinlich wird man auch bei diesen nicht alle Stoff wechselreaktionen während der Kälteadaptation allein dem Thyroxin zuschreiben dürfen.

URICH: Ich habe Bedenken, Begriffe der Sinnesphysiologie, wie „Reiz" und „Reaktion“, für die Beschreibung von Vorgängen in Stoffwechselsystemen zu verwenden. Insbesondere die energetischen Aspekte sind offenbar sehr verschieden.

LOCKER: Ich glaube nicht, daß man in bezug auf Antworten gegenüber Beeinflussungen zwischen Sinnesphysiologie und Stoff wechselphysiologie überhaupt unterscheiden kann; beide kön- 
nen sowohl reaktionskinetisch als auch informationstheoretisch behandelt werden. Erinnert sei, was erstere betriff, an die Vorstellungen, die Herrng, später HECHT und zuletzt Ranke über quantitative Beziehungen (Reiz, Reaktion, Adaptation etc.) in Sinnessystemen entwickelt haben. Beide Systeme (Sinnessystem mit "input" und „output" und Stoffwechselsystem mit „influx" und „efflux") sind „offene Systeme" und ihre formale Behandlung führt wahrscheinlich zu einem völlig isomorphen Aufbau. Biosysteme unterscheiden sich von den in der anorganischen Natur vorkommenden Gebilden, auf welche die Bezeichnung System nicht zutrifft (und als welche nicht etwa "Automaten", mechanische oder andere vom Menschen gemachte und diesem analoge Modelle aufgefaßt werden dürfen), schon hinsichtlich der Form der Kausalität. In der anorganischen Natur gilt jene Kausalität, die unter anderem auch LEIBNIZ als „causa aequat effectum" formuliert hat; bei einem Biosystem ist jedoch die phänomenologisch-kinetische wie energetische Außerung gegenüber einer Beeinflussung quantitativ größer und qualitativ anders als die Beeinflussung selbst. Auf diesen Sachverhalt haben als erste (voneinander unabhängig) J. MÜLleR und J. R. Maxer hingewiesen; man kann daher in Biosystemen von einer "Auslösungskausalität" sprechen. Weil aber nun die "Wirkung" größer und anders als die „Ursache" ist, soll dies aud terminologisch zum Ausdruck kommen und daher verwenden wir die Begriffe "Reiz" und "Reaktion". Die Reaktion ist letztlich Außerung des ganzen Systems und von seinen Bedingungen abhängig.

VON BERT'ALANFFY: With respect to stimulus response phenomena, it seems desirable to distinguish between transmission of energy and information. These are different and complementary viewpoints, requiring different models.

Knötig: Ich darf noch einmal zurückkommen auf die Definition der Termini "Reiz" und "Reaktion". Reize sind meiner Ansicht nach Vorgänge, bei denen der Informationsfluß im Vordergrund steht gegenüber dem Energieflußs.

LOCKER: Es ist richtig, daß Energie- und Informationsfluß unterschieden werden müssen. Tatsächlich geschieht dies auch schon in der kinetischen Betrachtung eines stoff wechselnden Systems. So unterscheidet Holzer $(1960$, Handb. PfPbysiol. 12, p. 1) zwischen "direkter Rückkopplung" (die dem von WIENER geprägten. Begriff der "energetischen Kopplung" entspricht) und „indirekter Rückkopplung“ (entsprechend der „informativen Rückkopplung“). Erstere setzt stöchiometrische Reaktionen voraus, letztere nicht; bei dieser kontrollieren bloß konstante Bruchteile bestimmter Intermediate die Bildung anderer.

GRAINGER: I compliment Dr. LockER on his stimulating paper. I too believe that many physiological processes can be explained in terms of steady states and transitions between steady states. I believe that for our subject to advance it is necessary to study realistic models of actual systems. I suggest that HEARON's model would be suitable for analysing the properties of glycolysis and the citric acid cycle. This should be done first for single cells where there are no cell-cell interactions, which complicate matters very much in multicellular animals. Have you considered this possibility?

LOCKeR: It would certainly be justified to compare the reactions in a model-system of a mechanical or electrical build-up with similar reactions of a living system, for instance, that of a cell. We may hope that a model-system gives us a more precise insight into the conditions upon which such reactions depend. However, I have never considered model-systems in my own studies, although I agree with Dr. Grainger that this would be desirable. I regret also not having mentioned the work of HEARoN in my paper. This author has indeed contributed considerably to the theory of steady-state kinetics.

VON BeRTALANFF: There is in recent biology a certain tendency toward "model building at random" for intellectual fun and without much regard for actual experience. Also there is too much "experimentation at random", $i$. e. experimenting without consideration of what the experiments and their results are supposed to mean. I consider both rendencies to be dangerous and very often a loss of time and work. Fruitful development will only result from wellplanned experimentation in connection with models which should always be controlled by experience.

WrESER: Zur Erklärung der Regelung von Stoff wechselprozessen sind bereits einige empirische Modelle entwickelt worden, die auf zelluläre Systeme anwendbar sind und die auf der Wechsel- 
wirkung von Systembestandteilen (Endprodukt, „branchpoint enzyme“, Mitochondrien, Kern etc.) beruhen. Diese sollten bei Betrachtungen uber Fließgleichgewichte in stoffwechselnden Systemen mitberücksichtigt werden.

LOCKER: In meiner Darstellung habe ich Enzym-Modelle zur Veranschaulichung der allgemeinen Gesetzmäßjigkeiten stoffwechselnder Systeme (bzw. der Reiz-Reaktionsgesetze) herangezogen. Der Schwerpunkt der Darstellung lag nicht auf Enzymmodellen, sondern in dem Versuch nachzuweisen, daß analoge Reaktionen auf jedem Organisationsniveau (zellulär, histionär, organismisch) angetroffen werden.

VON BERTALANFFY: In regard to LOCKER's "concluding remarks", I agree that deterministic and stochastic models represent two different approaches, which are often applicable to the same process; both should eventually prove to be isomorphic (cf. the relation of classic thermodynamics and statistical mechanics). I do not agree with his identification of mathematics with "quantitative conceptualization". There are non-quantitative systems in mathematics (e. g. graph, game, decision theory). It can well be imagined that such fields may play an increasing role in future biology. If so, they would be concerned with "qualitative" and "morphologic" aspects as emphasized by Locker. According to Gödel (quoted by Orpennemer, 1956, in Am. Psychol. 11,127 ), it was a historical accident that our Western mathematics developed in quantative lines; quite different mathematical evolutions are possible and are in fact developing. Hence the identification of "mathematics" with "science of quantities" is not correct. Also the modern trend toward quantitative methods in taxonomy (systematics) may be mentioned; hence there is no antithesis between "systematics" and "mathematics". Rather diverse attempts have been made to mathematize biology, and although the work has just begun, it is perhaps indicative of future developments. Notwithstanding the honor of being quoted in one line with Heraccrrus and Leibniz, I have to correct the statement that the General Systems Theory (G. S. T.) is "metaphysics". Admittedly, the field is novel and hence contains more "philosophy" (i.e. generalizations not sufficiently grounded in experimental data) than is desirable. But such was the case in e very new scientific development: KEPLER's astronomy, LEIBNIZ' calculus and DAR WIN's theory of selection were also highly "philosophical", "speculative" and even "metaphysical" in their beginnings. However, in structure and goal G.S.T. is $n$ o $t$ metaphysics but a scientific theory intended especially for application in those realms (biological, behavioral, social) where physical theory is inapplicable (cf. L. von BerTaLANFFY, General system theory - a critical review. Gen. Syst. Yearb. Sac. Gen. Syst. Res. 7, 1, 1963). This program has been carried through for a remarkable multitude of specific problems, as a perusal of the publication mentioned (Gen. Syst., since 1956) may show.

LOCRER: Ich danke Herrn vON BERTALANFFY für die Berichtigung mancher meiner Vorstellungen, besonders für den Hinweis auf nicht-quantitative Mathematik und ihre mögliche Bedeutung in einer zukünftigen Biologie. Was den metaphysischen Gehalt (oder "die Metaphysik") irgendeiner Theorie anlangt, so ist zunächst klar, daß eine Theorie immer schon vor ihrer vollständigen Verifizierung existiert. Weiterhin enthält jede Theorie Teile (Postulate, Axiome etc.), die nicht direkt verifiziert werden können, bei denen die Erfahrung vielmehr bloß als Regulativ dafür dient, ob die angenommene Grundkonzeption aufrechterhalten werden kann oder nicht. In diesem Sinne ist z. B. aud der 1. Hauptsatz Metaphysik und lange vor J. Mayer schon von KANT in seinen „Metaphysischen Anfangsgründen der Naturwissenschaft" rein apriorisch formuliert worden. Wieder etwas anderes ist es, ob die metaphysische Ausgangsbasis der Naturwissenschaft vom Naturwissenschaftler aud dann anerkannt wird, wenn die entsprechende Wissenschaft (oder Theorie) formalisiert werden konnte. Unter Metaphysik verstehe ich zunächst hier (nach KANT) die apriorische Voraussetzung oder Ermöglichung der Erkenntnis und sehe vorläufig von der Annahme "metaphysischer Wesenheiten" ab, wenngleich diese beim Ubergang vom "transzendentalen " in den "transzendenten" Bereich unumgänglich wird. Ich glaube, daß zwischen uns Ubereinstimmung bestehen kann in der Auffassung, daß die „Allgemeine System-Theorie" (als im wesentlichen apriorische Theorie) zumindest "transzendentale" Metaphysik ist. Die eingehendere Diskussion dieser Frage würde natürlich den Rahmen unseres Symposions bei weitem überschreiten und darf vielleicht bis zum Kongreß über "Ganzheit und System in den Wissenschaften", der im September 1964 in Salzburg stattfindet, aufgeschoben werden. 